UNIVERSIDADE DE SÃO PAULO

FACULDADE DE MEDICINA

PRISCILA TAVARES FRANCO E SEMPREBOM

Capacidade funcional e práticas de autocuidado de idosos:

norteadores para atenção integral a idosos a partir da atenção primária à saúde

São Paulo

2021 
PRISCILA TAVARES FRANCO E SEMPREBOM

Capacidade funcional e práticas de autocuidado de idosos:

norteadores para atenção integral a idosos a partir da atenção primária à saúde

Dissertação apresentada à Faculdade de Medicina da Universidade de São Paulo para obtenção do título de Mestre em Ciências

Programa de Ciências da Reabilitação do Departamento de Fisioterapia Fonoaudiologia e Terapia Ocupacional

Orientadora: Prof ${ }^{\mathrm{a}}$. Dr ${ }^{\mathrm{a}}$. Maria Helena Morgani de Almeida

São Paulo 
Dados Internacionais de Catalogaçăo na Publicaçăo (CIP)

Preparada pela Biblioteca da

Faculdade de Medicina da Universidade de Săo Paulo

Creproduçăo autorizada pelo autor

Semprebom, Priscila Tavares Franco e

Capacidade funcional e práticas de autocuidado

de idosos : norteadores para atençăo integral a

idosos a partir da atenção primáría à saúde ?

Priscila Tavares Franco e Semprebom. -- Säo Paulo, 2021.

Dissertação (mestrado)--Faculdade de Medicina da Universidade de São Paulo.

Programa de Ciências da Reabilitaçăo.

Orientadora: Maria Helena Morgani de Almeida.

Descritores: 1. Autocuidado 2. Idoso 3.Capacidade funcional 4. Atenção primária à saúde 5.Centros de saúde 6.Atividades cotidianas

$\mathrm{USP} / \mathrm{EM} / \mathrm{DBD}-102 / 21$

Responsável: Erinalva da Conceiçāo Batista, CRB-8 6755 
Semprebom PTF. Capacidade funcional e práticas de autocuidado de idosos: norteadores para atenção integral a idosos a partir da atenção primária à saúde [dissertação]. São Paulo: Faculdade de Medicina, Universidade de São Paulo; 2021.

Aprovada em:

\section{Banca Examinadora}

Prof.(a) Dr.(a)

Instituição:

Julgamento:

Prof.(a) Dr.(a)

Instituição:

Julgamento:

Prof.(a) Dr.(a)

Instituição:

Julgamento: 
Agradeço a Deus por ter me dado forças para concluir essa longa jornada, agradeço a minha professora Helena, a melhor professora que eu poderia ter, ao meu marido, por toda paciência e apoio, a minha filha, luz da minha vida, e às minhas amigas que me ajudaram na conclusão da minha dissertação. 


\section{Agradecimentos}

Minha eterna gratidão a minha orientadora Maria Helena Morgani de Almeida, por todo carinho, paciência, dedicação, profissionalismo, competência, generosidade e ética empenhados durante todo esse trabalho. Não imagino conseguir chegar ao fim dessa jornada sem todo seu apoio, com certeza fez desse caminho uma experiência linda de aprendizado e desafios.

Agradeço também os meus queridos pacientes do Itaim Paulista por todo carinho, disponibilidade e confiança depositados em mim, e que tornaram possível a realização desse trabalho.

Aos meus pais que tornaram possível o meu grande sonho, ser Terapeuta Ocupacional, ao meu marido e filha por toda paciência e compreensão durante minhas ausências.

A minhas amigas Aline, Gabriela, Camila e Lígia que tanto me apoiaram e ajudaram na realização desse trabalho.

Agradeço também aos meus familiares e amigos que dispensaram algum tempo para me ajudar nos cuidados com a minha filha para que eu pudesse concluir esse trabalho, em especial a Karine, por toda paciência nos cuidados com a Rafa.

Por fim, a todas as pessoas que direta ou indiretamente contribuíram para a realização da minha pesquisa.

O presente trabalho foi realizado com apoio da Coordenação de Aperfeiçoamento de Pessoal de Nível Superior - Brasil (CAPES) - Código de Financiamento 001. 
“Desistir... eu já pensei seriamente nisso, mas nunca levei realmente a sério, é que tem mais chão nos meus olhos do que cansaço nas minhas pernas, mais esperança nos meus passos do que tristeza nos meus ombros, mais estrada no meu coração do que medo na minha cabeça." Cora Coralina 


\section{RESUMO}

Semprebom PTF. Capacidade funcional e práticas de autocuidado de idosos: norteadores para atenção integral a idosos a partir da atenção primária à saúde [dissertação]. São Paulo: Faculdade de Medicina, Universidade de São Paulo; 2021.

Introdução: $\mathrm{O}$ envelhecimento populacional é considerado um fenômeno mundial, relacionado à redução das taxas de natalidade e mortalidade. A manutenção da capacidade funcional, independência e autonomia da pessoa idosa têm sido considerada primordial pelas políticas públicas para essa população. A identificação das dificuldades funcionais para as atividades de vida diária - básicas e instrumentais (ABVD e AIVD), das práticas de autocuidado utilizadas para seu enfrentamento e de fatores associados mostra-se necessária para intervenções efetivas com foco na manutenção ou melhora da capacidade funcional de idosos. Objetivos: Avaliar capacidade funcional e práticas de autocuidado adotadas por idosos usuários de serviços no âmbito da atenção primária em saúde na região do Itaim Paulista e sua associação com alguns indicadores de vulnerabilidade social. Método: Estudo de natureza quantitativa e delineamento transversal, descritivo e analítico, conduzido junto a idosos usuários das unidades básicas de saúde Jd. Camargo Novo e UBS Dr. Júlio de Gouveia (n=128). O estudo foi realizado por meio de entrevistas com aplicação de instrumentos padronizados: Avaliação Multidimensional da Pessoa Idosa na Atenção Básica (AMPI-AB) e o Instrumento para a Classificação de idosos quanto à Capacidade para o Autocuidado (CICAc). Foram conduzidas análises descritivas e estatísticas com uso dos testes qui-quadrado, teste exato de Fisher ou testes da razão de verossimilhanças, com intervalos com $95 \%$ de confiança e uso de regressão logística bivariada. Resultados: A amostra de conveniência foi predominantemente de mulheres (72,7\%), na faixa etária de 60 a 69 anos (55,5\%), casadas (58,6\%), com até 4 anos de escolaridade $(55,4 \%)$, com recursos financeiros oriundos de aposentadoria $(53,1 \%)$, que referem ter trabalhado durante a vida principalmente em serviços de limpeza $(28,1 \%)$, com recursos financeiros que satisfazem mais ou menos suas necessidades básicas (45,3\%), com autopercepção de saúde regular/ruim/muito ruim (53,9\%), apresentando 3 ou mais condições crônicas $(62,5 \%)$ e classificadas como pré-frágeis pela AMPI-AB $(47,7 \%)$. Quanto às ABVD, 25\% referiram dificuldades, a maioria referiu de 1 a 2 dificuldades $(21,1 \%)$, sendo que metade dessas dificuldades encontram-se compensada $(10,9 \%)$ e estão relacionadas à locomoção $(19,5 \%)$. Quanto às AIVD, a grande maioria 
dos idosos referiu dificuldades $(84,8 \%)$, possuindo em sua maioria de 1 a 2 atividades com dificuldades $(52,3 \%)$, sendo que a maioria requer ajuda $(53,9)$ e pequena parte mencionou realizar práticas de autocuidado $(8,6 \%)$. As dificuldades predominaram nas tarefas domésticas $(64 \%)$, compras $(46,1 \%)$, uso de meio de transporte $(23,4)$, controle do orçamento $(21,3 \%)$ e lavagem de roupas $(19,8)$. Quanto às análises estatísticas, sexo, nível de fragilidade, autopercepção de saúde, diabetes, AVC, depressão e dor crônica influenciaram na presença, grau e número de dificuldades para $\operatorname{ABVD}(\mathrm{p}<0,05)$. Pessoas do sexo masculino apresentaram chance de terem dificuldades para ABVD 6,06 vezes maior que a chance de pessoas do sexo feminino, as pessoas com fragilidade apresentaram chance de terem dificuldades para ABVD 16,59 vezes maior que a chance de pessoas saudáveis, pessoas com diabetes apresentaram chance de terem dificuldades para ABVD 4,65 vezes maior que a chance de pessoas sem diabetes e pessoas com depressão apresentaram chance de terem dificuldade para ABVD 3,62 vezes maior que pessoas sem depressão, independente das demais características avaliadas. No tocante às AIVD sexo, faixa etária, nível de fragilidade, autopercepção de saúde, condições crônicas, anemia, osteoartrose e depressão influenciaram em algum ou todos os desfechos funcionais ( $\mathrm{p}<$ $0,05)$. Osteoartrose influenciou estatisticamente presença de dificuldade para AIVD ( $\mathrm{p}=$ 0,042) independente das demais características avaliadas, sendo que pessoas com osteoartrose apresentaram chance de apresentar alguma dificuldade para AIVD 4,01 vezes maior que a chance de pessoas sem osteoartrose. Nenhuma das características avaliadas influenciou estatisticamente na compensação da dificuldade para ABVD (p > 0,05), mas pessoas com osteoartrose apresentaram estatisticamente menor frequência de compensação das dificuldades AIVD $(p=0,016)$. Conclusão: A caracterização sociodemográfica, clínica e funcional dos idosos participantes, bem como associação entre parte dessas caraterísticas com presença, número e grau de dificuldades para atividades diárias, incluindo adoção ou não de práticas de autocuidado podem contribuir para o planejamento de ações no território, setoriais e intersetoriais, com foco na capacidade funcional e autocuidado de idosos, a partir da atenção primária em saúde.

Descritores: Autocuidado; Idoso; Capacidade Funcional; Atenção Primária à Saúde; Centros de Saúde; Atividades Cotidianas. 


\begin{abstract}
Semprebom PTF. Functional capacity and self-care practices of the elderly: guidelines for comprehensive care of the elderly based on primary health care service [dissertation]. São Paulo: "Faculdade de Medicina, Universidade de São Paulo”; 2021.
\end{abstract}

Introduction: Population aging is considered a worldwide phenomenon, related to the reduction of birth and mortality rates. The maintenance of functional capacity, independence and autonomy of the elderly has been considered paramount by public policies for this population. The identification of functional difficulties in activities of daily living - basic and instrumental (ADLs and IADLs), self-care practices used for coping with them and associated factors is necessary for effective interventions focused on maintaining or improving the functional capacity of the elderly. Objectives: To evaluate the functional capacity and self-care practices adopted by elderly users of primary health care services in the region of Itaim Paulista and its association with some indicators of social vulnerability. Method: A quantitative, cross-sectional, descriptive and analytical study was conducted with elderly users of the Basic Health Units Jd. Camargo Novo and UBS Dr. Júlio de Gouveia $(n=128)$. The study was carried out by means of interviews with use of standardized instruments: Multidimensional Assessment of the Elderly in Primary Care (AMPI-AB) and the Instrument for the Classification of the Elderly regarding Capacity for Self-Care (CICAc). Descriptive and statistical analysis were conducted using chi-square tests, Fisher's exact test or likelihood ratio tests, with 95\% confidence intervals and use of bivariate logistic regression. Results: The convenience sampling was predominantly women $(72.7 \%)$, aged 60 to 69 years $(55.5 \%)$, married $(58.6 \%)$, with up to 4 years of schooling (55.4\%), with financial resources coming from retirement (53.1\%), who report having worked during their lives mainly in cleaning services $(28,1 \%)$, with financial resources that generally meet their basic needs (45.3\%), with regular/poor/very poor self-perception of health $(53.9 \%)$, with 3 or more chronic conditions (62.5\%) and classified as pre-fragile by AMPI-AB (47.7\%). As for ADLs, 25\% reported difficulties, most reported 1 to 2 difficulties (21.1\%), and half of these difficulties are compensated (10.9\%) and related to locomotion $(19.5 \%)$. As for the IADLs, the vast majority of the elderly reported difficulties (84.8\%), having mostly 1 to 2 activities with difficulties (52.3\%), most of which require help (53.9) and a small part 
mentioned performing self-care practices $(8.6 \%)$. The difficulties predominated in household chores (64\%), shopping (46.1\%), use of means of transportation (23.4), budget control (21.3\%), and washing clothes (19.8). As for the statistical analysis, gender, frailty level, self-perceived health, diabetes, stroke, depression, and chronic pain influenced the presence, degree, and number of difficulties for ADLs ( $p<0.05)$. Males had a 6.06 times greater chance of having difficulties in ADLs than females, people with frailty had a 16.59 times greater chance of having difficulties in ADLs than healthy people, people with diabetes had a 4.65 times greater chance of having difficulties in ADLs than people without diabetes, and people with depression had a 3.62 times greater chance of having difficulties in ADLs than people without depression, regardless of the other assesssed characteristics. Regarding IADLs, gender, age group, frailty level, self-perceived health, chronic conditions, anemia, osteoarthritis, and depression influenced some or all functional outcomes $(p<0.05)$. Osteoarthrosis statistically influenced the presence of difficulty in IADLs $(\mathrm{p}=0.042)$ regardless of other evaluated characteristics, and people with osteoarthrosis had a 4.01 times greater chance of presenting some difficulty in IADLs than people without osteoarthrosis. None of the evaluated characteristics influenced statistically in the compensation of difficulty for ADLs $(p>0.05)$, but people with osteoarthrosis presented statistically lower frequency of compensation for IADLs difficulties $(\mathrm{p}=0.016)$. Conclusion: The socio-demographic, clinical, and functional characterization of the elderly participants, as well as the association between some of these characteristics with the presence, number, and degree of difficulties in daily activities, including the adoption or not of self-care practices, can contribute to the planning of actions in the sectorial and intersectorial territory, focusing on functional capacity and self-care of the elderly, based on primary health care service.

Descriptors: Self-care; Aged; Functional capacity; Primary health care; Health centers; Activities of daily living. 


\section{LISTA DE FIGURAS}

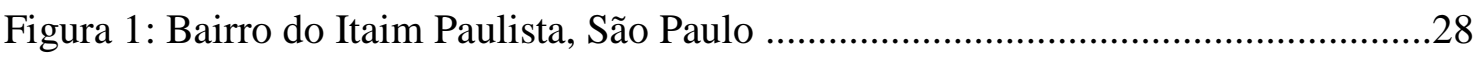

Figura 2: Bairro do Itaim Paulista, São Paulo.........................................................28

Figura 3: Mapa das regiões da cidade de São Paulo com destaque para as UBS Jd. Camargo Novo e UBS Dr. Júlio de Gouveia (2019) .....................................................36 


\section{LISTA DE TABELAS}

Tabela 1 - Distribuição de idosos segundo dados demográficos e socioeconômicos, CICAc e AMPI- AB, SP, 2019

Tabela 2 - Distribuição de idosos segundo percepção de saúde, presença de doenças crônicas, uso de medicamentos, episódios de internação, alterações funcionais, necessidade de ajuda para atividades cotidianas e níveis de fragilidade. AMPI-AB, SP, 2019

Tabela 3 - Distribuição de idosos segundo dados referentes às doenças crônicas referidas, AMPI, SP, 2019

Tabela 4 - Distribuição de idosos quanto à presença de dificuldades, tipos de dificuldades e níveis de dificuldade, incluindo adoção de práticas de autocuidado referentes a cada uma das atividades básicas da vida diária, CICAc, SP, 2019

Tabela 5 - Distribuição de idosos quanto à presença de dificuldades, tipos de dificuldades e níveis de dificuldade, incluindo adoção de práticas de autocuidado referentes a cada uma das atividades instrumentais da vida diária, CICAc, SP, 2019

Tabela 6 - Distribuição de idosos quanto à presença de dificuldades, tipos de dificuldades e níveis de dificuldade, incluindo adoção de práticas de autocuidado referentes a cada uma das atividades de lazer, CICAc, SP, 2019

Tabela 7 - Distribuição de idosos de acordo com as atividades desejadas, CICAc, SP, 2019.

Tabela 8 - Distribuição de idosos quanto às dificuldades para os blocos das ABVD, AIVD (presença, número de atividades para as quais referem dificuldade e grau de dificuldade), CICAc, SP, 2019.

Tabela 9 - Distribuição de idosos quanto às dificuldades para ABVD, AIVD (presença, número de atividades para as quais referem dificuldade e grau de dificuldades) e sexo, CICAc, SP, 2019

Tabela 10 - Distribuição de idosos quanto às dificuldades para ABVD, AIVD (presença, número de atividades e grau de dificuldades) e faixa etária, CICAc, SP, 2019 .

Tabela 11 - Distribuição de idosos quanto às dificuldades para ABVD, AIVD (presença, número de atividades para as quais referem dificuldade e grau de dificuldades) e morar sozinho, CICAc, SP, 2019

Tabela 12 - Distribuição de idosos quanto às dificuldades para ABVD, AIVD (presença, número de atividades para as quais referem dificuldade e grau de dificuldades) e ter alguém com quem contar, CICAc, SP, 2019 
Tabela 13 - Distribuição de idosos quanto às dificuldades para ABVD, AIVD (presença, número de atividades para as quais referem dificuldade e grau de dificuldades) e escolaridade, CICAc, SP, 2019.

Tabela 14 - Distribuição de idosos quanto às dificuldades para ABVD, AIVD (presença, número de atividades para as quais referem dificuldade e grau de dificuldades) e nível de fragilidade (saudável, pré-frágil e frágil), AMPI e CICAc, SP, 2020

Tabela 15 - Descrição dos graus de dificuldade para ABVD segundo características, clínicas e nível de fragilidade, associadas a esse desfecho e resultado dos testes de associação, AMPI e CICAc, SP, 2020

Tabela 16 - Descrição do número de dificuldades para ABVD segundo características demográficas, clínicas e nível de fragilidade, associadas a esse desfecho e resultado dos testes de associação, AMPI e CICAc, SP, 2020

Tabela 17 - Descrição de presença de dificuldade para ABVD segundo características demográficas, clínicas e nível de fragilidade, associadas a esse desfecho, resultado dos testes de associação e análise bivariada, AMPI e CICAc, SP, 2020

Tabela 18 - Modelo múltiplo para explicar presença de dificuldades para ABVD segundo características demográficas, clínicas, de saúde e níveis de fragilidade, AMPI e CICAc, SP, 2020.

Tabela 19 - Descrição dos graus de dificuldade para AIVD segundo características demográficas, clínicas, de saúde, nível de fragilidade, associadas a esse desfecho e resultado dos testes de associação, AMPI e CICAc, SP, 2020

Tabela 20 - Descrição do número de dificuldades para AIVD segundo características demográficas, clínicas, de saúde, nível de fragilidade, associadas a esse desfecho e resultado dos testes de associação, AMPI e CICAc, SP, 2020

Tabela 21 - Descrição de presença de dificuldade para AIVD segundo características sociais, clínicas, de saúde e nível de fragilidade, associadas a esse desfecho e resultado dos testes de associação e das análises bivariadas, AMPI e CICAc, SP, 2020. .68

Tabela 22 - Modelo múltiplo para explicar presença de dificuldade para AIVD segundo características demográficas, sociais, clínicas, de saúde e níveis de fragilidade, AMPI e CICAc, SP, 2020 .69 


\section{LISTA DE ABREVIATURAS E SIGLAS}

$\mathrm{AB}$

ABVD

AIVD

AMA

AMPI-AB

$\mathrm{AO}$

APS

AVC

AVD

CAPS

CAPS-AD

CAPSIj

CECCO

CICAc

CNDSS

$\mathrm{COE}$

CRAS

CTA

DA

DC

DNC

ELSI

$\mathrm{ESF}$

FIBRA

HAS

IBGE

ILPI

IPGG

MA

$\mathrm{MC}$
Atenção Básica

Atividades Básicas da Vida Diária

Atividades Instrumentais da Vida Diária

Assistência Médica Ambulatorial

Avaliação Multidimensional da Pessoa Idosa na Atenção Básica

Osteoartrose

Atenção Primária em Saúde

Acidente Vascular Cerebral

Atividades da Vida Diária

Centro de Atenção Psicossocial

Centro de Atenção Psicossocial álcool e outras drogas

Centro de Atenção Psicossocial Infanto-Juvenil

Centros de Convivência e Cooperativa

Instrumento para a Classificação de idosos quanto à Capacidade para

o Autocuidado

Comissão Nacional sobre os Determinantes Sociais da Saúde

Centro Odontológico Especializado

Centro de Referência de Assistência Social

Centro de Testagem e Aconselhamento

Dispositivo Auxiliar

Dificuldade Compensada

Dificuldade Não Compensada

Estudo Longitudinal Brasileiro de Envelhecimento

Estratégia de Saúde da Família

Fragilidade de Idosos Brasileiros

Hipertensão Arterial Sistêmica

Instituto Brasileiro de Geografia e Estatística

Instituição de Longa Permanência para Idosos

Instituto Paulista de Geriatria e Gerontologia

Mudança Ambiental

Mudança Comportamental 
ND

OMS

PA

PAI

PNS

PNSI

PNSPI

RA

RASPI

SABE

UBS

URSI
Não tem Dificuldade

Organização Mundial da Saúde

Pronto Atendimento

Programa Acompanhante de Idosos

Pesquisa Nacional de Saúde

Política Nacional de Saúde do Idoso

Política Nacional de Saúde da Pessoa Idosa

Requer Ajuda

Rede de Atenção à Saúde da Pessoa Idosa

Saúde e Bem-Estar no Envelhecimento

Unidade Básica de Saúde

Unidade de Referência à Saúde do Idoso 
Esta dissertação ou tese está de acordo com as seguintes normas, em vigor no momento desta

publicação:

Referências: adaptado de International Committee of Medical Journals Editors (Vancouver).

Universidade de São Paulo. Faculdade de Medicina. Divisão de Biblioteca e Documentação. Guia de

apresentação de dissertações, teses e monografias. Elaborado por Anneliese Carneiro da Cunha,

Maria Julia de A. L. Freddi, Maria F. Crestana, Marinalva de Souza Aragão, Suely Campos Cardoso,

Valéria Vilhena. 3a ed. São Paulo: Divisão de Biblioteca e Documentação; 2011.

Abreviaturas dos títulos dos periódicos de acordo com List of Journals Indexed in Index Medicus. 


\section{SUMÁRIO}

Resumo

Lista de figuras

Lista de tabelas

Lista de abreviaturas

1 INTRODUÇÃO .21

1.1 CAPACIDADE FUNCIONAL E AUTOCUIDADO: ENFRENTAMENTO DE FRAGILIDADE EM IDOSOS

1.2 AVALIAÇÃO DA CAPACIDADE FUNCIONAL NA ATENÇÃO BÁSICA: ORGANIZAÇÃO DO CUIDADO DO IDOSO PELA RASPI .25

1.3 ENVELHECER EM CONTEXTO DE VULNERABILIDADE SOCIAL: A EXPERIÊNCIA DE IDOSOS DA REGIÃO DO ITAIM PAULISTA..........................27

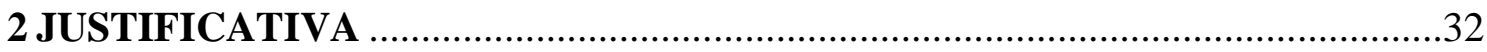

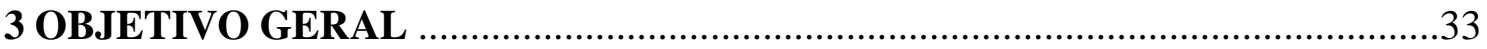

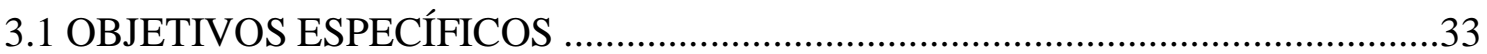

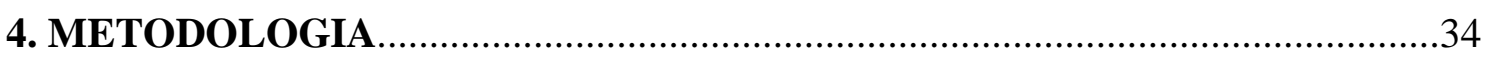

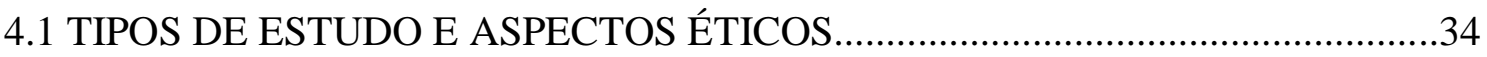

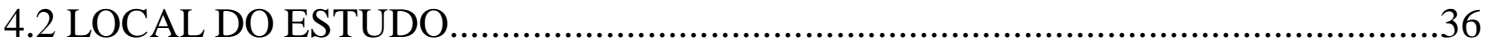

4.3 CARACTERIZAÇÃO E CÁLCULO DA AMOSTRA................................................37

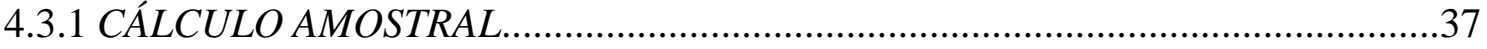

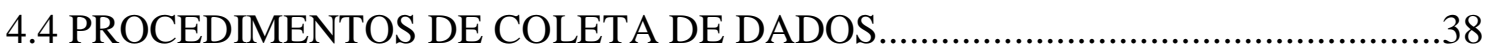

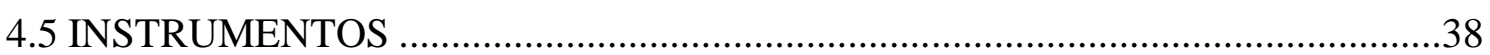

5 FORMA DE ANÁLISE DE DADOS ...............................................................40

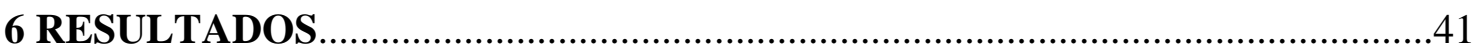

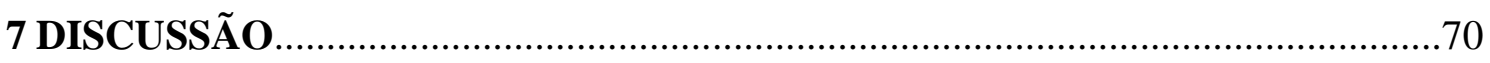

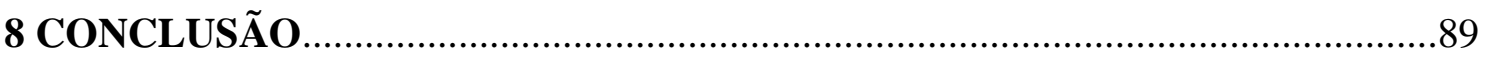

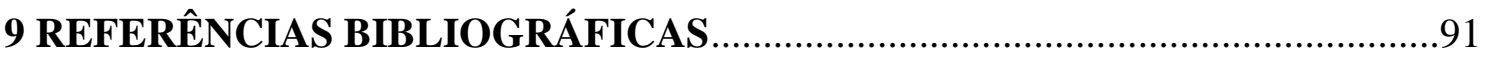

ANEXO I - TERMO DE CONSENTIMENTO LIVRE E ESCLARECIDO................100

ANEXO II - AVALIAÇÃO MULTIDIMENSIONAL DA PESSOA IDODA NA

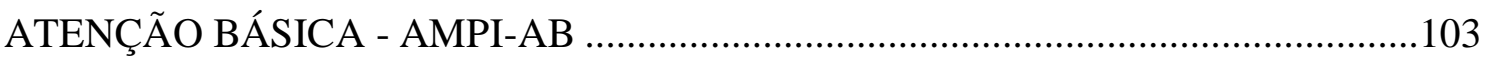

ANEXO III - INSTRUMENTO DE CLASSIFICAÇÃO DE IDOSOS QUANTO À CAPACIDADE PARA O AUTOCUIDADO - CICAC 104 
ANEXO IV - AUTORIZAÇÃO PARA CADASTRO DE PESQUISA ........................112 ANEXO V - PARECER CONSUBSTANCIADO DO CÔMITE DE ÉTICA EM PESQUISA DA FACULDADE DE MEDICINA DA UNIVERSIDADE DE SÃO PAULO - CEP

ANEXO VI - PARECER CONSUBSTANCIADO DO CÔMITE DE ÉTICA EM PESQUISA DA SECRETARIA MUNICIPAL DE SAÚDE DE SÃO PAULO SMS. .118 


\section{INTRODUÇÃO}

\subsection{CAPACIDADE FUNCIONAL E AUTOCUIDADO: ENFRENTAMENTO DE FRAGILIDADE EM IDOSOS}

Atualmente o envelhecimento populacional é considerado um fenômeno mundial, relacionado à redução das taxas de fecundidade e mortalidade. Nos países desenvolvidos a transição demográfica ocorreu lentamente e foi acompanhada pela ampliação dos sistemas de proteção social e elevação da qualidade de vida das populações urbanas e rurais (Chaimowicz, 1997; Gordilho e Universidade Aberta da Terceira Idade, 2000).

Contudo, em países em desenvolvimento como o Brasil a transição demográfica se deu de forma rápida, em decorrência de avanços na área médica e sanitária, e ao contrário do que foi visto em países desenvolvidos, tal condição não refletiu na melhoria da qualidade de vida da população. Essa transição está diretamente relacionada à diminuição da mortalidade infantil e de crianças ao longo do século XX e também está relacionada ao declínio da fertilidade e ao aumento da expectativa de vida após a década de 1950 (Camarano, 2013). Segundo o Instituto Brasileiro de Geografia e Estatística - IBGE (2019), o contingente de cerca de 210 milhões de habitantes residentes no Brasil em 2019 resulta de uma história populacional marcada por um crescimento econômico desigual e os consequentes desequilíbrios regionais.

As taxas mais altas de crescimento populacional observam-se na população idosa desde 1940, sendo que entre os anos de 1980 e 2005 foram pontuados crescimentos na ordem de $126,3 \%$ para essa população e 55,3\% para a população total (IBGE, 2010). Em 2010 a proporção de idosos na população brasileira era de 10,8\% e para 2050, as projeções estatísticas apontam que o Brasil terá a sexta maior população de idosos no mundo, com mais de 32 milhões de pessoas, representando $16 \%$ da população brasileira (IBGE, 2010). Ainda segundo o IBGE (2017) a população brasileira manteve a tendência de envelhecimento dos últimos anos e ganhou 4,8 milhões de idosos desde 2012, superando o expressivo número de 30,2 milhões em 2017.

Parte da população idosa brasileira, definida pela Organização Mundial da Saúde (OMS) como pessoas com 60 anos ou mais, preenche critérios de risco definidos para incapacidades, institucionalização e mortalidade. São considerados em situação de risco, idosos que se enquadram em uma ou mais das seguintes condições: ter idade igual ou 
superior a 80 anos; morar sozinho; ser mulher; estar socialmente isolado; não ter filhos; possuir limitações severas ou incapacidades; contar com recursos econômicos muito escassos, ser analfabeto; e estar exposto a maus tratos e/ou a situações de conflito (OMS, 2005; OPAS/OMS, 1994).

A presença de incapacidades foi também adotada como um dos importantes critérios de fragilidade em idosos pela Política Nacional de Saúde da Pessoa Idosa (PNSPI) (Brasil, 2006). São considerados frágeis ou em situação de fragilidade aqueles idosos que residem em Instituição de Longa Permanência para Idosos (ILPI), encontramse acamados, estiveram hospitalizados recentemente, apresentem doenças que resultem em incapacidade funcional e vivam em situações de violência doméstica. Segundo a PNSPI, aqueles que ainda não desenvolveram incapacidades, mas possuem condições predisponentes para isso, como acidente vascular encefálico, síndromes demenciais ou outras doenças degenerativas também podem ser considerados idosos frágeis. Segundo Fried et al. (2001) fragilidade refere-se ao "estado clínico de vulnerabilidade aos fatores estressores que resulta em declínio das reservas fisiológicas, com subsequente diminuição da eficiência da homeostase" (pg 146). Corroborando com tal conceito, pesquisadores definem fragilidade como uma síndrome biológica onde os sinais e sintomas podem ser oportunamente reconhecidos, sendo nesse contexto, uma síndrome passível de intervenção precoce com desfecho mais favorável. Por outro lado, outros estudiosos reforçam o caráter multidimensional dessa síndrome, que pode ser agravada por fatores sociais e econômicos como insuficiência de rede de suporte, de renda e baixa escolaridade (Brasil, 2006).

Segundo os Cadernos da Atenção Básica (AB), a fragilidade refere-se a uma síndrome multidimensional envolvendo fatores biológicos, psicológicos e sociais que resultam num estado de maior vulnerabilidade, associado ao maior risco de ocorrências de condições, tais como: declínio funcional, quedas, hospitalização, institucionalização e morte. A presença de um ou dois componentes citados a seguir são indicativos de alto risco de desenvolver a síndrome relacionada à fragilidade: perda de peso não intencional $(=4,5 \mathrm{~kg} \mathrm{ou}=5 \%$ do peso corporal no último ano $)$, fadiga, diminuição da força de preensão, baixo nível de atividade física e diminuição da velocidade da marcha (Brasil, 2006). 
O aumento do número de idosos frágeis na população brasileira, especialmente em condições de incapacidades e dependência impõe desafios aos diversos setores da sociedade (Ramos, 2003).

Para Ramos (2003) a saúde do idoso não pode ser mais considerada exclusivamente pela presença ou não de doenças, e sim pela preservação de sua capacidade funcional. A funcionalidade é considerada como importante indicador de saúde da população idosa, fator primordial para promover, manter e recuperar a autonomia e independência dos idosos, direcionando medidas individuais e coletivas. Segundo Gordilho et al. (2000) a capacidade funcional pode ser entendida como a capacidade de manter as funções físicas e mentais necessárias para conservação da autonomia e independência. O conceito de autonomia pode ser entendido como a habilidade do indivíduo em tomar decisões em relação à sua própria vida, com base em seus valores, regras e preferências e; independência pode ser entendida como habilidade de exercer funções relacionadas à vida diária, com alguma ou nenhuma ajuda de outros (OMS, 2005).

No sentido de orientar ações específicas de acordo com o perfil de funcionalidade, o Ministério da Saúde estratificou os idosos em 3 perfis:

1. Pessoas idosas independentes e autônomas para realizar as atividades da vida diária: esse grupo de idosos não precisa de ajuda de terceiros, e de nenhum tipo de adaptação ou modificação. Os cuidados para esses idosos devem voltar-se às ações para promoção e proteção à saúde, prevenção de agravos e intervenções terapêuticas. Se necessário, os profissionais da Atenção Básica podem contar com recursos da atenção especializada, utilizando instrumentos adequados de organização de fluxos e garantindo a gestão compartilhada do cuidado;

2. Pessoas idosas com necessidades de adaptação ou supervisão de terceiros para a realização das atividades da vida diária: fazem parte desse grupo pessoas idosas que realizam as atividades de forma adaptada, com modificação do ambiente ou mobiliário ou mais lentamente que o habitual, e pessoas que realizam as atividades com auxílio (sem contato físico) ou supervisão de terceiros. Para esse grupo os cuidados devem objetivar manutenção das funções preservadas e a reabilitação de dificuldades funcionais;

3. Pessoas idosas dependentes de terceiros para realizar as atividades da vida diária: nesses casos a capacidade funcional é comprometida, e o foco de cuidado deve ser o gerenciamento das condições crônicas e cuidados prolongados. O cuidado domiciliar 
deve ser planejado, assim como a reabilitação, cuidados paliativos e suporte às famílias e cuidadores (Brasil, 2014).

Nessa perspectiva, as diretrizes primordiais da Política Nacional de Saúde da Pessoa Idosa (PNSPI) são: promoção do envelhecimento ativo e saudável; ações integrais e intersetoriais incluindo intervenções no processo que origina a dependência funcional e; levantamento de dados sobre a capacidade funcional dos idosos (Brasil, 2006).

Segundo essa Política, intervenções voltadas à preservação ou melhoria da capacidade funcional e autonomia de idosos, devem enfatizar o autocuidado (Brasil, 2006). Almeida et al. (2012) afirmam que o autocuidado é reconhecido como estratégia fundamental para a promoção da capacidade funcional de idosos.

Corroborando com a concepção de autocuidado como "práticas de atividades voltadas para manter a vida, saúde e bem-estar” Orem et al. (2001) a serem realizadas por meio da administração de fatores comportamentais e ambientais (Litvoc e Derntl, 2002). Em consonância, Chompré (1994) afirma que o autocuidado favorece a participação do indivíduo e comunidade no controle do processo saúde-doença.

Segundo Norris apud Almeida (2004) alguns déficits de autocuidado decorrem do envelhecimento e muitos interferem no desempenho das atividades da vida diária. Nesse contexto, práticas de autocuidado são formas de compensar esses déficits e melhorar capacidade funcional.

Estudos reconhecem mudanças comportamentais, ambientais e uso de dispositivos auxiliares como práticas de autocuidado adotadas por idosos para compensar déficits nas atividades diárias (Almeida, 2004).

Norburn em seu estudo refere que é possível refletir sobre a presença de incapacidades em três dimensões: básicas, mobilidade e atividades instrumentais da vida diária, onde podem ser definidas três estratégias de autocuidado para lidar com as mesmas: uso de equipamentos ou dispositivos, mudanças comportamentais ou modificações ambientais (Norburn et al., 1995).

As mudanças comportamentais referem-se a: reorganização, adaptação ou substituição de técnicas ou atividades necessárias para a manutenção das atividades cotidianas. Essas mudanças incluem adaptação das atividades de modo que essas estejam de acordo com a capacidade de quem as realiza, como evitar escadas, carregar objetos pesados, fracionar compras, equilibrar realização de atividades que impliquem alto esforço, tornando-as mais confortáveis e seguras. (Almeida et al., 2012). 
Modificações ambientais também podem compensar dificuldades e envolver desde reorganização de mobiliário, instalações de barras e corrimãos até reformas. Modificações ambientais devem se nortear pelo significado atribuído pelo idoso ao seu ambiente, oferecendo-lhe segurança e equilibrando necessidades objetivas e subjetivas (Almeida et al., 2012).

A utilização de dispositivos auxiliares e de tecnologia assistiva também pode se configurar como prática de autocuidado, pois itens podem ser adquiridos ou modificados para manter ou melhorar a capacidade funcional de indivíduos com incapacidades (Mann et al., 1995).

À medida que capacitam o sujeito para desempenhar tarefas cotidianas, as práticas de autocuidado podem ser utilizadas como estratégia para promoção de saúde, prevenção ou combate ao isolamento social e, resgate da participação social.

\subsection{AVALIAÇÃO DA CAPACIDADE FUNCIONAL NA ATENÇÃO BÁSICA: ORGANIZAÇÃO DO CUIDADO DO IDOSO PELA REDE DE ATENÇÃO À SAÚDE DA PESSOA IDOSA (RASPI)}

O contato e acesso dos usuários aos sistemas de saúde se estabelecem preferencialmente por meio da Atenção Básica (AB). O cuidado prestado nesse nível de atenção baseia-se em princípios tais como acessibilidade e coordenação do cuidado, vínculo e continuidade, integralidade e humanização. Através de práticas interdisciplinares, as equipes se responsabilizam pela saúde da população, na perspectiva de uma atenção integral humanizada (Brasil, 2006).

A atenção integral baseia-se no fato de que o ser humano é um ser biopsicossocial, e para tanto necessita de ações voltadas para suas diversas demandas e necessidades. Isso equivale a dizer que as práticas em saúde devem superar a tradicional fragmentação e se articularem do ponto de vista multiprofissional e intersetorial, aumentando a resolutividade e qualidade dos serviços de saúde (Scherer et al., 2013).

De acordo com as diretrizes do Ministério da Saúde, os profissionais da AB devem buscar a atenção integral, de qualidade e resolutiva, o que implica considerar as necessidades sociais e de saúde da população, conhecer a realidade local e fazer uso da clínica ampliada, contínua, organizada, e atuar de maneira articulada multiprofissional e intersetorial (Brasil, 2017). 
Segundo a Política Nacional de Atenção Básica, regulamentada pela Portaria GM nº48 de 28 de março de 2006, a AB caracteriza-se por desenvolver um conjunto de ações de saúde, individuais e coletivas, incluindo a promoção e a proteção à saúde, prevenção de agravos, diagnóstico, tratamento, reabilitação e a manutenção da saúde. As ações são desenvolvidas por equipe, se pautam por necessidades sociais e de saúde da população do território de abrangência e levam em consideração as especificidades e dinâmicas desse território. A AB utiliza tecnologias de elevada complexidade (conhecimento) e baixa densidade (equipamentos), que devem solucionar os problemas de saúde de maior frequência e relevância em seu território (Brasil, 2006a).

Considerando-se os princípios que regem a $\mathrm{AB}$ e o escopo de suas ações, espera-se que a mesma desempenhe o papel de coordenadora do cuidado integral à pessoa idosa, promova trabalho em equipe com ações específicas para as necessidades dessa população, orientadas pelas perspectivas de resolutividade, organização dos fluxos e responsabilização integral pela saúde dos usuários, apoiadas por outros tipos de serviços de diferentes densidades e tecnologias, a depender da necessidade da população (Brasil, 2018).

$\mathrm{Na} \mathrm{AB}$ espera-se oferecer à pessoa idosa e à sua rede de suporte social, incluindo familiares e cuidadores, uma atenção humanizada com orientação, acompanhamento e apoio necessários, ressaltando o acolhimento às necessidades dos idosos com respeito às culturas locais, às diferentes formas de envelhecer e à diminuição das barreiras arquitetônicas, de forma a facilitar o acesso conforme proposto no Manual de Estrutura Física, do Ministério da Saúde (Brasil, 2006a).

No âmbito municipal, em consonância com a PNSPI, a Área Técnica de Saúde da Pessoa Idosa da Prefeitura da Cidade de São Paulo propõe a Rede de Atenção à Saúde da Pessoa Idosa (RASPI), que tem como eixo principal a avaliação da capacidade funcional dessa população a partir da Atenção Básica e organização de seu cuidado com base nos resultados dessa avaliação (São Paulo, 2014).

Idosos com distintos níveis de capacidade funcional requerem um sistema integrado no qual as condições mais prevalentes e de baixa complexidade são atendidas no nível primário - Unidade Básica de Saúde (UBS) e Estratégia de Saúde da Família (ESF) enquanto as patologias de maior complexidade e os problemas específicos da população 
idosa são atendidas no nível secundário de atenção - Unidade de Referência à Saúde do Idoso (URSI) e o Programa Acompanhante de Idosos (PAI) (São Paulo, 2014).

\subsection{ENVELHECER EM CONTEXTO DE VULNERABILIDADE SOCIAL: A EXPERIÊNCIA DE IDOSOS DA REGIÃO DO ITAIM PAULISTA}

O bairro do Itaim Paulista é um dos mais antigos da capital paulista, por volta de 1600 estava nas mãos da Ordem católica do Carmo, que lhe colocou o nome de Itaim, que significa "pedra pequena". No fim do século XVIII recebeu moradores, era constituído por fazendas, sítios e chácaras. A região começou a tomar corpo, ali por volta dos anos 1920, com a chegada da ferrovia, o que lhe trouxe mais habitantes. O bairro foi crescendo, historicamente com pouca ou nenhuma infraestrutura (SPBairros, 2020).

A Subprefeitura do Itaim Paulista é uma das 32 subprefeituras do município de São

Paulo. É composta pelos distritos Itaim Paulista e Vila Curuçá, que somados representam uma área de 21,7 km². Segundo dados do IBGE 2010, a região é habitada por mais de 358 mil pessoas (São Paulo, 2019).

Segundo o Índice Paulista de Vulnerabilidade, a região do Itaim Paulista faz parte do grupo 5 - sendo considerado de alta vulnerabilidade urbana. Dentre os indicadores de vulnerabilidade podemos mencionar que a região apresenta $9,85 \%$ de crianças de 0 a 5 anos na população; renda domiciliar per capita nos domicílios particulares permanentes do setor censitário de $\mathrm{R} \$ 380,68$; rendimento médio das mulheres responsáveis pelo domicílio no valor de $\mathrm{R} \$ 571,62$. Outros indicadores incluem média de moradores em domicílios particulares de 3,28 pessoas; idade média das pessoas responsáveis de 43,08 anos e 95,52\% de pessoas responsáveis (CEM-CEBRAP, 2004). 
Seguem abaixo algumas fotos do bairro:

Figura 1: Bairro do Itaim Paulista, São Paulo

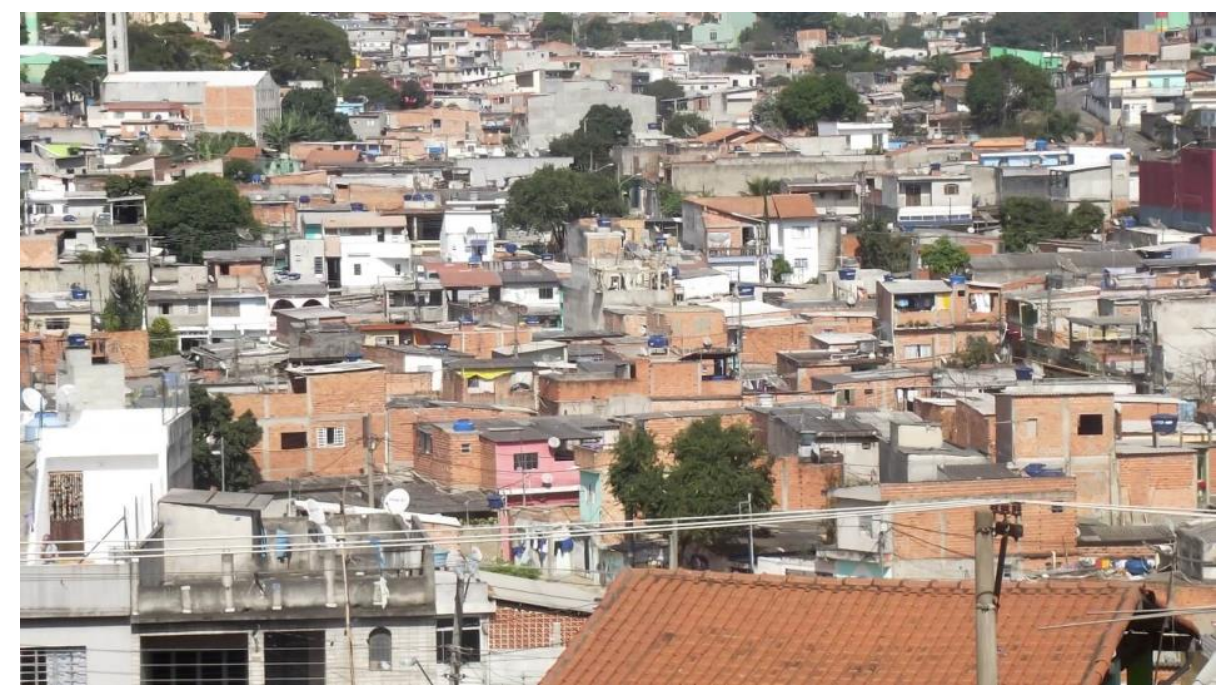

FONTE: Grupo Acontece a partir de: https://aconteceagora.com.br/raio-x-dos-bairrositaim-paulista-e-vila-curuca/ [data desconhecida]

Figura 2: Bairro do Itaim Paulista, São Paulo

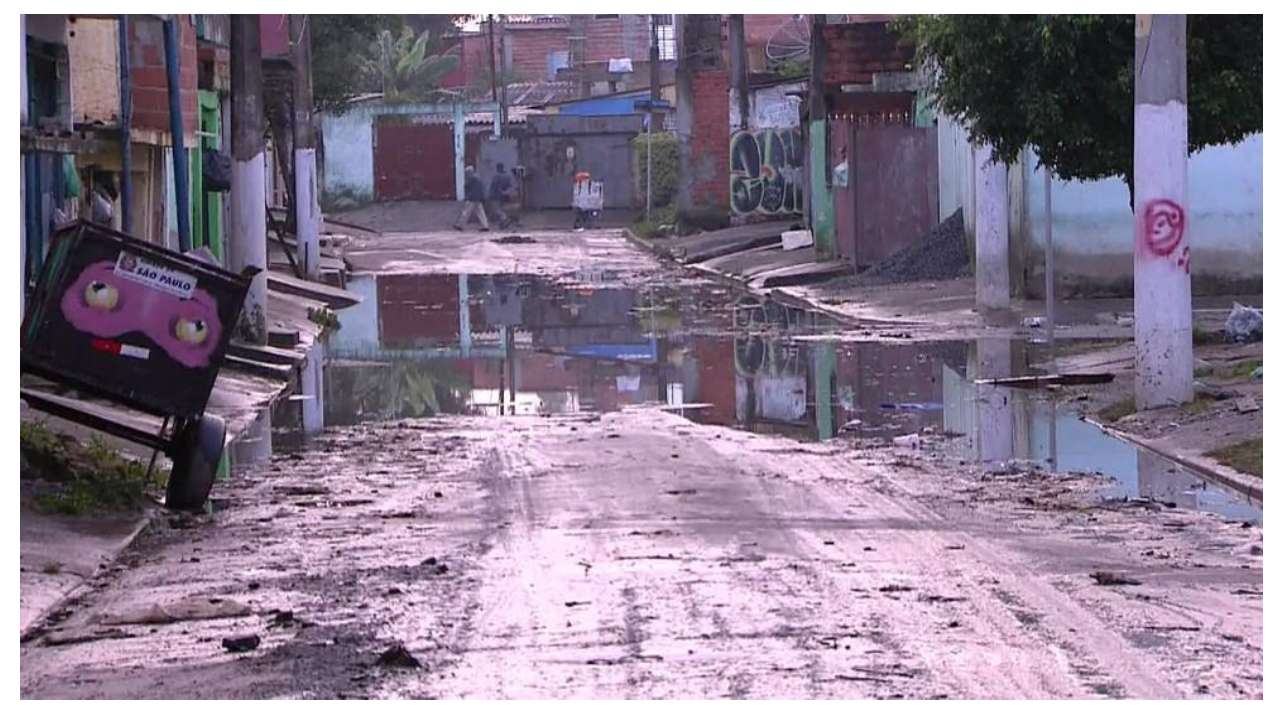

FONTE: Reprodução TV Globo (2020)

Segundo Sevalho (2018), vulneráveis seriam pessoas enfraquecidas, por razões biológicas ou sociais, em sua capacidade de agir e de se defender, necessitando, portanto, de proteção diferenciada para garantia de seus direitos.

Em consonância, Ayres et al., (2009) relaciona vulnerabilidade ao prejuízo de garantia de cidadania vivenciado por populações politicamente fragilizadas. Conforme 
Kowarick (2009), o termo vulnerabilidade no Brasil remete a questões ligadas a desigualdade perante as leis, fragilização da cidadania, suscetibilidade a situações de violência, dificuldade de acesso à moradia, aos serviços de saúde, de assistência social e emprego, destacando a vulnerabilidade socioeconômica, que se refere à falta de proteção quanto a garantias de trabalho, saúde, educação e direitos sociais básicos.

Nesse sentido para Nichiata et al. (2008) o termo vulnerabilidade pode ser usado como sinônimo de risco a que está exposto o indivíduo que pode estar associado a características biológicas, ciclos de vida, condições sociais, percepção pessoal do processo saúde-doença e a diminuição da capacidade de proteção ligada ao poder de escolha e decisão.

Sevalho (2018) cita três componentes que abrangem ações e mecanismos de enfrentamento de riscos de vulnerabilidade. Articulam-se entre si o componente individual, que se refere às informações que a pessoa tem sobre o problema e sua capacidade de usá-las na vida cotidiana; o componente social, referente à obtenção de informações e ao poder de influência social e política para alcançar expressão, segurança e proteção; e o componente programático, que se refere à qualidade e ao funcionamento efetivo dos programas de controle e serviços. Esses três componentes estão interligados, sendo a vulnerabilidade definida pela inter-relação de condições materiais, psicológicas, culturais, morais, jurídicas e políticas.

Nessa mesma perspectiva instituiu-se no Brasil a Comissão Nacional sobre os Determinantes Sociais da Saúde (CNDSS). Essa Comissão considera que uma série de aspectos exponha a população à risco e determine a ocorrência de problemas de saúde como sociais, econômicos, culturais, étnico-raciais, psicológicos e comportamentais (Buss and Pellegrini Filho, 2007).

Sevalho (2018) acrescenta que doenças, deficiências e o próprio envelhecimento podem aprisionar populações em situações e estados de vulnerabilidade, diminuindo seu potencial de agir. Pelo exposto torna-se possível afirmar que circunstâncias econômicas e sociais desfavoráveis, tornam o idoso ainda mais susceptível à determinação social pela acumulação das exposições aos fatores de risco (Geib, 2012), especialmente se ele estiver em condição de fragilidade ou em risco de desenvolvê-la.

Em consonância com Sevalho (2018), que identifica ações para enfrentamento da vulnerabilidade a serem reunidas em um componente programático. Hildon et al. (2010) 
afirma que a vulnerabilidade social está associada à escassez de programas de suporte às necessidades sociais e de saúde.

Nessa perspectiva a região do Itaim Paulista no município de São Paulo pode ser considerada como um território de grande vulnerabilidade, pois além dos indicadores reunidos no Mapa da vulnerabilidade social da população da cidade de São Paulo (2004), possui indicadores de vulnerabilidade como baixa escolaridade, prejuízo no saneamento básico, na oferta de transportes públicos, alto índice de homicídios de pessoas entre $15 \mathrm{a}$ 29 anos de idade, precárias condições de habitação, alto percentual de mães jovens (CEMCEBRAP, 2004) e, especialmente, não se identifica nesse território serviços específicos e exclusivos de atendimento à saúde previsto pela RASPI - tais como URSI e PAI.

O Itaim Paulista, segundo a Relação dos Estabelecimentos/Serviços da Secretaria Municipal da Saúde conta com 16 Unidades Básicas de Saúde, 2 Centros Especializados em Reabilitação (CER), 3 Centros de Atenção Psicossociais (CAPS) - sendo um para usuários adultos com sofrimento psíquico grave e persistente (CAPS adulto), um para o público infanto-juvenil com sofrimento psíquico grave e persistente (CAPSIj) e um para usuários com transtornos decorrentes do uso de substâncias psicoativas, álcool e outras drogas (CAPS-AD) - 2 Centros de Convivência e Cooperativa (CECCO), 1 serviço de Assistência Médica Ambulatorial (AMA), 1 Centro Odontológico Especializado (COE), 1 Centro de Testagem e Aconselhamento (CTA), 1 Hospital Dia da Rede Hora Certa e 1 Pronto Atendimento (PA) (São Paulo, 2020).

Considerando os serviços presentes da região, os profissionais da $\mathrm{AB}$ ao avaliarem e se depararem com idosos frágeis ou em condições para o desenvolvimento de fragilidades, dispõem de escassas referências para encaminhamento desses idosos na região, expondo-os ao desenvolvimento ou agravamento de tais condições.

Caso necessitem de atendimento especializado em geriatria/gerontologia, os idosos têm a possibilidade de serem referenciados para o Instituto Paulista de Geriatria e Gerontologia (IPGG) - José Ermírio de Moraes, na região de São Miguel Paulista. Admite-se, entretanto, que a distância dos serviços em relação à moradia do idoso, suas frequentes dificuldades de deslocamentos e dificuldade de acesso a vagas de especialistas por conta da grande demanda configuram-se grandes desafios para sua inserção ao serviço especializado.

Considera-se que uma ampla e detalhada avaliação da capacidade funcional, com ênfase no autocuidado, no âmbito da atenção primária em saúde (APS), poderá contribuir 
para o planejamento e desenvolvimento de intervenções nesse nível de atenção, voltadas à preservação e melhora da capacidade funcional de idosos, postergando o surgimento ou o agravamento de incapacidades e fragilidades nessa população. Ações com foco na capacidade funcional e autocuidado pela APS não respondem às demandas por serviços especializados, mas ampliam possibilidade de resolutividade e, responsabilização dos usuários idosos, incluindo aqueles em condições de fragilidade e vulnerabilidade, bem como apoiam e qualificam fluxos e encaminhamentos para serviços de maior densidade tecnológica na região. Em síntese, admite-se que ações com este foco configuram-se potenciais norteadores para atenção integral aos idosos, a partir da atenção primária a saúde. 


\section{JUSTIFICATIVA}

Considerando-se que dificuldades funcionais, prejuízos de saúde e vulnerabilidade social, compõem condições de fragilidade de idosos e/ou contribuem para seu agravamento e que o autocuidado inclui-se como parte das estratégias para prevenção e redução de fragilidades nessa população, propõe-se: a) caracterizar usuários idosos de duas unidades básicas da região do Itaim Paulista quanto aos aspectos demográficos, sociais e de saúde; b) avaliar capacidade funcional e adoção de práticas de autocuidado adotadas por esses idosos, seus familiares e cuidadores para enfrentamento de dificuldades funcionais; c) associar aspectos demográficos, sociais e de saúde à capacidade funcional e uso de práticas de autocuidados de idosos.

Após a finalização do estudo e com base em seus resultados espera-se propor intervenções junto à população estudada que considerem suas necessidades sociais, de saúde e funcionais e que deem ênfase à proposição, reforço e ampliação de práticas de autocuidado correspondentes a essas necessidades, visando manter ou melhorar a capacidade funcional, independência e autonomia dessa população. Assim a proposição de intervenções não comporá o presente estudo, mas será realizada com base nele.

Considera-se que os resultados do estudo e intervenções derivadas dele poderão vir a contribuir para que as unidades básicas de saúde da região do Itaim Paulista ampliem sua atuação como ordenadoras da atenção aos usuários idosos na perspectiva da integralidade, contribuindo para o desenvolvimento da RASPI na região. 


\section{OBJETIVO GERAL}

Avaliar capacidade funcional e práticas de autocuidado adotadas por idosos usuários de serviços no âmbito da atenção primária em saúde na região do Itaim Paulista e sua associação com alguns indicadores de vulnerabilidade social.

\subsection{OBJETIVOS ESPECÍFICOS}

- Identificar dificuldades para atividades cotidianas de idosos participantes do estudo;

- Reconhecer adoção de práticas de autocuidado por esses idosos para reduzir dificuldades em suas atividades cotidianas;

- Verificar possíveis associações entre fatores sociais, demográficos e condições de saúde com dificuldades funcionais e adoção de práticas de autocuidado desses idosos. 


\section{METODOLOGIA}

\subsection{TIPO DE ESTUDO E ASPECTOS ÉTICOS}

Trata-se de uma pesquisa de natureza quantitativa e delineamento transversal do tipo descritiva e analítica, realizada por meio de entrevistas individuais a idosos usuários das unidades UBS Jd. Camargo Novo e UBS Dr. Júlio de Gouveia / Região do Itaim Paulista.

A entrevista individual compreendeu a aplicação de dois instrumentos padronizados que reuniram as seguintes informações: condições de saúde, histórico de internações e de quedas, perda de peso não intencional, aspectos demográficos e sociais, entre outros indicadores de fragilidades, com destaque para dificuldades funcionais e, adoção de práticas de autocuidado por esses idosos para seu enfrentamento.

Em caso de impossibilidade de compreensão e expressão de informações por parte dos idosos, previu-se que as entrevistas fossem conduzidas com cuidador ou familiar mais próximo do idoso.

A seguir foram estabelecidas associações entre variáveis relacionadas à saúde, aspectos sociais, demográficos e de funcionalidade. Essas informações deverão amparar futuras intervenções voltadas para proposição, reforço ou ampliação de práticas de autocuidado para os idosos e/ou cuidadores participantes da pesquisa bem como proposição ou ampliação de articulações com a rede de serviços para prevenir e reduzir fragilidades e incapacidades de idosos. As intervenções não comporão a presente pesquisa.

A pesquisa foi submetida e aprovada pelos Comitês de Ética em Pesquisa da Faculdade de Medicina da Universidade de São Paulo (CAAE: 97957718.8.0000.0065) e da Secretaria Municipal da Saúde de São Paulo como instituição coparticipante (CAAE: 97957718.8.3001.0086).

Os idosos, e/ou cuidadores / familiares, foram convidados a participar da pesquisa e esclarecidos quanto aos seus objetivos, procedimentos, riscos e benefícios por meio de leitura do Termo de Consentimento Livre e Esclarecido TCLE (ANEXO 1). Salientou-se que os riscos de participação na entrevista eram mínimos e referiram-se ao receio quanto à exposição de ideias, eventuais desconfortos ou constrangimentos em relação às perguntas do entrevistador. Esses riscos poderiam ser atenuados ou superados por meio 
de esclarecimentos, orientação dos pesquisadores e garantia quanto ao sigilo e ao anonimato.

O estudo prevê benefícios diretos aos participantes, considerando que as informações coletadas nas entrevistas serão analisadas e, com base nelas, os pesquisadores deverão, após a conclusão do estudo, propor e realizar intervenções voltadas a reduzir dificuldades para atividades do dia a dia. Ainda a identificação de fatores sociais e de saúde relacionados às dificuldades para atividades cotidianas deverão apoiar futuro planejamento de ações para os demais idosos usuários das unidades básicas envolvidas no estudo.

Após o consentimento em participar do estudo, os participantes assinaram o TCLE em duas vias, sendo uma entregue ao participante e outra mantida junto aos pesquisadores. 


\subsection{LOCAL DE ESTUDO}

O estudo foi realizado em 2 (duas) Unidades Básicas de Saúde tradicionais na região do Itaim Paulista, extremo leste da cidade de São Paulo, identificadas no mapa a seguir:

Figura 3: Mapa das regiões da cidade de São Paulo com destaque para as UBS Jd. Camargo Novo e UBS Dr. Júlio de Gouveia (2019)

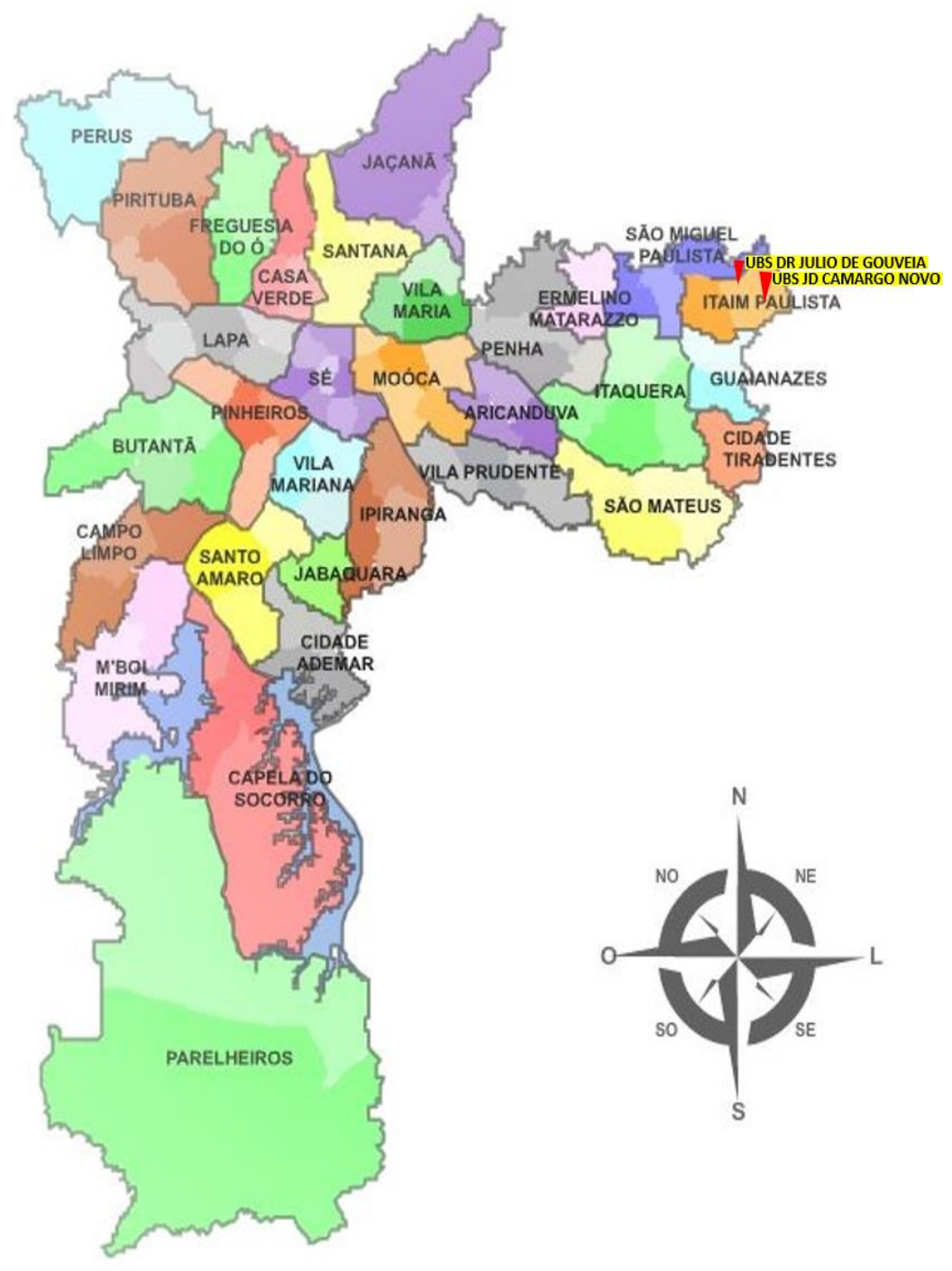

FONTE: Prefeitura de São Paulo a partir de:

http://transparencia.prefeitura.sp.gov.br/prefeituras_regionais/default.aspx (2019b) 


\subsection{CARACTERIZAÇÃO E CÁLCULO DA AMOSTRA}

Optou por estudar uma amostra de convivência, selecionada conforme os seguintes critérios de inclusão da população na pesquisa:

a) Ter 60 anos ou mais;

b) Ser usuário ativo da UBS Jardim Camargo Novo ou da UBS Júlio de Gouveia no período de 1 de junho de 2018 a 31 de outubro de 2019;

c) Residir em área definida para a pesquisa

\subsubsection{CÁLCULO AMOSTRAL}

Considerando-se as variáveis de interesse do presente estudo e que o percentual máximo de sujeitos com uma ou mais dificuldade para atividades de vida diária é de 48\% (Almeida et al., 2012), pôde se calcular uma amostra de 128 sujeitos, utilizando se a seguinte fórmula:

$$
n=\frac{N \cdot Z^{2} \cdot p \cdot(1-p)}{Z^{2} \cdot p \cdot(1-p)+e^{2} \cdot(N-1)}
$$

Onde:

$\mathrm{n}$ - amostra calculada

$\mathrm{N}$ - população

Z - variável normal padronizada associada ao nível de confiança

p - verdadeira probabilidade do evento

e - erro amostral

b) definição de erro amostral: $5 \%$

c) definição de nível de confiança: $95 \%$

d) percentual máximo de sujeitos com uma ou mais dificuldade para atividades de vida diária: 48\% (Almeida et al, 2012) 


\subsection{PROCEDIMENTOS DE COLETA DE DADOS}

Foram entrevistados 128 idosos, os mesmos foram abordados no período das 7 às 12 horas, de segunda a sexta-feira, entre os meses de junho 2018 a outubro de 2019, a amostra foi de conveniência conforme sua presença nas Unidades referidas para quaisquer tipos de procedimento. Na condição de potenciais participantes, os idosos e/ou seus cuidadores foram convidados a participarem da pesquisa e esse convite foi feito em sala de espera ou consultório médico, durante atendimento de enfermagem ou em agendamento com terapeuta ocupacional, fonoaudiologia ou nutrição. Após consentirem formalmente em participarem do estudo e após assinarem o TCLE, os participantes foram entrevistados no mesmo momento ou foi agendada a aplicação do instrumental para dia e horário de maior conveniência do idoso, a média de tempo de aplicação foi de 1hora e 20 minutos por participante.

\subsection{INSTRUMENTOS}

Neste estudo foram utilizados dois instrumentos padronizados. Sua aplicação no âmbito da presente pesquisa gera informações que se complementam, se reafirmam mutuamente e, fundamentalmente, a aplicação desses instrumentos permite levantar indicadores de fragilidade, avaliar capacidade funcional em sua complexidade e identificar se idosos adotam práticas de autocuidado para seu enfrentamento, contemplando desse modo, em conjunto, a totalidade de variáveis de interesse da pesquisa. Esses instrumentos são respectivamente:

1) Avaliação Multidimensional da Pessoa Idosa na Atenção Básica-AMPI/AB

Esse instrumento baseia-se no Caderno da Atenção Básica no 19 do Ministério da Saúde e compõe-se de questionário auto-referido com 17 questões para avaliação social, física, cognitiva, funcional e aplicação de Testes de Rastreamento Funcional. Possibilita a organização dos idosos em três categorias: 0 - 5 pontos: idoso saudável, 6 - 10 pontos: idoso pré-frágil e > 11 pontos: idoso frágil. Quanto maior a pontuação, maior será a necessidade de cuidado. Este instrumento de avaliação e gerenciamento de casos permite também a elaboração de ações de cuidados coletivos na Atenção Básica e Especializada voltadas para essa população (Lima et al., 2016). 
Recentemente foi publicado artigo examinando a validade e a confiabilidade do instrumento AMPI-AB, onde a mesma foi considerada instrumento válido e confiável para avaliar idosos em ambiente de atenção primária com recursos escassos. Sendo precisa na detecção de fragilidade física e prévia de mortalidade, agravo de incapacidades, hospitalizações, consultas de emergência e quedas entre os idosos na atenção primária (Saraiva et al., 2020). Trata-se do primeiro estudo que avalia um instrumento para gerenciar cuidados de saúde de idosos em um sistema de saúde pública em países de média-baixa renda, foi desenvolvido por um conjunto de especialistas em saúde pública, geriatria e gerontologia. Segundo o estudo o objetivo da AMPI-AB é identificar idosos com alta complexidade e necessidades de cuidados, que podem se beneficiar de atendimento especializado, orientar os cuidados profissionais na avaliação de idosos e formulação de projetos terapêuticos de saúde individualizados.

2) Instrumento para a Classificação de idosos quanto à Capacidade para o Autocuidado (CICAc) - Versão simplificada

Esse instrumento é aplicado por meio de entrevista. Ele contém questões abertas e fechadas correspondentes às dimensões: arranjo doméstico e potencial rede de suporte, perfil social, universo ocupacional e capacidade funcional. O CICAc informa níveis de dificuldade para atividades básicas, instrumentais, lazer e trabalho (não apresenta dificuldade; apresenta dificuldade compensada com práticas de autocuidado; apresenta dificuldade não compensada por práticas de autocuidado; apresenta dificuldade e faz com ajuda; deixou de fazer devido à dificuldade). O instrumento contempla a natureza das dificuldades (física, sensorial, emocional, cognitiva, social, econômica, restrições clínicas, relativa ao ambiente físico e outras) e identifica ainda práticas de autocuidado para compensação de dificuldades, que compreendem modificação comportamental, modificação ambiental, adoção de tecnologia assistiva e ajuda de outrem (Almeida et al., 2016).

O instrumento CICAc - Versão simplificada foi validado em seu conteúdo e confiabilidade, permite classificar idosos quanto à capacidade para o autocuidado para os blocos de atividades básicas e atividades de vida diárias, e para cada uma das atividades de lazer e trabalho contidas no Instrumento. Ele pode ser considerado apropriado para uso 
na atenção primária em saúde, e em pesquisas ao classificar idosos quanto à capacidade para o autocuidado nas atividades cotidianas, além de possibilitar descrever aspectos que gerem dificuldades para essas atividades (Almeida, 2004).

\section{FORMA DE ANÁLISE DOS DADOS}

Foram realizadas análises - descritiva e estatística - de informações. No que se refere à análise descritiva foram geradas frequências absolutas e relativas dos idosos segundo características sociodemográficas, clínicas, de saúde e funcionais, com ênfase para presença, número e grau de dificuldades dos participantes para cada uma das ABVD, AIVD e atividades de lazer, bem como para os blocos da ABVD e AIVD.

No tocante à análise estatística de informações, foram realizadas distribuições de presença, número e grau de dificuldades dos participantes para ABVD e AIVD segundo características demográficas, sociais, clínicas e níveis de fragilidade e, verificadas associações entre dificuldades para ABVD / AIVD e demais variáveis analisadas.

Para tanto, foram realizados testes qui-quadrado ou testes exatos (teste exato de Fisher ou testes da razão de verossimilhanças) (Kirkwood and Sterne, 2010), estimados os Odds Ratio de cada variável em relação aos desfechos funcionais com os respectivos intervalos com 95\% de confiança com uso de regressão logística bivariada (Hosmer Jr et al., 2013), criados os modelos de regressão logística múltipla, selecionando-se as variáveis que apresentaram nível de significância inferior a $0,2(\mathrm{p}<0,2)$ nas análises bivariadas e cujas categorias não apresentaram "caselas" com zero, o que lhes permitiu entrarem nos modelos múltiplos, sendo mantidas todas as variáveis no modelo "full model". Para realização das análises foi utilizado o software IBM-SPSS for Windows versão 22.0 e para tabulação dos dados foi utilizado o software Microsoft Excel 2010. Os testes foram realizados com nível de significância de $5 \%$.

Reitera-se que a análise quantitativa das informações coletadas deverão gerar informações que amparem futuro reforço ou proposição de práticas de autocuidado para os idosos e/ou cuidadores participantes da pesquisa bem como proposição ou ampliação de articulações com a rede de serviços para prevenir e reduzir fragilidades e incapacidades de idosos. Essas ações não compõem a presente pesquisa e serão conduzidas após sua finalização. 


\section{RESULTADOS}

Os resultados da pesquisa serão apresentados a seguir. Estes resultados abrangem no primeiro momento e, em linhas gerais, caracterização demográfica, socioeconômica, clínica, de saúde, funcional e relativa aos níveis de fragilidades dos participantes do estudo.

No segundo momento serão apresentadas distribuições dos idosos quanto às dificuldades para ABVD e AIVD, segundo características acima mencionadas, bem como presença ou ausência de associações.

No momento seguinte serão descritas as dificuldades funcionais segundo características que se mostraram associadas a estas dificuldades e resultados dos testes de associação. Por fim, em relação às variáveis independentes associadas às dificuldades funcionais, buscou-se estimar as chances dessas variáveis provocarem essas dificuldades e, para aquelas que se associaram às dificuldades com maior nível de significância buscou-se avaliar sua influência no desfecho funcional com controle das demais variáveis analisadas.

Os dados apresentados nas Tabelas de 1 a 8 referem-se à caracterização demográfica, socioeconômica, clínica e de saúde, funcional e, em relação aos níveis de fragilidades dos entrevistados. Os dados da Tabela 1 combinam informações obtidas por meio da aplicação do CICAc e da AMPI- AB, enquanto as informações descritas nas Tabelas de 2 a 8, são específicas de cada um desses instrumentos.

Tabela 1 - Distribuição de idosos segundo dados demográficos e socioeconômicos, CICAc e AMPI- AB, SP, 2019

\begin{tabular}{|c|c|c|}
\hline Variável & Frequência & $\%$ \\
\hline \multicolumn{3}{|l|}{ Sexo } \\
\hline Feminino & 93 & 72,7 \\
\hline Masculino & 35 & 27,3 \\
\hline \multicolumn{3}{|l|}{ Idade } \\
\hline 60 a 69 & 71 & 55,5 \\
\hline 70 a 79 & 49 & 38,3 \\
\hline $80 \mathrm{e}+$ & 8 & 6,3 \\
\hline \multicolumn{3}{|l|}{ Morar só } \\
\hline Sim & 26 & 20,3 \\
\hline Não & 102 & 79,7 \\
\hline
\end{tabular}




\begin{tabular}{|c|c|c|}
\hline & \multicolumn{2}{|c|}{ continuação } \\
\hline Variável & Frequência & $\%$ \\
\hline \multicolumn{3}{|l|}{ Estado Civil } \\
\hline Solteiro & 10 & 7,8 \\
\hline Casado & 75 & 58,6 \\
\hline Divorciado & 15 & 11,7 \\
\hline Viúvo & 27 & 21,1 \\
\hline \multicolumn{3}{|l|}{ Escolaridade } \\
\hline Analfabeto & 19 & 14,9 \\
\hline Até 4 anos & 71 & 55,4 \\
\hline De 5 a 8 anos & 16 & 12,5 \\
\hline 9 anos ou + & 22 & 17,2 \\
\hline \multicolumn{3}{|l|}{ Recursos financeiros } \\
\hline Aposentadoria & 68 & 53,1 \\
\hline Recebe ajuda & 46 & 35,9 \\
\hline Atividades Informais & 23 & 18 \\
\hline Salário & 17 & 13,3 \\
\hline Pensão & 15 & 11,7 \\
\hline Aluguel & 10 & 7,8 \\
\hline Benefício Assistencial & 6 & 4,7 \\
\hline \multicolumn{3}{|l|}{ Filhos } \\
\hline Não & 19 & 14,8 \\
\hline Sim & 109 & 85,2 \\
\hline \multicolumn{3}{|l|}{ Possui alguém com quem contar } \\
\hline Não & 15 & 11,7 \\
\hline Sim & 113 & 88,3 \\
\hline \multicolumn{3}{|l|}{ Principal cuidador } \\
\hline Filho & 60 & 46,9 \\
\hline Cônjuge & 38 & 29,7 \\
\hline $\begin{array}{l}\text { Outros (enteado, genro, nora, irmãos, } \\
\text { vizinho, cuidador profissional e sobrinho) }\end{array}$ & 30 & 23,4 \\
\hline \multicolumn{3}{|l|}{ Sexo do cuidador } \\
\hline Feminino & 83 & 73,5 \\
\hline Masculino & 30 & 26,5 \\
\hline \multicolumn{3}{|l|}{ Idade do cuidador } \\
\hline De 25 a 59 anos & 78 & 69 \\
\hline $60+$ & 50 & 31 \\
\hline \multicolumn{3}{|l|}{ Exerce profissão } \\
\hline Não & 104 & 81,3 \\
\hline Sim & 24 & 18,8 \\
\hline
\end{tabular}


conclusão

\begin{tabular}{lcc}
\hline \multicolumn{1}{c}{ Variável } & Frequência & \% \\
\hline Principal profissão durante a vida & & \\
\hline $\begin{array}{l}\text { Serviços de limpeza (empregada doméstica, } \\
\text { faxineira, diarista e serviços gerais) }\end{array}$ & 36 & 28,1 \\
\hline $\begin{array}{l}\text { Metalúrgica (manutenção, operador e } \\
\text { projetista de máquinas) }\end{array}$ & 16 & 12,5 \\
\hline Costura & 15 & 11,7 \\
\hline Do lar & 8 & 6,3 \\
\hline Enfermagem (aux. e tec.) & 7 & 5,5 \\
\hline Comerciante & 7 & 5,5 \\
\hline Trabalhador Rural & 6 & 4,7 \\
\hline Pedreiro & 3 & 2,3 \\
\hline Babá & 3 & 2,3 \\
\hline Segurança & 2 & 1,6 \\
\hline Motorista & 2 & 1,6 \\
\hline Secretária & 2 & 1,6 \\
\hline Carpinteiro & 2 & 1,6 \\
\hline Funcionário Público & 2 & 1,6 \\
\hline Porteiro & 2 & 1,6 \\
\hline $\begin{array}{l}\text { Outros (advogado, marceneiro, cobrador, } \\
\text { cozinheiro, feirante, merendeira, podóloga, } \\
\text { policial, soldador, entre outros) }\end{array}$ & 14 & 10,9 \\
\hline $\begin{array}{l}\text { Satisfação quanto às necessidades } \\
\text { (alimentação, moradia, saúde, etc.) }\end{array}$ & & \\
\hline Muito bem & 17 & 13,3 \\
\hline Bem & 37 & 28,9 \\
\hline Mais ou menos & 58 & 45,3 \\
\hline Mal & 11 & 8,6 \\
\hline Muito mal & 5 & 3,9 \\
\hline & & \\
\hline
\end{tabular}

Na Tabela 1 observa-se que a amostra é predominantemente de mulheres, com até 69 anos, casadas, com até 4 anos de escolaridade. Os participantes informam recursos financeiros oriundos especialmente de aposentadoria e avaliam que esses recursos satisfazem mais ou menos suas necessidades básicas. Esses identificam como principais atividades profissionais durante a vida, aquelas relacionada a serviços de limpeza. 
Tabela 2 - Distribuição de idosos segundo percepção de saúde, presença de doenças crônicas, uso de medicamentos, episódios de internação, alterações funcionais, necessidade de ajuda para atividades cotidianas e níveis de fragilidade, AMPI-AB, SP, 2019

\begin{tabular}{|c|c|c|}
\hline Variável & Frequência & $\%$ \\
\hline \multicolumn{3}{|l|}{ Percepção de Saúde } \\
\hline Muito Boa/Boa & 59 & 46,1 \\
\hline Regular/Ruim/Muito Ruim & 69 & 53,9 \\
\hline \multicolumn{3}{|l|}{ Condições Crônicas } \\
\hline Nenhum & 7 & 5,5 \\
\hline $1 \mathrm{a} 2$ & 41 & 32 \\
\hline 3 ou mais & 80 & 62,5 \\
\hline \multicolumn{3}{|l|}{ Medicamentos } \\
\hline $1 \mathrm{a} 4$ & 80 & 62,5 \\
\hline $5 \mathrm{ou}+$ & 48 & 37,5 \\
\hline \multicolumn{3}{|c|}{ Internações nos últimos 12 meses } \\
\hline Nenhuma & 119 & 93 \\
\hline 1 Episódio & 8 & 6,3 \\
\hline 2 Episódios & 1 & 0,8 \\
\hline \multicolumn{3}{|l|}{ Quedas nos últimos 12 meses } \\
\hline Nenhuma & 90 & 70,3 \\
\hline 1 Episódio & 25 & 19,5 \\
\hline 2 Episódios & 13 & 10,2 \\
\hline \multicolumn{3}{|l|}{ Dificuldades para enxergar } \\
\hline Não & 68 & 53,1 \\
\hline Sim & 60 & 46,9 \\
\hline \multicolumn{3}{|l|}{ Dificuldades para ouvir } \\
\hline Não & 77 & 60,2 \\
\hline Sim & 51 & 39,8 \\
\hline \multicolumn{3}{|l|}{ Limitação Física } \\
\hline Não & 101 & 78,9 \\
\hline Sim & 27 & 21,1 \\
\hline \multicolumn{3}{|l|}{ Dificuldades cognitivas } \\
\hline Não & 68 & 53,1 \\
\hline Sim & 60 & 46,9 \\
\hline \multicolumn{3}{|l|}{ Alterações de humor } \\
\hline Não & 48 & 37,5 \\
\hline Sim & 80 & 62,5 \\
\hline
\end{tabular}


conclusão

\begin{tabular}{lcc}
\hline \multicolumn{1}{c}{ Variável } & Frequência & $\%$ \\
\hline Necessita de ajuda para ABVD & 123 & \\
\hline Não & 5 & 96,1 \\
\hline Sim & & 3,9 \\
\hline Necessita de ajuda para AIVD & 88 & 68,8 \\
\hline Não & 40 & 31,3 \\
\hline Sim & & \\
\hline Incontinência & 85 & 66,4 \\
\hline Não & 43 & 33,6 \\
\hline Sim & & \\
\hline Perda de peso não intencional & 103 & 80,5 \\
\hline Não & 25 & 19,5 \\
\hline Sim & & \\
\hline Alterações nas condições bucais & 72 & 56,3 \\
\hline Não & 56 & 43,8 \\
\hline Sim & & 39,1 \\
\hline Classificação & 50 \\
\hline Saudável - 0 a 5 & 61 & 47,7 \\
\hline Pré-Frágil - 6 a 10 & 17 \\
\hline Frágil > 11 &
\end{tabular}

Na Tabela 2 observa-se que a maioria dos participantes referiu sua percepção de saúde como Regular/Ruim/Muito Ruim, dificuldades para enxergar, dificuldades cognitivas e de humor, apresentando 3 ou mais condições crônicas, sendo grande parte classificada como pré-frágil.

Tabela 3 - Distribuição de idosos segundo dados referentes às doenças crônicas referidas, AMPI, SP, 2019

\begin{tabular}{|c|c|c|}
\hline Variável & Frequência & $\%$ \\
\hline \multicolumn{3}{|l|}{ Diabetes } \\
\hline Não & 69 & 57 \\
\hline Sim & 52 & 43 \\
\hline \multicolumn{3}{|l|}{ Hipertensão } \\
\hline Não & 23 & 19 \\
\hline Sim & 98 & 81 \\
\hline
\end{tabular}




\begin{tabular}{|c|c|c|}
\hline Variável & Frequência & $\%$ \\
\hline \multicolumn{3}{|c|}{ Acidente Vascular Encefálico } \\
\hline Não & 109 & 90,1 \\
\hline Sim & 12 & 9,9 \\
\hline \multicolumn{3}{|c|}{ Doença Arterial Coronariana } \\
\hline Não & 98 & 81 \\
\hline Sim & 23 & 19 \\
\hline \multicolumn{3}{|l|}{ Doenças Vasculares } \\
\hline Não & 93 & 76,9 \\
\hline Sim & 28 & 23,1 \\
\hline \multicolumn{3}{|l|}{ Lesão por Pressão } \\
\hline Não & 121 & 94,5 \\
\hline Sim & 7 & 5,5 \\
\hline \multicolumn{3}{|l|}{ Anemia } \\
\hline Não & 101 & 83,5 \\
\hline Sim & 20 & 16,5 \\
\hline \multicolumn{3}{|l|}{ Asma } \\
\hline Não & 111 & 91,7 \\
\hline Sim & 10 & 8,3 \\
\hline \multicolumn{3}{|l|}{ DPOC } \\
\hline Não & 120 & 99,2 \\
\hline Sim & 1 & 0,8 \\
\hline \multicolumn{3}{|l|}{ Úlcera Péptica } \\
\hline Não & 118 & 97,5 \\
\hline Sim & 3 & 2,5 \\
\hline \multicolumn{3}{|l|}{ Osteoartrose } \\
\hline Não & 63 & 52,1 \\
\hline Sim & 58 & 47,9 \\
\hline \multicolumn{3}{|l|}{ Obesidade } \\
\hline Não & 99 & 81,8 \\
\hline Sim & 22 & 18,2 \\
\hline \multicolumn{3}{|l|}{ Neoplasia } \\
\hline Não & 112 & 92,6 \\
\hline Sim & 9 & 7,4 \\
\hline \multicolumn{3}{|l|}{ Demência } \\
\hline Não & 119 & 98,3 \\
\hline Sim & 2 & 1,7 \\
\hline
\end{tabular}


conclusão

\begin{tabular}{|c|c|c|}
\hline Variável & Frequência & $\%$ \\
\hline \multicolumn{3}{|l|}{ Epilepsia } \\
\hline Não & 120 & 99,2 \\
\hline $\operatorname{Sim}$ & 1 & 0,8 \\
\hline \multicolumn{3}{|l|}{ Depressão } \\
\hline Não & 93 & 76,9 \\
\hline Sim & 28 & 23,1 \\
\hline \multicolumn{3}{|l|}{ Doença de Parkinson } \\
\hline Não & 119 & 98,3 \\
\hline Sim & 2 & 1,7 \\
\hline \multicolumn{3}{|l|}{ DST/HIV/AIDS } \\
\hline Não & 120 & 99,2 \\
\hline Sim & 1 & 0,8 \\
\hline \multicolumn{3}{|l|}{ Amputação do Membro } \\
\hline Não & 120 & 99,2 \\
\hline Sim & 1 & 0,8 \\
\hline \multicolumn{3}{|c|}{ Tabagismo/Alcoolismo/Drogas } \\
\hline Não & 113 & 93,4 \\
\hline Sim & 8 & 6,6 \\
\hline \multicolumn{3}{|l|}{ Dor Crônica } \\
\hline Não & 93 & 76,9 \\
\hline $\operatorname{Sim}$ & 28 & 23,1 \\
\hline
\end{tabular}

A Tabela 3 refere- se à distribuição dos idosos segundo suas doenças crônicas referidas, onde se observa que grande parte possui diabetes, osteoartrose, depressão, doenças vasculares e dor crônica e, a maioria apresenta hipertensão arterial. 
Tabela 4 - Distribuição de idosos quanto à presença de dificuldades, tipos de dificuldades e níveis de dificuldade, incluindo adoção de práticas de autocuidado referentes a cada uma das atividades básicas da vida diária, CICAc, SP, 2019

\begin{tabular}{|c|c|c|c|c|c|c|c|c|c|c|c|c|c|c|c|c|c|}
\hline \multicolumn{18}{|c|}{ Atividades básicas da vida diária } \\
\hline \multirow{3}{*}{ ATIVIDADES } & \multirow{2}{*}{\multicolumn{2}{|c|}{$\begin{array}{c}\text { Presença } \\
\text { de } \\
\text { Dificuldade }\end{array}$}} & \multirow{2}{*}{\multicolumn{8}{|c|}{ Tipos de dificuldade }} & \multicolumn{7}{|c|}{ Níveis de dificuldade } \\
\hline & & & & & & & & & & & \multicolumn{3}{|c|}{$\begin{array}{c}\text { Práticas } \\
\text { autocuidado }\end{array}$} & \multirow[t]{2}{*}{ FD } & \multicolumn{2}{|c|}{$\begin{array}{c}\text { Ajuda } \\
\text { de } \\
\text { alguém }\end{array}$} & \multirow[t]{2}{*}{ DF } \\
\hline & $\mathbf{F r}$ & $\%$ & $\mathbf{F}$ & $\mathbf{S}$ & $\mathbf{E}$ & $\mathbf{C}$ & $\mathbf{R}$ & EC & $\mathrm{AC}$ & $\mathbf{O}$ & MC & MA & DA & & SU & AS & \\
\hline Banho & 7 & 5,5 & 5 & & & 2 & & & & & 1 & 1 & 1 & 2 & & 2 & \\
\hline Vestuário & 6 & 4,7 & 6 & 1 & & 1 & & & & & 2 & & & 2 & & 2 & \\
\hline Uso do toalete & 2 & 1,6 & 1 & & & 1 & & & & & & & & 1 & & 1 & \\
\hline $\begin{array}{l}\text { Transferências } \\
\text { posturais }\end{array}$ & 1 & 0,8 & & & & 1 & & & & & & & & & & 1 & \\
\hline Continência & 4 & 3,1 & 4 & & & 1 & 3 & & & & 2 & & 1 & 1 & & 1 & \\
\hline Alimentação & 2 & 1,6 & 1 & & & & & & & & & & & 1 & & 1 & \\
\hline Locomoção & 25 & 19,5 & 21 & 1 & 2 & 3 & 1 & & & & 13 & 2 & 9 & 5 & 3 & 3 & \\
\hline $\begin{array}{l}\text { Cuidar pele, } \\
\text { cabelo, unhas, } \\
\text { dentes, face }\end{array}$ & 4 & 3,1 & 4 & & & 1 & & & & & 1 & & & 2 & & 2 & \\
\hline Comunicação & 1 & 0,8 & 1 & & & 1 & & & & & & & & & & 1 & \\
\hline
\end{tabular}

Legenda: FR: Frequência; F: Física; S: Sensorial; E: Emocional; C: Cognitiva; EC: Econômica; R: Restrições clínicas; A: Ambiente físico; O: Outros; MC: Mudança Comportamental; MA: Mudança Ambiental; DA: Dispositivo Auxiliar; FD: Faz mesmo com Dificuldades; SU: Supervisão; AS: Assistência Física; DF: Deixou de Fazer.

A Tabela 4 refere-se à distribuição de idosos quanto às dificuldades para cada uma das ABVD. Nota-se que predominam dificuldades na atividade de locomoção e que o tipo de dificuldade mencionado com maior frequência é a dificuldade física. Quando idosos adotam uma ou mais práticas de autocuidado, realizam mudanças na forma de locomover-se (MC) e usam dispositivos auxiliares (DA). 
Tabela 5 - Distribuição de idosos quanto à presença de dificuldades, tipos de dificuldades e níveis de dificuldade, incluindo adoção de práticas de autocuidado referentes a cada uma das atividades instrumentais da vida diária, CICAc, SP, 2019

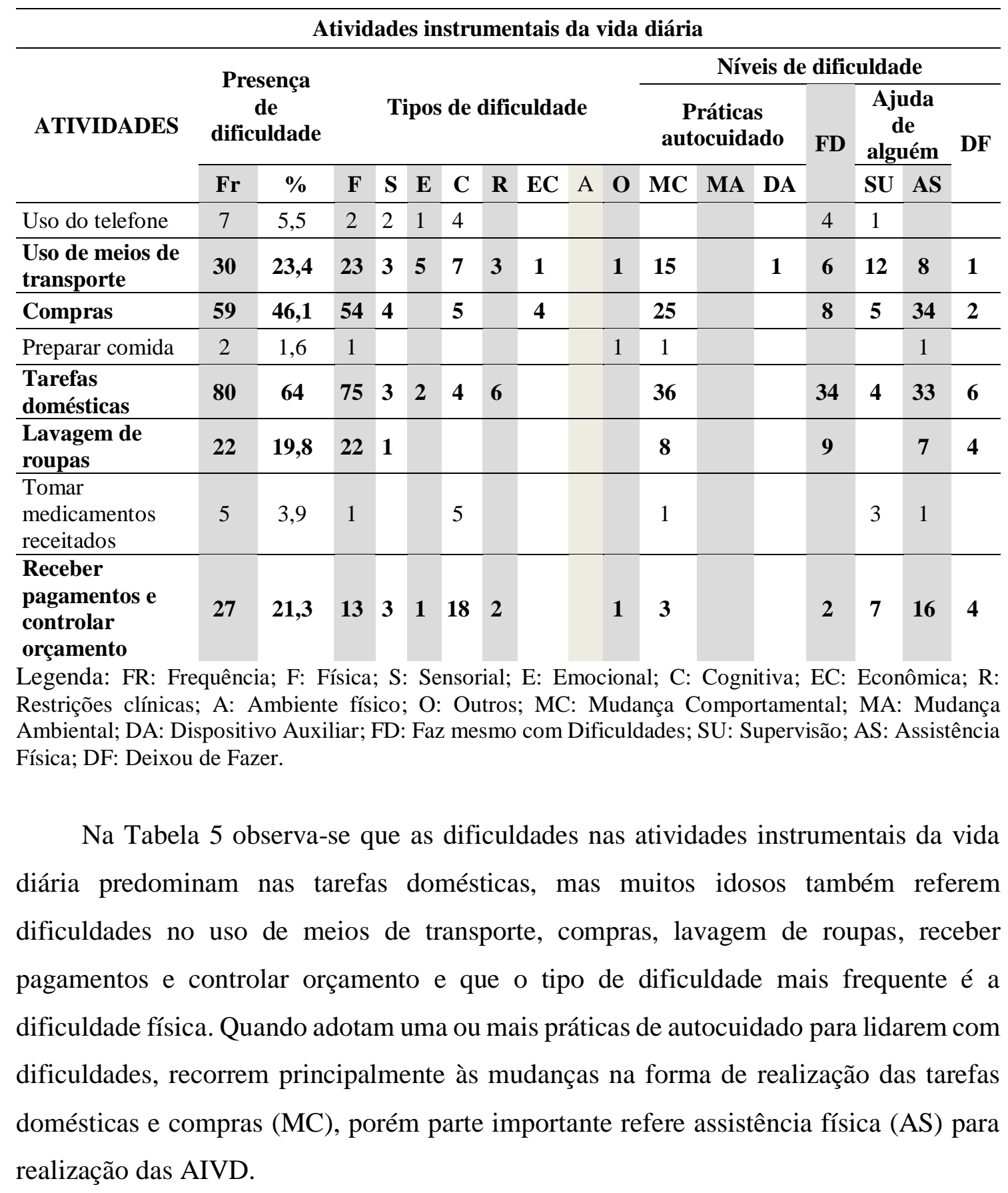


Tabela 6 - Distribuição de idosos quanto à presença de dificuldades, tipos de dificuldades e níveis de dificuldade, incluindo adoção de práticas de autocuidado referentes a cada uma das atividades de lazer, CICAc, SP, 2019

\begin{tabular}{|c|c|c|c|c|c|c|c|c|c|c|c|c|c|c|c|c|c|c|}
\hline \multicolumn{19}{|c|}{ Atividades de Lazer } \\
\hline \multirow{3}{*}{$\begin{array}{c}\text { ATIVIDADE } \\
\mathbf{S}\end{array}$} & \multirow{2}{*}{\multicolumn{5}{|c|}{$\begin{array}{cc} & \text { Presença } \\
\text { Prática } & \text { de } \\
& \text { Dificuldad } \\
& \text { e }\end{array}$}} & \multirow{2}{*}{\multicolumn{6}{|c|}{ Tipos de dificuldade }} & \multicolumn{7}{|c|}{ Níveis de dificuldade } \\
\hline & & & & & & & & & & & & \multicolumn{3}{|c|}{$\begin{array}{c}\text { Práticas } \\
\text { autocuidado }\end{array}$} & FD & \multicolumn{3}{|c|}{$\begin{array}{c}\text { Ajuda } \\
\text { de } \\
\text { alguém }\end{array}$} \\
\hline & Fr & $\%$ & Fr & $\%$ & $\mathbf{F}$ & $\mathbf{S}$ & $\mathbf{E}$ & $\mathbf{C}$ & $\mathbf{R}$ & EC & A & $\mathbf{O}$ & MC & MA & DA & $\mathbf{S U}$ & AS & \\
\hline Físico & 93 & 73,2 & 5 & 3.9 & 5 & & 1 & 2 & 1 & & & & 2 & & 1 & 1 & & 1 \\
\hline Religioso & 92 & 71,9 & 1 & 0.8 & 1 & & & 1 & & & & & & & & 1 & & \\
\hline Social & 32 & 25 & 3 & 2.3 & & 1 & 2 & & & & & & & & 1 & 1 & & 2 \\
\hline Manual & 11 & 8,6 & & & & & & & & & & & & & & & & \\
\hline Intelectual & 2 & 1,6 & & & & & & & & & & & & & & & & \\
\hline Diversos & 2 & 1,6 & 1 & 0.8 & 1 & & & & & & & & & & & & & 1 \\
\hline Artístico & 1 & 0,8 & & & & & & & & & & & & & & & & \\
\hline
\end{tabular}

Legenda: FR: Frequência; F: Física; S: Sensorial; E: Emocional; C: Cognitiva; EC: Econômica; R: Restrições clínicas; A: Ambiente físico; O: Outros; MC: Mudança Comportamental; MA: Mudança Ambiental; DA: Dispositivo Auxiliar; FD: Faz mesmo com Dificuldades; SU: Supervisão; AS: Assistência Física; DF: Deixou de Fazer.

$\mathrm{Na}$ Tabela 6 nota-se que pequeno número de idosos refere dificuldades nas atividades de lazer, para aqueles que mencionam dificuldades, essas predominam nas atividades físicas e sociais de lazer. Quando adotam uma ou mais práticas de autocuidado para lidarem com suas dificuldades, lançam mão principalmente de mudanças na forma de realizar as atividades físicas de lazer (MC).

Tabela 7 - Distribuição de idosos de acordo com as atividades desejadas, CICAc, SP, 2019

\section{Atividades desejadas}

\begin{tabular}{lcc}
\hline \multicolumn{1}{c}{ Atividade } & Fr & $\mathbf{\%}$ \\
\hline Estudar & 59 & 46,1 \\
\hline Viajar & 15 & 11,7 \\
\hline $\begin{array}{l}\text { Planejamento financeiro (Compra da casa própria, Investimentos, } \\
\text { Poupança, pagamento de INSS) }\end{array}$ & 11 & 8,6 \\
\hline Trabalhar & 8 & 6,3 \\
\hline $\begin{array}{l}\text { Outros (Casar, ter filhos, rever parentes, jogar futebol, dançar, tocar } \\
\text { instrumento musical, entre outros) }\end{array}$ & 24 & 19,4 \\
\hline Não mencionam atividades desejadas & 11 & 8,6 \\
\hline Total & 128 & 100 \\
\hline
\end{tabular}


$\mathrm{Na}$ Tabela 7 observa-se que a grande maioria dos idosos tem como atividade desejada estudar, seguida por viajar, não as realizam respectivamente em sua maioria devido a fatores extrínsecos, ou seja, fatores externos que dificultam ou impedem a realização de tais atividades, comumente referidos como falta de oportunidade e ausência ou insuficiência de recursos financeiros.

Tabela 8 - Distribuição de idosos quanto às dificuldades para os blocos das ABVD, AIVD (presença, número de atividades para as quais referem dificuldade e grau de dificuldade), CICAc, SP, 2019

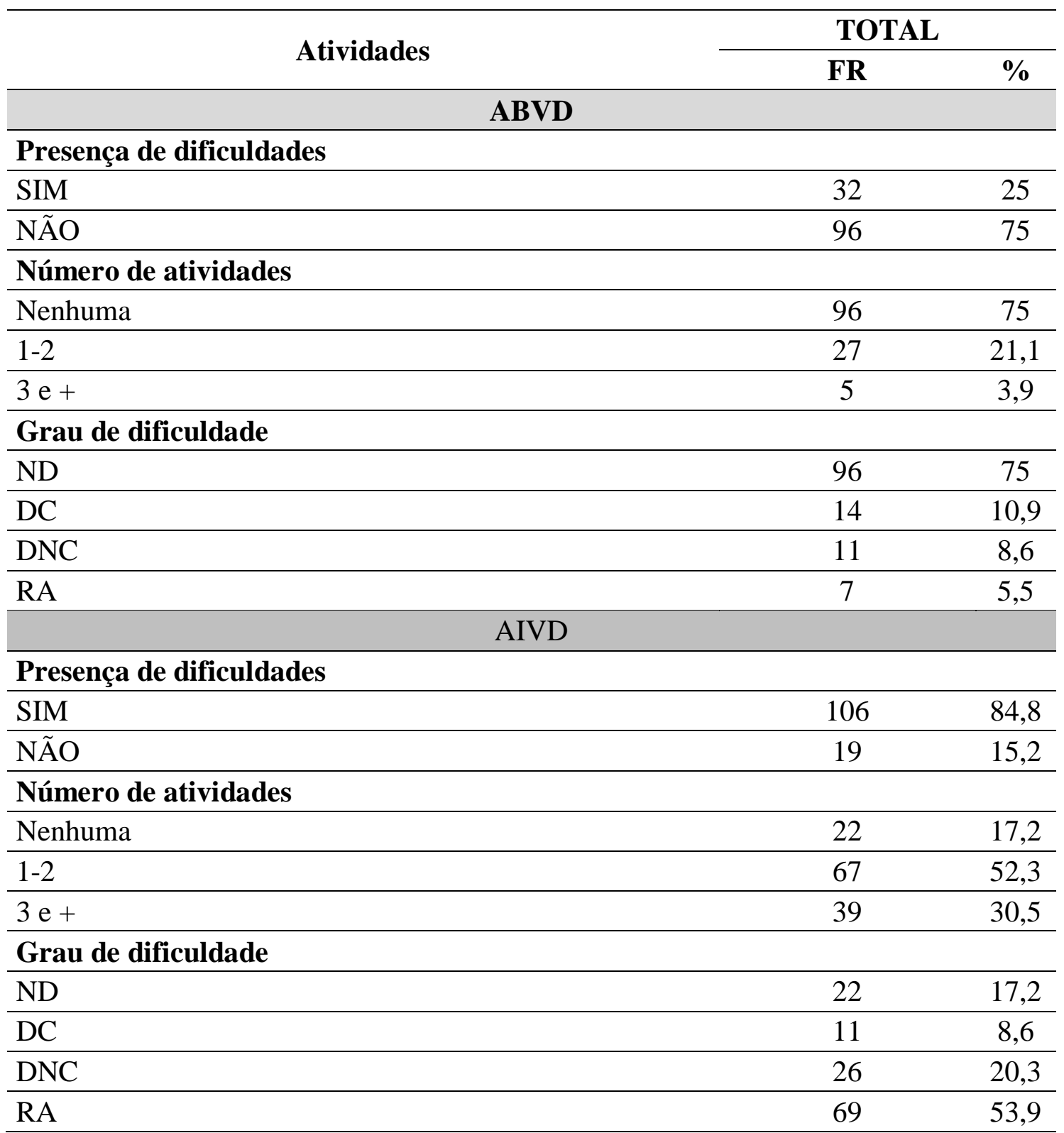

Legenda: ND: Não tem Dificuldade em nenhuma atividade; DC: Tem todas as Dificuldades Compensadas com práticas de autocuidado; DNC: Tem Dificuldade Não Compensada em uma ou mais atividades, mas não requer ajuda; RA: Requer Ajuda em uma ou mais atividades 
Na Tabela 8 nota-se que dos idosos que tem dificuldades para as ABVD (25\%) a maioria referiu de 1-2 atividades para as quais têm dificuldades $(21,1 \%)$, sendo que estas se encontram compensadas (DC) para parte dos informantes (10,9\%). Já para as AIVD, a grande maioria dos idosos referiu dificuldades (84,8\%), possuindo em sua maioria de 1 a 2 atividades com dificuldades $(52,3 \%)$, sendo que a maioria requer ajuda (RA) $(53,9 \%)$ para a realização destas atividades, pequena parte mencionou realizar práticas de autocuidado $(8,6 \%)$.

A seguir, por meio das Tabelas de 9 a 14, serão apresentadas distribuições dos idosos quanto à presença, número e grau de dificuldades para ABVD e AIVD segundo características demográficas, socioeconômicas e nível de fragilidade e, informadas presença ou ausência de associações com respectivos valores de $\mathrm{p}$.

Tabela 9 - Distribuição de idosos quanto às dificuldades para ABVD, AIVD (presença, número de atividades para as quais referem dificuldade e grau de dificuldades) e sexo, CICAc, SP, 2019

\begin{tabular}{|c|c|c|c|c|c|c|c|}
\hline \multirow{3}{*}{ Atividades } & \multicolumn{4}{|c|}{ Sexo } & \multirow{2}{*}{\multicolumn{2}{|c|}{ TOTAL }} & \multirow{3}{*}{$\mathbf{p}$} \\
\hline & & lino & & ino & & & \\
\hline & FR & $\%$ & FR & $\%$ & $\mathbf{F R}$ & $\%$ & \\
\hline \multicolumn{7}{|c|}{ ABVD } & \\
\hline $\begin{array}{l}\text { Presença de } \\
\text { dificuldades }\end{array}$ & & & & & & & 0,016 \\
\hline SIM & 18 & 19,4 & 14 & 40 & 32 & 25 & \\
\hline$\overline{\mathrm{NÃO}}$ & 75 & 80,6 & 21 & 60 & 96 & 75 & \\
\hline Número de atividades & & & & & & & 0,013 \\
\hline Nenhuma & 75 & 80,6 & 21 & 60 & 96 & 75 & \\
\hline $1-2$ & 17 & 18,3 & 10 & 28,6 & 27 & 21,1 & \\
\hline $3 \mathrm{e}+$ & 1 & 1,1 & 4 & 11,4 & 5 & 3,9 & \\
\hline Grau de dificuldade & & & & & & & 0,101 \\
\hline $\mathrm{ND}$ & 75 & 80,6 & 21 & 60 & 96 & 75 & \\
\hline $\mathrm{DC}$ & 8 & 8,6 & 6 & 17,1 & 14 & 10,9 & \\
\hline $\mathrm{DNC}$ & 7 & 7,5 & 4 & 11,4 & 11 & 8,6 & \\
\hline RA & 3 & 3,2 & 4 & 11,4 & 7 & 5,5 & \\
\hline
\end{tabular}


conclusão

Sexo

\begin{tabular}{lcccc|ccc}
\hline \multirow{2}{*}{ Atividades } & \multicolumn{2}{c|}{ Feminino } & \multicolumn{2}{c|}{ Masculino } & \multicolumn{2}{c|}{ TOTAL } & p \\
\cline { 2 - 10 } & FR & $\mathbf{\%}$ & FR & $\mathbf{\%}$ & FR & \% & \\
\hline \multicolumn{1}{c}{$\begin{array}{c}\text { Presença de } \\
\text { dificuldades }\end{array}$} & & & AIVD & & & & \\
\hline SIM & 79 & $\mathbf{8 5 , 9}$ & 27 & 81,8 & 106 & 84,8 & 0,297 \\
\hline NÃO & 13 & 14,1 & 6 & 18,2 & 19 & 15,2 & \\
\hline Número de atividades & & & & & & & \\
\hline Nenhuma & 14 & 15,1 & 8 & 22,9 & 22 & 17,2 & $\mathbf{0 , 0 3 6}$ \\
\hline $1-2$ & 45 & $\mathbf{4 8 , 4}$ & 22 & $\mathbf{6 2 , 9}$ & 67 & 52,3 & \\
\hline 3 e + & 34 & 36,6 & 5 & 14,3 & 39 & 30,5 & \\
\hline Grau de dificuldade & & & & & & & \\
\hline ND & 14 & 15,1 & 8 & 22,9 & 22 & 17,2 & 0,448 \\
\hline DC & 8 & 8,6 & 3 & 8,6 & 11 & 8,6 & \\
\hline DNC & 17 & 18,3 & 9 & 25,7 & 26 & 20,3 & \\
\hline RA & 54 & $\mathbf{5 8 , 1}$ & 15 & 42,9 & 69 & 53,9 & \\
\hline
\end{tabular}

Legenda: ND: Não tem Dificuldade em nenhuma atividade; DC: Tem todas as Dificuldades Compensadas com práticas de autocuidado; DNC: Tem Dificuldade Não Compensada em uma ou mais atividades, mas não requer ajuda; RA: Requer Ajuda em uma ou mais atividades.

Na Tabela 9, o percentual de homens que apresentam dificuldades é maior e essa diferença é estatisticamente significante $(\mathrm{p}=0,016)$. Observa-se também que a maior parte dos idosos não apresenta dificuldades nas ABVD. Dos que as referem, a maioria apresenta dificuldades no desempenho de 1 a 2 destas atividades e é do sexo masculino. Salientase também a diferença percentual entre homens e mulheres em relação à dificuldade para 3 e + atividades, sendo maior nos homens. A diferença entre homens e mulheres no número de dificuldades para as ABVD é significativa do ponto de vista estatístico $(\mathrm{p}=0,013)$. A maioria dos idosos com dificuldades nas ABVD refere que estas dificuldades estão compensadas com práticas de autocuidado (DC), e isso ocorre tanto no sexo feminino quanto no masculino, embora não haja diferença significativa em relação aos demais graus de dificuldade.

No que se refere às AIVD mais mulheres que homens apresentam dificuldades, mas sem diferença estatística. Entretanto, em relação ao número de AIVD para as quais os idosos apresentam dificuldade, uma proporção maior de homens apresenta dificuldades para 1 a 2 e uma proporção maior de mulheres apresenta dificuldades para 3 e + AIVD. 
A diferença entre mulheres e homens no número de dificuldades para as AIVD é significativa do ponto de vista estatístico $(p=0,0036)$. Em consonância com esses dados, observa-se que, mais mulheres que homens requerem ajuda (RA), ainda que essa diferença não tenha significância estatística.

Tabela 10 - Distribuição de idosos quanto às dificuldades para ABVD, AIVD (presença, número de atividades e grau de dificuldades) e faixa etária, CICAc, SP, 2019

\begin{tabular}{|c|c|c|c|c|c|c|c|c|c|c|c|c|c|}
\hline \multicolumn{14}{|c|}{ Faixa Etária } \\
\hline \multirow{2}{*}{ Atividades } & \multicolumn{2}{|c|}{$60-64$} & \multicolumn{2}{|c|}{$65-69$} & \multicolumn{2}{|c|}{ 70-74 } & \multicolumn{2}{|c|}{$75-79$} & \multicolumn{2}{|c|}{$80+$} & \multicolumn{2}{|c|}{ TOTAL } & \multirow[t]{2}{*}{$\mathbf{p}$} \\
\hline & FR & $\%$ & FR & $\%$ & FR & $\%$ & FR & $\%$ & FR & $\%$ & FR & $\%$ & \\
\hline \multicolumn{14}{|c|}{ ABVD } \\
\hline Presença de dificuldades & & & & & & & & & & & & & 0,215 \\
\hline SIM & 9 & 24,3 & 11 & 32,4 & 9 & 25 & 1 & 7,7 & 2 & 25 & 32 & 25 & \\
\hline NÃO & 28 & 75,7 & 23 & 67,6 & 27 & 75 & 12 & 92,3 & 6 & 75 & 96 & 75 & \\
\hline Número de atividades & & & & & & & & & & & & & 0,250 \\
\hline Nenhuma & 28 & 75,7 & 23 & 67,6 & 27 & 75 & 12 & 92,3 & 6 & 75 & 96 & 75 & \\
\hline $1-2$ & 7 & 18,9 & 9 & 26,5 & 8 & 22,2 & 1 & 7,7 & 2 & 25 & 27 & 21,1 & \\
\hline $3 e+$ & 2 & 5,4 & 2 & 5,9 & 1 & 2,8 & 0 & 0 & 0 & 0 & 5 & 3,9 & \\
\hline Grau de dificuldade & & & & & & & & & & & & & 0,070 \\
\hline ND & 28 & 75,7 & 23 & 67,6 & 27 & 75 & 12 & 92,3 & 6 & 75 & 96 & 75 & \\
\hline $\mathrm{DC}$ & 3 & 8,1 & 4 & 11,8 & 4 & 11,1 & 1 & 7,7 & 2 & 25 & 14 & 10,9 & \\
\hline DNC & 3 & 8,1 & 4 & 11,8 & 4 & 11,1 & 0 & 0 & 0 & 0 & 11 & 8,6 & \\
\hline $\mathrm{RA}$ & 3 & 8,1 & 3 & 8,8 & 1 & 2,8 & 0 & 0 & 0 & 0 & 7 & 5,5 & \\
\hline \multicolumn{14}{|c|}{ AIVD } \\
\hline \multicolumn{14}{|l|}{ Presença de dificuldades } \\
\hline SIM & 32 & 86,5 & 27 & 84,4 & 27 & 75 & 12 & 100 & 8 & 100 & 106 & 84,8 & $0,122^{*}$ \\
\hline NÃO & 5 & 13,5 & 5 & 15,6 & 9 & 25 & 0 & 0 & 0 & 0 & 19 & 15,2 & \\
\hline Número de atividades & & & & & & & & & & & & & 0,072 \\
\hline Nenhuma & 5 & 13,5 & 7 & 20,6 & 9 & 25 & 1 & 7,7 & 0 & 0 & 22 & 17,2 & \\
\hline $1-2$ & 24 & 64,9 & 15 & 44,1 & 17 & 47,2 & 5 & 38,5 & 6 & 75 & 67 & 52,3 & \\
\hline $3 e+$ & 8 & 21,6 & 12 & 35,3 & 10 & 27,8 & 7 & 53,8 & 2 & 25 & 39 & 30,5 & \\
\hline
\end{tabular}


conclusão

\begin{tabular}{|c|c|c|c|c|c|c|c|c|c|c|c|c|c|}
\hline \multicolumn{14}{|c|}{ Faixa Etária } \\
\hline \multirow{2}{*}{ Atividades } & \multicolumn{2}{|c|}{$60-64$} & \multicolumn{2}{|c|}{$65-69$} & \multicolumn{2}{|c|}{ 70-74 } & \multicolumn{2}{|c|}{ 75-79 } & \multicolumn{2}{|c|}{$80+$} & \multicolumn{2}{|c|}{ TOTAL } & \multirow[t]{2}{*}{$\mathbf{p}$} \\
\hline & FR & $\%$ & FR & $\%$ & FR & $\%$ & FR & $\%$ & FR & $\%$ & FR & $\%$ & \\
\hline Grau de dificuldade & & & & & & & & & & & & & $\mathbf{0 , 0 3 8}$ \\
\hline ND & 5 & 13,5 & 7 & 20,6 & 9 & 25 & 1 & 7,7 & 0 & 0 & 22 & 17,2 & \\
\hline $\mathrm{DC}$ & 4 & 10,8 & 2 & 5,9 & 5 & 13,9 & 0 & 0 & 0 & 0 & 11 & 8,6 & \\
\hline DNC & 10 & 27 & 7 & 20,6 & 4 & 11,1 & 3 & 23,1 & 2 & 25 & 26 & 20,3 & \\
\hline RA & 18 & 48,6 & 18 & 52,9 & 18 & 50 & 9 & 69,2 & 6 & 75 & 69 & 53,9 & \\
\hline
\end{tabular}

Legenda: ND: Não tem Dificuldade em nenhuma atividade; DC: Tem todas as Dificuldades Compensadas com práticas de autocuidado; DNC: Tem Dificuldade Não Compensada em uma ou mais atividades, mas não requer ajuda; RA: Requer Ajuda em uma ou mais atividades.

Na Tabela 10, identifica-se, ainda que sem significância estatística, que a faixa de 65 a 69 anos reúne o maior número de indivíduos que referem dificuldades nas ABVD. Observa-se também que há o predomínio de dificuldades para 1 a 2 atividades, com maior contribuição justamente do grupo etário de 65 a 69 anos Ainda, dos idosos que apresentam dificuldades nas ABVD os grupos etários de 65 a 69 e 70 a 74 anos referem na mesma proporção DC e DNC, já os idosos de 80 ou mais apresentam predomínio de DC.

No que se refere às dificuldades para as AIVD em relação às faixas etárias, embora a maior parte dos idosos com dificuldades esteja concentrada no grupo etário de 60 a 64 anos, nos grupos de 75 a 79 e 80 anos ou mais, cem por cento referiram dificuldades. Observa-se em termos percentuais há um predomínio de idosos com 80 anos ou mais, que referem dificuldades para 1 a 2 AIVD. Diferenças em relação à presença e número de dificuldades conforme faixa etária, embora existentes, não se mostraram estatisticamente significantes. Observa-se, entretanto, diferença significativa nos graus de dificuldade em relação grupos etários, predominando idosos que requerem ajuda (RA) $(p=0,038)$, com destaque para a faixa de 80 anos ou mais. 
Tabela 11 - Distribuição de idosos quanto às dificuldades para ABVD, AIVD (presença, número de atividades para as quais referem dificuldade e grau de dificuldades) e morar sozinho, CICAc, SP, 2019

\begin{tabular}{|c|c|c|c|c|c|c|c|}
\hline \multicolumn{8}{|c|}{ Morar sozinho } \\
\hline \multirow{2}{*}{ Atividades } & \multicolumn{2}{|c|}{ NÃO } & \multicolumn{2}{|c|}{ SIM } & \multicolumn{2}{|c|}{ TOTAL } & $\mathbf{p}$ \\
\hline & FR & $\%$ & FR & $\%$ & FR & $\%$ & \\
\hline \multicolumn{8}{|c|}{ ABVD } \\
\hline Presença de dificuldades & & & & & & & 0,800 \\
\hline$\overline{\text { SIM }}$ & 26 & 25,5 & 6 & 23,1 & 32 & 25 & \\
\hline NÃO & 76 & 74,5 & 20 & 76,9 & 96 & 75 & \\
\hline Número de atividades & & & & & & & 0,965 \\
\hline Nenhuma & 76 & 74,5 & 20 & 76,9 & 96 & 75 & \\
\hline $1-2$ & 22 & 21,6 & 5 & 19,2 & 27 & 21,1 & \\
\hline $3 \mathrm{e}+$ & 4 & 3,9 & 1 & 3,8 & 5 & 3,9 & \\
\hline Grau de dificuldade & & & & & & & 0,319 \\
\hline ND & 76 & 74,5 & 20 & 76,9 & 96 & 75 & \\
\hline$\overline{\mathrm{DC}}$ & 11 & 10,8 & 3 & 11,5 & 14 & 10,9 & \\
\hline $\mathrm{DNC}$ & 8 & 7,8 & 3 & 11,5 & 11 & 8,6 & \\
\hline$\overline{\mathrm{RA}}$ & 7 & 6,9 & 0 & 0 & 7 & 5,5 & \\
\hline & & IVD & & & & & \\
\hline
\end{tabular}

\section{Presença de dificuldades}

\begin{tabular}{lccccccc}
\hline SIM & 85 & 85,9 & 21 & $\mathbf{8 0 , 8}$ & 106 & 84,8 & \\
\hline NÃO & 14 & 14,1 & 5 & 19,2 & 19 & 15,2 & \\
\hline \multicolumn{1}{c}{ Número de atividades } & & & & & & & 0,501 \\
\hline Nenhuma & 17 & 16,7 & 5 & 19,2 & 22 & 17,2 & \\
\hline $1-2$ & 56 & 54,9 & 11 & $\mathbf{4 2 , 3}$ & 67 & 52,3 & \\
\hline 3 e + & 29 & 28,4 & 10 & 38,5 & 39 & 30,5 & \\
\hline \multicolumn{1}{c}{ Grau de dificuldade } & & & & & & & 0,988 \\
\hline ND & 17 & 16,7 & 5 & 19,2 & 22 & 17,2 & \\
\hline DC & 9 & 8,8 & 2 & 7,7 & 11 & 8,6 & \\
\hline DNC & 21 & 20,6 & 5 & 19,2 & 26 & 20,3 & \\
\hline RA & 55 & 53,9 & 14 & $\mathbf{5 3 , 8}$ & 69 & 53,9 & \\
\hline
\end{tabular}

Legenda: ND: Não tem Dificuldade em nenhuma atividade; DC: Tem todas as Dificuldades Compensadas com práticas de autocuidado; DNC: Tem Dificuldade Não Compensada em uma ou mais atividades, mas não requer ajuda; RA: Requer Ajuda em uma ou mais atividades. 
$\mathrm{Na}$ Tabela 11 parte dos idosos $(23,1 \%)$ refere residir sozinha e apresentar dificuldades nas ABVD, sendo que 19,2\% referem dificuldades para 1 a 2 atividades e se distribuem em proporções iguais entre os que compensam (DC) e os que não compensam essas dificuldades (DNC). Embora digna de nota, a diferença em relação às demais respostas não se mostrou estatisticamente significante.

No que se refere às AIVD observa-se que dos idosos que residem sozinhos, grande parte possui dificuldades na realização de 1 e + dessas atividades. Observa-se também um número considerável de idosos que requerem ajuda e que residem sozinhos, ainda que esse grupo não se diferencie estatisticamente daquele que resida com outras pessoas.

Tabela 12 - Distribuição de idosos quanto às dificuldades para ABVD, AIVD (presença, número de atividades para as quais referem dificuldade e grau de dificuldades) e ter alguém com quem contar, CICAc, SP, 2019

\begin{tabular}{|c|c|c|c|c|c|c|c|}
\hline \multicolumn{8}{|c|}{ Ter alguém com quem contar } \\
\hline \multirow{2}{*}{ Atividades } & \multicolumn{2}{|c|}{ Sim } & \multicolumn{2}{|c|}{ Não } & \multicolumn{2}{|c|}{ TOTAL } & \multirow[t]{2}{*}{$\mathbf{p}$} \\
\hline & FR & $\%$ & FR & $\%$ & FR & $\%$ & \\
\hline \multicolumn{8}{|c|}{ ABVD } \\
\hline $\begin{array}{l}\text { Presença de } \\
\text { dificuldades }\end{array}$ & & & & & & & $>0,999 *$ \\
\hline SIM & 4 & 26,7 & 28 & 24,8 & 32 & 25 & \\
\hline $\mathrm{NÃO}$ & 11 & 73,3 & 85 & 75,2 & 96 & 75 & \\
\hline Número de atividades & & & & & & & 0,476 \\
\hline Nenhuma & 11 & 73,3 & 85 & 75,2 & 96 & 75 & \\
\hline $1-2$ & 4 & 26,7 & 23 & 20,4 & 27 & 21,1 & \\
\hline $3 \mathrm{e}+$ & 0 & 0 & 5 & 4,4 & 5 & 3,9 & \\
\hline Grau de dificuldade & & & & & & & 0,527 \\
\hline $\mathrm{ND}$ & 11 & 73,3 & 85 & 75,2 & 96 & 75 & \\
\hline $\mathrm{DC}$ & 2 & 13,3 & 12 & 10,6 & 14 & 10,9 & \\
\hline $\mathrm{DNC}$ & 2 & 13,3 & 9 & 8 & 11 & 8,6 & \\
\hline $\mathrm{RA}$ & 0 & 0 & 7 & 6,2 & 7 & 5,5 & \\
\hline
\end{tabular}


conclusão

\begin{tabular}{|c|c|c|c|c|c|c|c|}
\hline \multicolumn{8}{|c|}{ Ter alguém com quem contar } \\
\hline \multirow{2}{*}{ Atividades } & \multicolumn{2}{|c|}{ Sim } & \multicolumn{2}{|c|}{ Não } & \multicolumn{2}{|c|}{ TOTAL } & $\mathbf{p}$ \\
\hline & FR & $\%$ & FR & $\%$ & FR & $\%$ & \\
\hline \multicolumn{8}{|c|}{ AIVD } \\
\hline $\begin{array}{l}\text { Presença de } \\
\text { dificuldades }\end{array}$ & & & & & & & $0,465 *$ \\
\hline SIM & 14 & 93,3 & 92 & 83,6 & 106 & 84,8 & \\
\hline NÃO & 1 & 6,7 & 18 & 16,4 & 19 & 15,2 & \\
\hline Número de atividades & & & & & & & 0,249 \\
\hline Nenhuma & 1 & 6,7 & 21 & 18,6 & 22 & 17,2 & \\
\hline $1-2$ & 7 & 46,7 & 60 & 53,1 & 67 & 52,3 & \\
\hline $3 \mathrm{e}+$ & 7 & 46,7 & 32 & 28,3 & 39 & 30,5 & \\
\hline Grau de dificuldade & & & & & & & 0,051 \\
\hline ND & 1 & 6,7 & 21 & 18,6 & 22 & 17,2 & \\
\hline $\mathrm{DC}$ & 2 & 13,3 & 9 & 8 & 11 & 8,6 & \\
\hline $\mathrm{DNC}$ & 7 & 46,7 & 19 & 16,8 & 26 & 20,3 & \\
\hline RA & 5 & 33,3 & 64 & 56,6 & 69 & 53,9 & \\
\hline
\end{tabular}

Legenda: ND: Não tem Dificuldade em nenhuma atividade; DC: Tem todas as Dificuldades Compensadas com práticas de autocuidado; DNC: Tem Dificuldade Não Compensada em uma ou mais atividades, mas não requer ajuda; RA: Requer Ajuda em uma ou mais atividades.

Na Tabela 12 parte dos idosos (24,8\%) refere ter dificuldades para ABVD e não ter alguém com quem contar quando ficam doentes, destes $20,4 \%$ apresentam dificuldades para 1 a 2 atividades, 4,4\% apresentam dificuldades para 3 e + atividades e apenas 10,6 $\%$ referem compensar efetivamente tais dificuldades com práticas de autocuidado. Essa realidade é digna de nota, ainda que os grupos de idosos que "tem" ou "não tem" com quem contar não se diferenciem estatisticamente.

No que se refere às AIVD observa-se que a maioria dos idosos refere dificuldades para 1 e + atividades e não têm alguém com quem contar quando ficam doentes. Paradoxalmente dentre os que não contam com ajuda, há um predomínio de que requer ajuda (RA). O valor de $\mathrm{p}(0,051)$ evidencia uma preocupante "tendência à diferença" entre o grupo de idosos que não tem com quem contar, em relação aquele que conta com ajuda em suas dificuldades. 
Tabela 13 - Distribuição de idosos quanto às dificuldades para ABVD, AIVD (presença, número de atividades para as quais referem dificuldade e grau de dificuldades) e escolaridade, CICAc, SP, 2019

Escolaridade

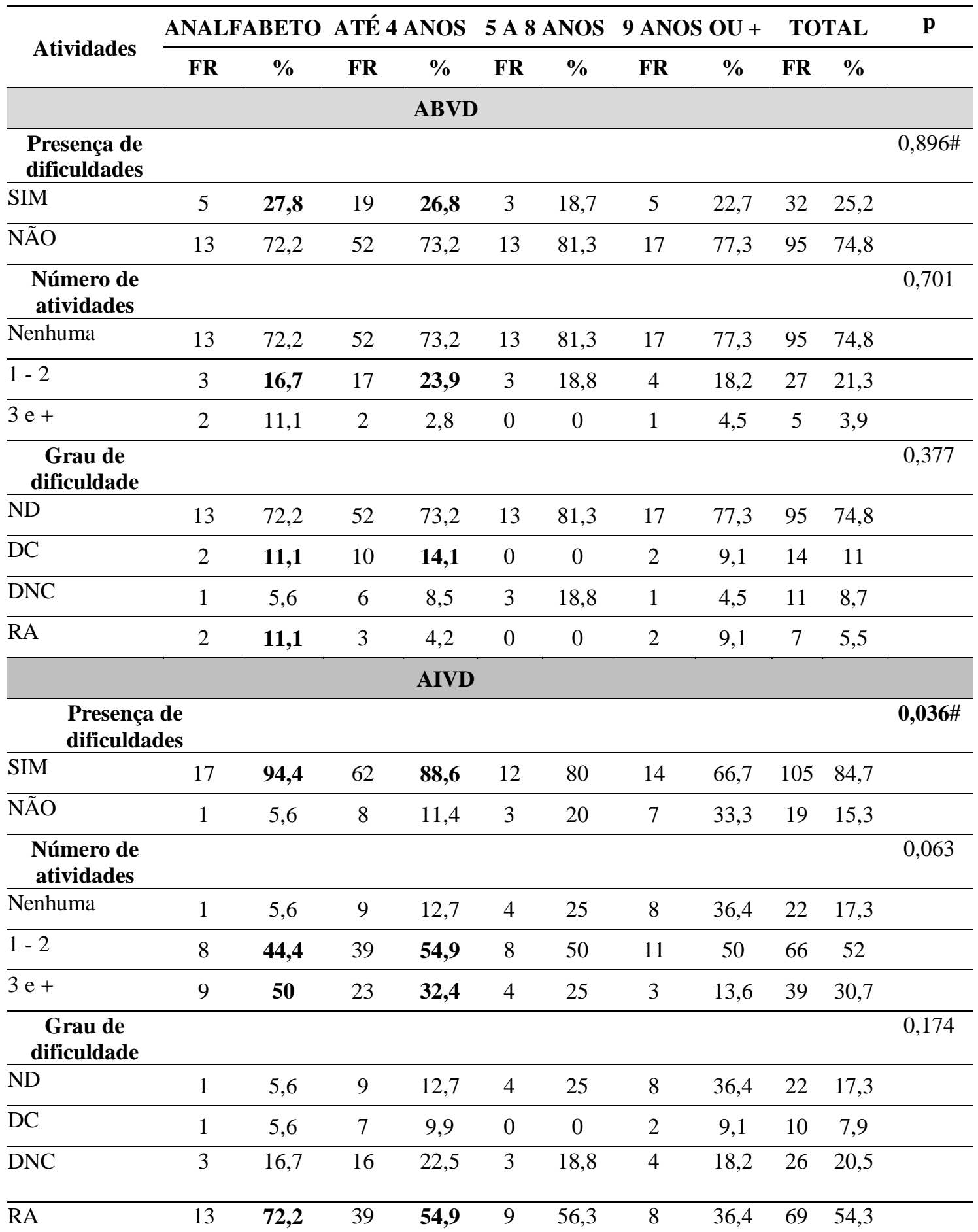

Legenda: ND: Não tem Dificuldade em nenhuma atividade; DC: Tem todas as Dificuldades Compensadas com práticas de autocuidado; DNC: Tem Dificuldade Não Compensada em uma ou mais atividades, mas não requer ajuda; RA: Requer Ajuda em uma ou mais atividades. 
Na Tabela 13, identifica-se que a maior parte dos idosos com dificuldades nas ABVD, se concentra entre analfabetos e escolaridade de até 4 anos. Observa-se também que dentre os idosos que referem dificuldades nas ABVD há um predomínio de idosos que compensam dificuldades (DC) nas categorias "analfabeto" e "até 4 anos de escolaridade" e, de idosos que não compensam dificuldades (DNC) entre "5 a 8 anos de escolaridade". Embora as diferenças entre grupos não tenham se mostrado significativa, é relevante observar dificuldades especialmente entre idosos analfabetos e com baixa escolaridade.

Situação um pouco distinta observa-se na distribuição de idosos com dificuldade nas AIVD em relação à escolaridade, onde os analfabetos referem mais dificuldades nessas atividades e a diferença em relação a grupos com maior escolaridade é significativa $(\mathrm{p}=0,036)$. Observa-se que idosos com escolaridade até 4 anos apresentam em sua maioria dificuldades para 1 a 2 AIVD, nota-se também que a maioria dos analfabetos apresentam dificuldades para $3 \mathrm{e}+$ atividades. A diferença entre os grupos apresenta tendência à significância o que se reveste ainda de maior preocupação. Observa-se também, embora sem significância estatística, predomínio de idosos que requerem ajuda entre os analfabetos e aqueles com até 4 anos de escolaridade.

Tabela 14 - Distribuição de idosos quanto às dificuldades para ABVD, AIVD (presença, número de atividades para as quais referem dificuldade e grau de dificuldades) e nível de fragilidade (saudável, pré-frágil e frágil), AMPI e CICAc, SP, 2020

\begin{tabular}{|c|c|c|c|c|c|c|}
\hline \multicolumn{7}{|c|}{ ABVD } \\
\hline \multirow[b]{2}{*}{$\begin{array}{l}\text { Nível de } \\
\text { fragilidade }\end{array}$} & \multicolumn{4}{|c|}{ Graus de dificuldade } & \multirow[b]{2}{*}{$\begin{array}{c}\text { Total } \\
(\mathbf{N}=\mathbf{1 2 8})\end{array}$} & \multirow[b]{2}{*}{$\mathbf{P}$} \\
\hline & $\begin{array}{c}\text { ND } \\
(\mathrm{N}=96)\end{array}$ & $\begin{array}{c}\text { DC } \\
(\mathrm{N}=14)\end{array}$ & $\begin{array}{c}\mathrm{DNC} \\
(\mathrm{N}=11)\end{array}$ & $\begin{array}{c}\text { RA } \\
(\mathrm{N}=7)\end{array}$ & & \\
\hline & & & & & & $<0,001$ \\
\hline Saudável & $46(92)$ & $0(0)$ & $2(4)$ & $2(4)$ & 50 & \\
\hline Pré-frágil & $44(72,1)$ & $9(14,8)$ & $4(6,6)$ & $4(6,6)$ & 61 & \\
\hline Frágil & $6(35,3)$ & $5(29,4)$ & $5(29,4)$ & $1(5,9)$ & 17 & \\
\hline
\end{tabular}


conclusão

\begin{tabular}{|c|c|c|c|c|c|c|}
\hline \multicolumn{7}{|c|}{ ABVD } \\
\hline \multirow[b]{2}{*}{$\begin{array}{l}\text { Nível de } \\
\text { fragilidade }\end{array}$} & \multicolumn{3}{|c|}{ Número de atividades } & & \multirow[b]{2}{*}{$\begin{array}{c}\text { Total } \\
(\mathrm{N}=\mathbf{1 2 8})\end{array}$} & \multirow[b]{2}{*}{$\mathbf{P}$} \\
\hline & $\begin{array}{l}\text { Nenhuma } \\
(\mathrm{N}=96)\end{array}$ & $\begin{array}{c}1 \text { a } 2 \\
(\mathrm{~N}=27)\end{array}$ & $\begin{array}{l}3 \mathrm{ou}+ \\
(\mathrm{N}=5)\end{array}$ & & & \\
\hline & & & & & & $<0,001$ \\
\hline Saudável & $46(92)$ & $3(6)$ & $1(2)$ & & 50 & \\
\hline Pré-frágil & $44(72,1)$ & $15(24,6)$ & $2(3,3)$ & & 61 & \\
\hline Frágil & $6(35,3)$ & $9(52,9)$ & $2(11,8)$ & & 17 & \\
\hline \multirow{2}{*}{$\begin{array}{l}\text { Nível de } \\
\text { fragilidade }\end{array}$} & \multicolumn{2}{|c|}{ Presença de dificuldades } & & & & \multirow[b]{2}{*}{$\mathbf{p}$} \\
\hline & Não $(\mathrm{N}=96)$ & $\operatorname{Sim}(N=32)$ & & & & \\
\hline & & & & & & $<0,001 \#$ \\
\hline Saudável & $46(92)$ & $4(8)$ & & & & \\
\hline Pré-frágil & $44(72,1)$ & $17(27,9)$ & & & & \\
\hline Frágil & $6(35,3)$ & $11(64,7)$ & & & & \\
\hline \multicolumn{7}{|c|}{ AIVD } \\
\hline \multirow[b]{2}{*}{$\begin{array}{l}\text { Nível de } \\
\text { fragilidade }\end{array}$} & \multicolumn{4}{|c|}{ Graus de dificuldade } & & \multirow[b]{2}{*}{$\mathbf{P}$} \\
\hline & $\begin{array}{c}\mathrm{ND} \\
(\mathrm{N}=22)\end{array}$ & $\begin{array}{c}\mathrm{DC} \\
(\mathrm{N}=11)\end{array}$ & $\begin{array}{c}\text { DNC } \\
(\mathrm{N}=26)\end{array}$ & $\begin{array}{c}\text { RA } \\
(\mathrm{N}=69)\end{array}$ & $\begin{array}{c}\text { Total } \\
(\mathrm{N}=\mathbf{1 2 8})\end{array}$ & \\
\hline & & & & & & 0,022 \\
\hline Saudável & $15(30)$ & $5(10)$ & $8(16)$ & $22(44)$ & 50 & \\
\hline Pré-frágil & $7(11,5)$ & $5(8,2)$ & $15(24,6)$ & $34(55,7)$ & 61 & \\
\hline Frágil & $0(0)$ & $1(5,9)$ & $3(17,6)$ & $13(76,5)$ & 17 & \\
\hline \multirow[b]{2}{*}{$\begin{array}{l}\text { Nível de } \\
\text { fragilidade }\end{array}$} & \multicolumn{3}{|c|}{ Número de atividades } & & & \\
\hline & $\begin{array}{l}\text { Nenhuma } \\
(\mathrm{N}=22)\end{array}$ & $\begin{array}{c}1 \text { a } 2 \\
(\mathrm{~N}=67)\end{array}$ & $\begin{array}{c}3 \text { ou }+ \\
(N=39)\end{array}$ & & $\begin{array}{c}\text { Total } \\
(\mathrm{N}=\mathbf{1 2 8})\end{array}$ & $\mathbf{P}$ \\
\hline & & & & & & $<0,001$ \\
\hline Saudável & $15(30)$ & $30(60)$ & $5(10)$ & & 50 & \\
\hline Pré-frágil & $7(11,5)$ & $30(49,2)$ & $24(39,3)$ & & 61 & \\
\hline Frágil & $0(0)$ & $7(41,2)$ & $10(58,8)$ & & 17 & \\
\hline \multirow{2}{*}{$\begin{array}{l}\text { Nível de } \\
\text { fragilidade }\end{array}$} & \multicolumn{2}{|c|}{ Presença de dificuldades } & & & & \multirow{2}{*}{$\mathbf{p}$} \\
\hline & Não $(\mathrm{N}=22)$ & $\operatorname{Sim}(N=106)$ & & & & \\
\hline & & & & & & 0,002\# \\
\hline Saudável & $15(30)$ & $35(70)$ & & & & \\
\hline Pré-frágil & $7(11,5)$ & $54(88,5)$ & & & & \\
\hline Frágil & $0(0)$ & $17(100)$ & $\&$ & & & \\
\hline
\end{tabular}

Teste qui-quadrado; * Teste exato de Fisher; \# Teste da razão de verossimilhanças; \& Não é possível estimar

Legenda: ND: Não tem Dificuldade em nenhuma atividade; DC: Tem todas as Dificuldades Compensadas com práticas de autocuidado; DNC: Tem Dificuldade Não Compensada em uma ou mais atividades, mas não requer ajuda; RA: Requer Ajuda em uma ou mais atividades. 
$\mathrm{Na}$ Tabela 14 é possível notar que o nível de fragilidade influenciou no grau de dificuldade, número de atividades para quais os idosos referem dificuldades e na presença de dificuldades para ABVD $(\mathrm{p}<0,05)$, sendo que pessoas frágeis apresentaram estatisticamente maior frequência de DNC e maior número de dificuldades.

Estatisticamente o nível de fragilidade influenciou em todos os desfechos funcionais $(\mathrm{p}<0,05)$ para as AIVD. Pessoas frágeis apresentaram maior frequência de RA e maior número de dificuldades para AIVD.

A seguir serão apresentadas, por meio das Tabelas de 15 a 24, distribuições das variáveis independentes que influenciaram estatisticamente nas dificuldades para ABVD e AIVD e resultados dos testes de associação; as chances dessas variáveis independentes provocarem as dificuldades funcionais e sua influência nesse desfecho com controle das demais variáveis analisadas.

Tabela 15 - Descrição dos graus de dificuldade para ABVD segundo características, clínicas e nível de fragilidade, associadas a esse desfecho e resultado dos testes de associação, AMPI e CICAc, SP, 2020

\begin{tabular}{|c|c|c|c|c|c|c|}
\hline \multirow[b]{2}{*}{ Variável } & \multicolumn{4}{|c|}{ Grau de dificuldade para ABVD } & \multirow[b]{2}{*}{$\begin{array}{c}\text { Total } \\
(\mathrm{N}=\mathbf{1 2 8})\end{array}$} & \multirow[b]{2}{*}{$\mathbf{P}$} \\
\hline & $\begin{array}{c}\mathrm{DC} \\
(\mathrm{N}=14)\end{array}$ & $\begin{array}{c}\text { DNC } \\
(\mathrm{N}=11)\end{array}$ & $\begin{array}{c}\mathrm{ND} \\
(\mathrm{N}=89)\end{array}$ & $\begin{array}{c}\mathrm{RA} \\
(\mathrm{N}=7) \\
\end{array}$ & & \\
\hline Nível de fragilidade & & & & & & $<0,001$ \\
\hline Saudável & $0(0)$ & $2(4)$ & $46(92)$ & $2(4)$ & 50 & \\
\hline Pré-frágil & $9(14,8)$ & $4(6,6)$ & $44(72,1)$ & $4(6,6)$ & 61 & \\
\hline Frágil & $5(29,4)$ & $5(29,4)$ & $6(35,3)$ & $1(5,9)$ & 17 & \\
\hline Condições crônicas & & & & & & $\mathbf{0 , 0 1 7}$ \\
\hline Nenhum & $0(0)$ & $0(0)$ & $7(100)$ & $0(0)$ & 7 & \\
\hline 1 a 2 & $1(2,4)$ & $1(2,4)$ & $36(87,8)$ & $3(7,3)$ & 41 & \\
\hline 3 ou mais & $13(16,3)$ & $10(12,5)$ & $53(66,3)$ & $4(5)$ & 80 & \\
\hline Diabetes & & & & & & 0,007 \\
\hline Não & $3(4,3)$ & $6(8,7)$ & $58(84,1)$ & $2(2,9)$ & 69 & \\
\hline Sim & $11(21,2)$ & $5(9,6)$ & $31(59,6)$ & $5(9,6)$ & 52 & \\
\hline AVC & & & & & & $\mathbf{0 , 0 2 1}$ \\
\hline Não & $11(10,1)$ & $8(7,3)$ & $85(78)$ & $5(4,6)$ & 109 & \\
\hline Sim & $3(25)$ & $3(25)$ & $4(33,3)$ & $2(16,7)$ & 12 & \\
\hline Depressão & & & & & & 0,017 \\
\hline Não & $8(8,6)$ & $5(5,4)$ & $74(79,6)$ & $6(6,5)$ & 93 & \\
\hline Sim & $6(21,4)$ & $6(21,4)$ & $15(53,6)$ & $1(3,6)$ & 28 & \\
\hline Dor crônica & & & & & & 0,005 \\
\hline Não & $8(8,6)$ & $5(5,4)$ & $73(78,5)$ & $7(7,5)$ & 93 & \\
\hline Sim & $6(21,4)$ & $6(21,4)$ & $16(57,1)$ & $0(0)$ & 28 & \\
\hline
\end{tabular}

Teste da razão de verossimilhanças 
Tabela 16 - Descrição do número de dificuldades para ABVD segundo características demográficas, clínicas e nível de fragilidade, associadas a esse desfecho e resultado dos testes de associação, AMPI e CICAc, SP, 2020

\begin{tabular}{|c|c|c|c|c|c|}
\hline \multirow[b]{2}{*}{ Variável } & \multicolumn{3}{|c|}{ Número de dificuldades ABVD } & \multirow[b]{2}{*}{$\begin{array}{c}\text { Total } \\
(\mathrm{N}=\mathbf{1 2 8})\end{array}$} & \multirow[b]{2}{*}{$\mathbf{P}$} \\
\hline & $\begin{array}{c}\text { Nenhuma } \\
(\mathrm{N}=96)\end{array}$ & $\begin{array}{c}1 \text { a } 2 \\
(\mathrm{~N}=27)\end{array}$ & $\begin{array}{l}3 \mathrm{ou}+ \\
(\mathrm{N}=5)\end{array}$ & & \\
\hline Sexo & & & & & $\mathbf{0 , 0 1 3}$ \\
\hline Feminino & $75(80,6)$ & $17(18,3)$ & $1(1,1)$ & 93 & \\
\hline Masculino & $21(60)$ & $10(28,6)$ & $4(11,4)$ & 35 & \\
\hline Nível de fragilidade & & & & & $<0,001$ \\
\hline Saudável & $46(92)$ & $3(6)$ & $1(2)$ & 50 & \\
\hline Pré-frágil & $44(72,1)$ & $15(24,6)$ & $2(3,3)$ & 61 & \\
\hline Frágil & $6(35,3)$ & $9(52,9)$ & $2(11,8)$ & 17 & \\
\hline Condições crônicas & & & & & 0,009 \\
\hline Nenhum & $7(100)$ & $0(0)$ & $0(0)$ & 7 & \\
\hline 1 a 2 & $36(87,8)$ & $3(7,3)$ & $2(4,9)$ & 41 & \\
\hline 3 ou mais & $53(66,3)$ & $24(30)$ & $3(3,8)$ & 80 & \\
\hline Diabetes & & & & & 0,008 \\
\hline Não & $58(84,1)$ & $10(14,5)$ & $1(1,4)$ & 69 & \\
\hline $\operatorname{Sim}$ & $31(59,6)$ & $17(32,7)$ & $4(7,7)$ & 52 & \\
\hline AVC & & & & & 0,002 \\
\hline Não & $85(78)$ & $22(20,2)$ & $2(1,8)$ & 109 & \\
\hline Sim & $4(33,3)$ & $5(41,7)$ & $3(25)$ & 12 & \\
\hline Demência & & & & & $\mathbf{0 , 0 3 3}$ \\
\hline Não & $89(74,8)$ & $26(21,8)$ & $4(3,4)$ & 119 & \\
\hline Sim & $0(0)$ & $1(50)$ & $1(50)$ & 2 & \\
\hline Depressão & & & & & 0,018 \\
\hline Não & $74(79,6)$ & $15(16,1)$ & $4(4,3)$ & 93 & \\
\hline Sim & $15(53,6)$ & $12(42,9)$ & $1(3,6)$ & 28 & \\
\hline Doença de Parkinson & & & & & 0,047 \\
\hline Não & $89(74,8)$ & $25(21)$ & $5(4,2)$ & 119 & \\
\hline Sim & $0(0)$ & $2(100)$ & $0(0)$ & 2 & \\
\hline Dor crônica & & & & & 0,007 \\
\hline Não & $73(78,5)$ & $15(16,1)$ & $5(5,4)$ & 93 & \\
\hline Sim & $16(57,1)$ & $12(42,9)$ & $0(0)$ & 28 & \\
\hline
\end{tabular}

Teste da razão de verossimilhanças 
Tabela 17 - Descrição de presença de dificuldade para ABVD segundo características demográficas, clínicas e nível de fragilidade, associadas a esse desfecho, resultado dos testes de associação e análise bivariada, AMPI e CICAc, SP, 2020

\begin{tabular}{|c|c|c|c|c|c|c|}
\hline \multirow[b]{2}{*}{ Variável } & \multicolumn{2}{|c|}{ ABVD } & \multirow[b]{2}{*}{ OR } & \multicolumn{2}{|c|}{ IC (95\%) } & \multirow[b]{2}{*}{$\mathbf{p}$} \\
\hline & $\begin{array}{c}\text { Sem } \\
\text { dificuldade } \\
(\mathrm{N}=96) \\
\end{array}$ & $\begin{array}{c}\text { Com dificuldade } \\
(\mathrm{N}=32)\end{array}$ & & Inferior & Superior & \\
\hline Sexo & & & & & & 0,016 \\
\hline Feminino & $75(80,6)$ & $18(19,4)$ & 1,00 & & & \\
\hline Masculino & $21(60)$ & $14(40)$ & 2,78 & 1,19 & 6,50 & \\
\hline Nível de fragilidade & & & & & & $<0,001 \#$ \\
\hline Saudável & $46(92)$ & $4(8)$ & 1,00 & & & \\
\hline Pré-frágil & $44(72,1)$ & $17(27,9)$ & 4,44 & 1,39 & 14,24 & \\
\hline $\begin{array}{l}\text { Frágil } \\
\text { Autopercepção de } \\
\text { saúde }\end{array}$ & $6(35,3)$ & $11(64,7)$ & 21,08 & 5,07 & 87,75 & 0,019 \\
\hline $\begin{array}{l}\text { Muito boa } \\
\text { Regular-Ruim-Muito } \\
\text { Ruim }\end{array}$ & $\begin{array}{l}50(84,7) \\
46(66,7)\end{array}$ & $\begin{array}{l}9(15,3) \\
23(33,3)\end{array}$ & $\begin{array}{l}1,00 \\
2,78\end{array}$ & 1,17 & 6,62 & \\
\hline Condições crônicas & & & & & & $0,004 \#$ \\
\hline Nenhum & $7(100)$ & $0(0)$ & 1,00 & & & \\
\hline 1 a 2 & $36(87,8)$ & $5(12,2)$ & $\&$ & & & \\
\hline 3 ou mais & $53(66,3)$ & $27(33,8)$ & $\&$ & & & \\
\hline Diabetes & & & & & & 0,003 \\
\hline Não & $58(84,1)$ & $11(15,9)$ & 1,00 & & & \\
\hline Sim & $31(59,6)$ & $21(40,4)$ & 3,57 & 1,53 & 8,36 & \\
\hline AVC & & & & & & $0,002 *$ \\
\hline Não & $85(78)$ & $24(22)$ & 1,00 & & & \\
\hline Sim & $4(33,3)$ & $8(66,7)$ & 7,08 & 1,96 & 25,55 & \\
\hline Depressão & & & & & & 0,006 \\
\hline Não & $74(79,6)$ & $19(20,4)$ & 1,00 & & & \\
\hline Sim & $15(53,6)$ & $13(46,4)$ & 3,38 & 1,38 & 8,28 & \\
\hline Dor crônica & & & & & & 0,025 \\
\hline Não & $73(78,5)$ & $20(21,5)$ & 1,00 & & & \\
\hline Sim & $16(57,1)$ & $12(42,9)$ & 2,74 & 1,12 & 6,71 & \\
\hline
\end{tabular}

Teste qui-quadrado; * Teste exato de Fisher; \# Teste da razão de verossimilhanças; \& Não é possível estimar

As Tabelas 15 a 17 mostram que, no geral, sexo, nível de fragilidade, autopercepção de saúde, condições crônicas em geral, diabetes, AVC, depressão e dor crônica influenciaram grau, número e presença de dificuldades para ABVD $(\mathrm{p}<0,05)$.

De modo específico, pessoas frágeis apresentaram estatisticamente maior número de dificuldades sendo essas, com maior frequência, não compensadas (DNC); pessoas com pior autopercepção de saúde apresentaram maior número de dificuldades, porém a 
frequência mostra-se relevante, embora não significativa, tanto para dificuldades compensadas (DC), quanto para dificuldades não compensadas (DNC).

Adicionalmente, pessoas com mais condições crônicas apresentaram estatisticamente maior número de dificuldades, sendo essas também distribuídas entre compensadas (DC) e não compensadas (DNC), enquanto pessoas com diabetes apresentaram maior frequência de dificuldades compensadas (DC). Salienta-se que pessoas com AVC apresentaram maior frequência de dificuldades compensadas (DC) e não compensadas (DNC) e também requerem ajuda (RA) e pessoas com depressão bem como pessoas com dor crônica apresentaram maior frequência de dificuldades compensadas (DC) e não compensadas (DNC). Ressalta-se que todas as doenças crônicas que foram estatisticamente significativas estiverem associadas ao maior número de dificuldades.

Tabela 18 - Modelo múltiplo para explicar presença de dificuldades para ABVD segundo características demográficas, clínicas, de saúde e níveis de fragilidade, AMPI e CICAc, SP, 2020

\begin{tabular}{|c|c|c|c|c|}
\hline \multirow{2}{*}{ Variável } & \multirow{2}{*}{ OR } & \multicolumn{2}{|c|}{ IC $(95 \%)$} & \multirow{2}{*}{$\mathbf{p}$} \\
\hline & & Inferior & Superior & \\
\hline \multicolumn{5}{|l|}{ Sexo } \\
\hline Feminino & 1,00 & & & \\
\hline Masculino & 6,06 & 1,80 & 20,42 & $\mathbf{0 , 0 0 4}$ \\
\hline \multicolumn{5}{|l|}{ Nível de fragilidade } \\
\hline Saudável & 1,00 & & & \\
\hline Pré-frágil & 2,90 & 0,71 & 11,95 & 0,140 \\
\hline Frágil & 16,59 & 2,21 & 124,26 & 0,006 \\
\hline \multicolumn{5}{|l|}{ Autopercepção de saúde } \\
\hline Muito boa & 1,00 & & & \\
\hline Regular-Ruim-Muito Ruim & 0,52 & 0,14 & 1,91 & 0,326 \\
\hline Diabetes & 4,65 & 1,47 & 14,73 & 0,009 \\
\hline AVC & 2,28 & 0,46 & 11,22 & 0,310 \\
\hline Depressão & 3,62 & 1,12 & 11,71 & $\mathbf{0 , 0 3 2}$ \\
\hline Dor crônica & 2,95 & 0,89 & 9,79 & 0,077 \\
\hline
\end{tabular}

A Tabela 18 mostra que, conjuntamente, pessoas do sexo masculino apresentaram chance de terem dificuldades para ABVD 6,06 vezes maior que a chance de pessoas do sexo feminino, pessoas com fragilidade apresentaram chance de terem dificuldades para ABVD 16,59 vezes maior que pessoas saudáveis, pessoas com diabetes apresentaram chance de terem dificuldades para ABVD 4,65 vezes maior que pessoas sem diabetes e 
pessoas com depressão apresentaram chance de terem dificuldade para ABVD 3,62 vezes maior que pessoas sem depressão, independente das demais características avaliadas.

Tabela 19 - Descrição dos graus de dificuldade para AIVD segundo características demográficas, clínicas, de saúde, nível de fragilidade, associadas a esse desfecho e resultado dos testes de associação, AMPI e CICAc, SP, 2020

\begin{tabular}{|c|c|c|c|c|c|c|}
\hline \multirow[b]{2}{*}{ Variável } & \multicolumn{4}{|c|}{ Graus de dificuldade para AIVD } & \multirow[b]{2}{*}{$\begin{array}{c}\text { Total } \\
(\mathrm{N}=\mathbf{1 2 8}) \\
\end{array}$} & \multirow[b]{2}{*}{$\mathbf{P}$} \\
\hline & $\begin{array}{c}\text { DC } \\
(\mathrm{N}=11)\end{array}$ & $\begin{array}{c}\mathrm{DNC} \\
(\mathrm{N}=26)\end{array}$ & $\begin{array}{c}\text { ND } \\
(\mathrm{N}=22)\end{array}$ & $\begin{array}{c}\text { RA } \\
(\mathrm{N}=69)\end{array}$ & & \\
\hline Faixa etária (anos) & & & & & & $\mathbf{0 , 0 3 8}$ \\
\hline 60 a 74 & $11(10,3)$ & $21(19,6)$ & $21(19,6)$ & $54(50,5)$ & 107 & \\
\hline 75 a 89 & $0(0)$ & $5(23,8)$ & $1(4,8)$ & $15(71,4)$ & 21 & \\
\hline Nível de fragilidade & & & & & & 0,022 \\
\hline Saudável & $5(10)$ & $8(16)$ & $15(30)$ & $22(44)$ & 50 & \\
\hline Pré-frágil & $5(8,2)$ & $15(24,6)$ & $7(11,5)$ & $34(55,7)$ & 61 & \\
\hline Frágil & $1(5,9)$ & $3(17,6)$ & $0(0)$ & $13(76,5)$ & 17 & \\
\hline Autopercepção de saúde & & & & & & 0,016 \\
\hline Muito boa & $7(11,9)$ & $10(16,9)$ & $16(27,1)$ & $26(44,1)$ & 59 & \\
\hline Regular-Ruim-Muito Ruim & $4(5,8)$ & $16(23,2)$ & $6(8,7)$ & $43(62,3)$ & 69 & \\
\hline Condições crônicas & & & & & & $\mathbf{0 , 0 0 7}$ \\
\hline Nenhum & $0(0)$ & $0(0)$ & $4(57,1)$ & $3(42,9)$ & 7 & \\
\hline 1 a 2 & $5(12,2)$ & $9(22)$ & $11(26,8)$ & $16(39)$ & 41 & \\
\hline 3 ou mais & $6(7,5)$ & $17(21,3)$ & $7(8,8)$ & $50(62,5)$ & 80 & \\
\hline Osteoartrose & & & & & & 0,002 \\
\hline Não & $9(14,3)$ & $15(23,8)$ & $14(22,2)$ & $25(39,7)$ & 63 & \\
\hline Sim & $2(3,4)$ & $11(19)$ & $4(6,9)$ & $41(70,7)$ & 58 & \\
\hline Depressão & & & & & & 0,016 \\
\hline Não & $11(11,8)$ & $21(22,6)$ & $16(17,2)$ & $45(48,4)$ & 93 & \\
\hline Sim & $0(0)$ & $5(17,9)$ & $2(7,1)$ & $21(75)$ & 28 & \\
\hline
\end{tabular}

Teste da razão de verossimilhanças 
Tabela 20 - Descrição do número de dificuldades para AIVD segundo características demográficas, clínicas, de saúde, nível de fragilidade, associadas a esse desfecho e resultado dos testes de associação, AMPI e CICAc, SP, 2020

\begin{tabular}{|c|c|c|c|c|c|}
\hline \multirow[b]{2}{*}{ Variável } & \multicolumn{3}{|c|}{ Número de dificuldades AIVD } & \multirow[b]{2}{*}{$\begin{array}{c}\text { Total } \\
(\mathbf{N}=\mathbf{1 2 8})\end{array}$} & \multirow[b]{2}{*}{$\mathbf{P}$} \\
\hline & $\begin{array}{c}\text { Nenhuma } \\
(\mathrm{N}=22)\end{array}$ & $\begin{array}{c}1 \text { a } 2 \\
(\mathrm{~N}=67) \\
\end{array}$ & $\begin{array}{c}3 \mathrm{ou}+ \\
(\mathrm{N}=39)\end{array}$ & & \\
\hline Sexo & & & & & $\mathbf{0 , 0 3 6}$ \\
\hline Feminino & $14(15,1)$ & $45(48,4)$ & $34(36,6)$ & 93 & \\
\hline Masculino & $8(22,9)$ & $22(62,9)$ & $5(14,3)$ & 35 & \\
\hline Nível de fragilidade & & & & & $<0,001$ \\
\hline Saudável & $15(30)$ & $30(60)$ & $5(10)$ & 50 & \\
\hline Pré-frágil & $7(11,5)$ & $30(49,2)$ & $24(39,3)$ & 61 & \\
\hline Frágil & $0(0)$ & $7(41,2)$ & $10(58,8)$ & 17 & \\
\hline Autopercepção de saúde & & & & & $<0,001$ \\
\hline Muito boa & $16(27,1)$ & $34(57,6)$ & $9(15,3)$ & 59 & \\
\hline Regular-Ruim-Muito Ruim & $6(8,7)$ & $33(47,8)$ & $30(43,5)$ & 69 & \\
\hline Condições crônicas & & & & & $<0,001$ \\
\hline Nenhum & $4(57,1)$ & $3(42,9)$ & $0(0)$ & 7 & \\
\hline 1 a 2 & $11(26,8)$ & $23(56,1)$ & $7(17,1)$ & 41 & \\
\hline 3 ou mais & $7(8,8)$ & $41(51,3)$ & $32(40)$ & 80 & \\
\hline Anemia & & & & & 0,004 \\
\hline Não & $16(15,8)$ & $59(58,4)$ & $26(25,7)$ & 101 & \\
\hline Sim & $2(10)$ & $5(25)$ & $13(65)$ & 20 & \\
\hline Osteoartrose & & & & & 0,001 \\
\hline Não & $14(22,2)$ & $37(58,7)$ & $12(19)$ & 63 & \\
\hline Sim & $4(6,9)$ & $27(46,6)$ & $27(46,6)$ & 58 & \\
\hline
\end{tabular}

Teste da razão de verossimilhanças 
Tabela 21 - Descrição de presença de dificuldade para AIVD segundo características sociais, clínicas, de saúde e nível de fragilidade, associadas a esse desfecho e resultado dos testes de associação e das análises bivariadas, AMPI e CICAc, SP, 2020

\begin{tabular}{|c|c|c|c|c|c|c|}
\hline \multirow[b]{2}{*}{ Variável } & \multicolumn{2}{|c|}{ AIVD } & \multirow[b]{2}{*}{ OR } & \multicolumn{2}{|c|}{ IC $(95 \%)$} & \multirow[b]{2}{*}{$\mathbf{p}$} \\
\hline & $\begin{array}{c}\text { Sem } \\
\text { dificuldade } \\
(\mathrm{N}=22)\end{array}$ & $\begin{array}{c}\text { Com dificuldade } \\
\quad(\mathrm{N}=106)\end{array}$ & & Inferior & Superior & \\
\hline Escolaridade & & & & & & 0,036\# \\
\hline Analfabeto & $1(5,6)$ & $17(94,4)$ & 1,00 & & & \\
\hline Até 4 anos & $9(12,7)$ & $62(87,3)$ & 0,41 & 0,05 & 3,43 & \\
\hline 5 a 8 anos & $4(25)$ & $12(75)$ & 0,18 & 0,02 & 1,78 & \\
\hline 9 anos ou + & $8(36,4)$ & $14(63,6)$ & 0,10 & 0,01 & 0,93 & \\
\hline \multicolumn{3}{|c|}{ Tem trabalho remunerado atualmente? } & & & & $\mathbf{0 , 0 3 6}$ \\
\hline Não & $12(12,9)$ & $81(87,1)$ & 1,00 & & & \\
\hline Sim & $10(28,6)$ & $25(71,4)$ & 0,37 & 0,14 & 0,96 & \\
\hline Nível de fragilidade & & & & & & 0,002\# \\
\hline Saudável & $15(30)$ & $35(70)$ & 1,00 & & & \\
\hline Pré-frágil & $7(11,5)$ & $54(88,5)$ & 3,31 & 1,23 & 8,92 & \\
\hline Frágil & $0(0)$ & $17(100)$ & $\&$ & & & \\
\hline Autopercepção de saúde & & & & & & 0,006 \\
\hline Muito boa & $16(27,1)$ & $43(72,9)$ & 1,00 & & & \\
\hline Regular-Ruim-Muito Ruim & $6(8,7)$ & $63(91,3)$ & 3,91 & 1,42 & 10,78 & \\
\hline Condições crônicas & & & & & & 0,002\# \\
\hline Nenhum & $4(57,1)$ & $3(42,9)$ & 1,00 & & & \\
\hline 1 a 2 & $11(26,8)$ & $30(73,2)$ & 3,64 & 0,70 & 18,91 & \\
\hline 3 ou mais & $7(8,8)$ & $73(91,3)$ & 13,91 & 2,58 & 75,05 & \\
\hline Osteoartrose & & & & & & 0,018 \\
\hline Não & $14(22,2)$ & $49(77,8)$ & 1,00 & & & \\
\hline Sim & $4(6,9)$ & $54(93,1)$ & 3,86 & 1,19 & 12,51 & \\
\hline
\end{tabular}

Teste qui-quadrado; * Teste exato de Fisher; \# Teste da razão de verossimilhanças; \& Não é possível estimar

As Tabelas 19 a 21 mostram que as variáveis que explicam os desfechos funcionais, ou seja, grau, número, e presença de dificuldade para AIVD, foram, no geral, bastante semelhantes. Estatisticamente, sexo, faixa etária, nível de fragilidade, autopercepção de saúde, condições crônicas, anemia, osteoartrose e depressão influenciaram em algum ou todos os desfechos funcionais $(\mathrm{p}<0,05)$.

As mulheres apresentaram estatisticamente maior número de dificuldades para AIVD, enquanto pessoas mais velhas referiram com maior frequência necessidade de ajuda (RA) para essas atividades. Pessoas frágeis, com autopercepção de saúde pior e com maior número de condições crônicas também mencionaram requerer com maior 
frequência ajuda (RA) e apresentaram maior número de dificuldades, enquanto entrevistados que referiram anemia apresentaram maior número de dificuldades e pessoas com osteoartrose, necessitaram com maior frequência, ajuda e apresentaram maior número de dificuldades para AIVD.

Tabela 22 - Modelo múltiplo para explicar presença de dificuldade para AIVD segundo características demográficas, sociais, clínicas, de saúde e níveis de fragilidade, AMPI e CICAc, SP, 2020

\begin{tabular}{lcccc}
\hline \multirow{2}{*}{ Variável } & \multirow{2}{*}{ OR } & \multicolumn{2}{c}{ IC (95\%) } & \multirow{2}{*}{ p } \\
\cline { 1 - 1 } & & Inferior & Superior & \\
\hline Faixa etária (anos) & & & & \\
75 a 89 & 1,00 & & & \\
Escolaridade & 3,17 & 0,31 & 32,80 & 0,334 \\
Analfabeto & & & & \\
Até 4 anos & 1,00 & & & \\
5 a 8 anos & 0,51 & 0,05 & 4,99 & 0,566 \\
9 anos ou + & 0,51 & 0,03 & 8,23 & 0,638 \\
Tem trabalho remunerado atualmente? & 0,27 & 0,02 & 3,01 & 0,287 \\
Nível de fragilidade & 0,78 & 0,20 & 2,99 & 0,717 \\
Saudável & & & & \\
Pré-frágil & 1,00 & & & \\
Frágil & 1,88 & 0,51 & 6,94 & 0,342 \\
Autopercepção de saúde & $\&$ & & & 0,998 \\
Muito boa & & & & \\
Regular-Ruim-Muito Ruim & 1,00 & & & \\
Hipertensão & 1,16 & 0,29 & 4,62 & 0,830 \\
Osteoartrose & 2,61 & 0,69 & 9,97 & 0,160 \\
\hline & 4,01 & 1,05 & 15,31 & $\mathbf{0 , 0 4 2}$ \\
\hline
\end{tabular}

Regressão logística múltipla (Full model)

A Tabela 22 mostra que, conjuntamente, apenas a osteoartrose (AO) influenciou estatisticamente presença de dificuldade para AIVD $(\mathrm{p}=0,042)$ independente das demais características avaliadas, sendo que pessoas com OA apresentaram chance de apresentar alguma dificuldade para AIVD, 4,01 vezes maior que pessoas sem osteoartrose. Acrescenta-se que pessoas com essa condição clínica apresentaram estatisticamente menor frequência de compensação de dificuldades (DC) com práticas de autocuidado para AIVD ( $\mathrm{p}=0,016)$, ou seja, presença de OA não esteve associada no presente estudo, a adoção dessas práticas. 


\section{DISCUSSÃO}

O presente estudo caracterizou uma amostra de idosos $(n=128)$, moradores da região do Itaim Paulista e usuários de unidades básicas de saúde inseridas nesse território, no que se refere às informações sociodemográficas, clínicas, referente à autopercepção de saúde, funcionais e nível de fragilidade. Algumas dessas informações são indicadores de vulnerabilidade social e fragilidade e compõem o perfil da maioria dos idosos entrevistados, como baixa escolaridade (70,3\%), satisfazer mais ou menos, mal ou muito mal suas necessidades básicas $(57,8 \%)$, perceber sua saúde como regular, ruim ou muito ruim $(53,9 \%)$, apresentar 3 ou mais condições crônicas $(94,5 \%)$ e ser classificado pela AMPI-AB como pré-frágil ou frágil $(61,0 \%)$. Avaliação pormenorizada da capacidade funcional, por meio do CICAc, corrobora com a classificação de fragilidade dos idosos pela AMPI-AB, ao revelar alto percentual de dificuldades para 1 e + AIVD (82,8\%), implicando realização de atividades sem compensação de dificuldades ou necessidade de ajuda $(74,2 \%)$, pela baixa adoção de práticas de autocuidado $(8,6 \%)$.

Buscaram-se também, por meio do presente estudo, associações - isoladas e conjuntas - entre dificuldades funcionais nas ABVD e AIVD e, informações sociodemográficas, clínicas, referente à autopercepção de saúde, funcionais e nível de fragilidade. Como se previa, as análises revelaram que as dificuldades funcionais estão associadas a muitas das características sociodemográficas, autopercepção de saúde, condições clínicas e ao perfil de fragilidade dos idosos, bem como demonstram as chances dos idosos virem a desenvolver dificuldades funcionais na presença dessas características.

Analisando os dados coletados na presente pesquisa, observou-se que a maior parte dos idosos era do sexo feminino, assim como no estudo de Araújo et al. (2019) que pesquisou 48 idosos inseridos num contexto de alta vulnerabilidade, cadastrados em um Centro de Referência de Assistência Social (CRAS) de um município do interior paulista, onde os participantes eram em sua maioria mulheres (70,8\%). Tais dados corroboram com a maior preocupação de mulheres em relação à sua saúde e autocuidado, utilização e busca frequente dos serviços de saúde por atendimento (Del Duca et al., 2012), além de pesquisas que apontam maior proporção de mulheres entre as pessoas idosas, em razão da mortalidade diferencial por sexo (IBGE, 2019). Na pesquisa de Araújo et al. (2019), que teve como objetivo estimar o nível de capacidade funcional, doenças autorreferidas e fatores associados de 159 idosos cadastrados na área de abrangência de três equipes de 
saúde da família de uma UBS no município de Recife, a maioria da população avaliada era do sexo feminino $(76,7 \%)$ e tinha entre 60 e 70 anos de idade $(53,5 \%)$. Tais dados corroboram com a presente pesquisa, onde 72,7 da população avaliada eram mulheres e $55,5 \%$ tinham entre 60 e 70 anos.

Parte importante dos idosos participantes desta pesquisa referiu residir só (20,3\%), esse percentual foi próximo ao obtido no estudo de Negrini et al. (2018) realizado com mais de 11000, que avaliou a prevalência de idosos que moram sozinhos. Tal estudo analisou as informações coletadas pela Pesquisa Nacional de Saúde realizada pelo Ministério da Saúde em 2013, e demonstrou que 15,3\% das pessoas idosas no Brasil moram sozinhas, sendo que esse fato está associado a maiores dificuldades nas atividades instrumentais da vida diária e quedas. Tais dados corroboram também com a pesquisa de Aguiar et al. (2019) onde 16,9\% dos idosos referiram residir sozinhos, porém nesta pesquisa, identificou-se menor incapacidade nesse grupo.

$\mathrm{Na}$ presente pesquisa, a maioria dos idosos referiu ser casado $(58,6 \%)$, dado também encontrado por Neri et al. (2013) no estudo FIBRA, onde 48\% também referiram este estado civil. Zanesco et al. (2020) refere que o suporte oferecido pela convivência com um companheiro (a) é aspecto importante nas dificuldades funcionais, sendo que o idoso que não divide residência com um companheiro (a) apresenta mais chances de desenvolver dificuldades funcionais decorrente de aspectos emocionais, isolamento e dependência.

Nesta pesquisa observou-se que a maioria dos idosos referiu até 4 anos de escolaridade, dado que também foi observado na pesquisa de Araújo et al. (2019), na qual a maioria dos participantes referiram 3,2 anos. Esse dado reforça o desvalor que anteriormente era atribuído à educação formal, quando condições socioeconômicas precárias corroboravam para dificuldade de acesso às escolas (Del Duca et al., 2012). Tais dados também foram encontrados na pesquisa FIBRA de Neri et al. (2013), que avaliou 3478 idosos integrantes de amostras de sete cidades brasileiras, e constatou que $49 \%$ dos idosos possuíam de 1 a 4 anos de escolaridade.

No presente estudo, a maioria dos participantes referiu ter recursos financeiros advindos de aposentadoria $(53,1 \%)$, tais dados corroboram com a pesquisa de Silva et al. (2016) que verificou o predomínio de indivíduos que recebiam aposentadoria $(77,1 \%)$, sendo a maioria de um salário mínimo. Estudo sugere que a aposentadoria está relacionada com a autonomia financeira e melhora da qualidade de vida do idoso, nessa 
perspectiva tem potencial para reduzir vulnerabilidade devendo ser assegurada (Pimentel and Loch, 2020).

A maioria dos participantes na atual pesquisa referiu possuir filhos $(85,2 \%)$, assim como no estudo de Almeida et al. (2012) onde a menor parcela $(23,7 \%)$ dos idosos referiu não ter filhos. Essa condição é relevante, pois a família é o primeiro suporte a ser acionado quando há a instalação de alguma incapacidade (Sluzki, 1997).

A grande maioria dos idosos, no presente estudo, identificou alguém com quem contar em caso necessite de ajuda $(88,3 \%)$, sendo que na maioria dos casos os filhos seriam essas pessoas de referência, seguidas pelo cônjuge. O cuidador de sexo feminino foi predominante, quando referida presença do mesmo, e com maior frequência situamse entre 25 a 59 anos. Tais dados corroboram com os da pesquisa de Aires et al. (2020) que realizaram estudo transversal com 125 cuidadores informais, na qual predominaram cuidadoras (73,6\%), filhas (68,0\%), com média de idade de 50 anos. Na referida pesquisa, a idade do cuidador apresentou relação estatisticamente significativa com a sobrecarga do mesmo. Em sintonia, o autor afirma que a tarefa de cuidar deve ser partilhada, devendo o cuidador recorrer a outras redes de apoio, como grupos de suporte na atenção primária a saúde, pois a capacidade funcional, a situação de saúde e o nível de dependência dos idosos são fatores que podem contribuir com a sobrecarga dos cuidadores.

Quanto ao exercício profissional, a maioria dos idosos entrevistados não exerce qualquer profissão, sendo que apenas 18,8\% referem exercer atividade profissional. $\mathrm{Na}$ pesquisa de Melo et al. (2016), que descreveu arranjos domiciliares no Brasil, 26,7\% dos idosos referiram ocupação, percentual acima dos dados do presente estudo, o autor concluiu em sua pesquisa que estes idosos, mesmo tento direito a aposentadoria, preferiam continuar ativos.

A maior parte dos idosos entrevistados referiu como principais atividades profissionais durante a vida, aquelas relacionada a serviços de limpeza $(28,1 \%)$. Para Almeida et al. (2016) trabalhos realizados durante a vida que exigem maior esforço configuram-se um provável fator para a incapacidade funcional, devido a maior exposição a comportamentos de risco e a adoecimentos crônicos.

Os participantes da pesquisa atual referiram predominantemente satisfazer mais ou menos, mal ou muito mal suas necessidades de alimentação, moradia e saúde $(57,8)$. A falta ou insuficiência de recursos financeiros foi mencionada na pesquisa de Silveira et 
al. (2018), sendo reconhecida como fator de adoecimento em idosos, fonte de desconforto e de prejuízo à qualidade de vida para essa população.

A autopercepção de saúde para a maioria dos idosos entrevistados foi regular/ruim/muito ruim. No estudo de Rocha et al. (2017), objetivando verificar fatores determinantes nos níveis de funcionalidade de idosos brasileiros, compreendeu análise secundária de dados obtidos na Pesquisa Nacional de Saúde e identificou que a maioria dos pesquisados também referiu autopercepção de saúde como regular (43\%) e ruim $(37,4 \%)$, com interferência direta na funcionalidade, onde melhores níveis de funcionalidade foram observados em percentuais mais elevados de autopercepção de saúde. Em sintonia, identificou-se em outra pesquisa autopercepção negativa de saúde (54\%), estando associada com fragilidade e perdas na capacidade funcional (Maia et al., 2020).

A maioria dos idosos da presente pesquisa referiu 3 ou mais condições crônicas de saúde, seguidas de 1 a 2, e a situação de nenhuma doença crônica foi referida por um pequeno número de idosos. Em conformidade, o estudo de Leme et al. (2019) cujo objetivo foi analisar o impacto da fragilidade, da multimorbidade e da incapacidade funcional na sobrevida de 133 idosos assistidos no Ambulatório de Geriatria do Hospital das Clínicas da Universidade Estadual de Campinas, demonstrou que a prevalência de doenças crônicas simultâneas foi de 3.22. Giacomin et al. (2018) realizaram estudo quantitativo e descritivo com 9412 idosos e verificaram que a presença de doenças crônicas foi associada de forma significativa com dificuldade nas atividades básicas da vida diária, 71,7\% dos idosos apresentavam pelo menos uma doença crônica, assim como no estudo nacional sueco sobre envelhecimento de Calderón-Larrañaga et al. (2019), que encontrou associações estatisticamente significantes entre a presença de doenças crônicas e dificuldades nas atividades básicas e instrumentais da vida diária.

A maioria dos idosos pesquisados faz uso de 1 a 4 medicamentos (62,5\%). Matos et al. (2018) que pesquisaram fatores de risco para a redução da capacidade funcional em 202 idosos também incluíram quantidade de medicamentos em uso por idosos dentre as variáveis analisadas e identificaram-se maior presença de dificuldades nos idosos que faziam uso de dois ou mais medicamentos.

Quanto as internações, 7,1\% dos idosos mencionaram sua ocorrência nos últimos 12 meses, dados que corroboram com a pesquisa de Zanesco et al. (2020) onde 10\% dos idosos referiram internação nos últimos 12 meses. Segundo o autor idosos que passaram 
por internação estão mais expostos ao desenvolvimento ou agravamento de dificuldades funcionais.

Um percentual considerável de idosos $(29,7 \%)$ relatou 1 ou 2 episódios de quedas nos últimos 12 meses, esse número é próximo ao relatado em estudo de Duran-Badillo et al. (2020) que teve como objetivo conhecer a relação entre a função sensorial, função cognitiva, capacidade de caminhar e dependência em 146 idosos onde 32,2\% dos participantes relataram ter sofrido queda nos últimos doze meses. Ainda, segundo a OMS (2010) as quedas respondem por $40 \%$ das mortes relacionadas a ferimentos e, aproximadamente $28 \%$ a $35 \%$ das pessoas com mais de 65 anos caem a cada ano, sendo que a frequência aumenta com a idade.

Quanto às dificuldades referidas para enxergar, 46,9\% dos idosos referiram dificuldade dessa natureza. Luiz et al. (2009) pesquisaram associação entre déficit visual e aspectos clínicos e funcionais em 96 idosos e concluíram que 17,7\% dos idosos apresentavam baixa visão, sendo que os idosos com maior déficit visual apresentavam maior comprometimento funcional no que se referia a equilíbrio, quedas, humor deprimido e maior número de AIVD comprometidas, em outra pesquisa identificou-se $87,8 \%$ de idosos caiadores, e que dificuldades para enxergar estiveram associadas a prejuízos no equilíbrio e a 2,8 vezes mais chances de cair (Araújo et al., 2019).

Parte importante dos idosos pesquisados referiram dificuldades para ouvir $(39,8)$. Carmona-Torres et al. (2019) em seu estudo identificaram 26,7\% com dificuldades para ouvir, portanto valor inferior ao encontrado na presente pesquisa. Afirma-se que a perda auditiva pode ocasionar redução na compreensão da fala, o que prejudica a comunicação, a vida social e profissional, provocando também sentimento de insegurança, medo, depressão e isolamento (Magni et al., 2005). Adverte-se que a perda auditiva esteve associada em outro estudo ao comprometimento na comunicação, isolamento social e prejuízo na função cognitiva (Chen and Zhou, 2020).

Parte importante dos idosos do presente estudo $(21,1 \%)$ referiu apresentar alguma limitação física. Na pesquisa de Clares et al. (2014), entretanto, a prevalência dessa condição foi bem maior $(71,2 \%)$ e esteve relacionada a redução de capacidade de moverse, rigidez articular e dor, constituindo-se dificuldades frequentes no processo de envelhecimento e decorrentes de perda de massa muscular e desgastes articulares, que se acentuam após os 70 anos. Prevalência maior do que no presente estudo também foi encontrada em pesquisa $(67,9 \%)$, onde a mesma esteve relacionada com dependência 
(Silva et al., 2019).

Dificuldades cognitivas foram mencionadas por $46,9 \%$ dos idosos participantes da pesquisa atual. No estudo de Soares et al. (2019) 80,1\% dos dependentes apresentaram algum comprometimento cognitivo e as dificuldades cognitivas estiveram associadas a dependência funcional. Observou-se ainda que um pior desempenho cognitivo associouse ao maior comprometimento funcional.

As alterações de humor foram referidas por 62,5\% dos idosos entrevistados. No estudo de Matos et al. (2018) que objetivou identificar fatores de risco para redução da capacidade funcional em idosos, 202 idosos residentes na comunidade e cadastrados na Estratégia Saúde da Família (ESF) foram avaliados e observou-se que a presença de sintomas de depressão é um importante fator de risco para declínio da capacidade funcional. Segundo Buurman et al. (2011) o isolamento social, frequente em pessoas com depressão, leva o idoso a reduzir participação em eventos comunitários e religiosos, a fazer ou receber menos visitas, com repercussão no desempenho das demais atividades de vida diária. Dados de outra pesquisa consideraram sintomas de depressão fator de risco para declínio da capacidade funcional (Matos et al., 2018).

A incontinência urinária foi mencionada por 33,6\% dos idosos participantes da presente pesquisa. No estudo de Soares et al (2019) 84,8\% dos dependentes apresentaram esta condição clínica, que esteve associada de modo significativo com a dependência funcional.

Pequena parte dos idosos referiu perda de peso não intencional nos últimos 12 meses (19,5\%), dados que se assemelham com os da pesquisa de Gross et al. (2018) que pesquisaram os níveis de fragilidade de idosos e identificaram que 14,9\% referiram essa condição, considerada importante critério da avaliação da fragilidade nessa população.

As alterações nas condições bucais foram mencionadas por 43,8\% dos idosos pesquisados. No estudo de Silva et al. (2016) que teve como objetivo analisar a relação entre as condições de saúde bucal de uma população de idosos e a capacidade funcional na realização das atividades básicas da vida diária em 441 idosos, a perda total dos dentes foi observada em mais da metade da amostra estudada e o edentulismo funcional (ausência de até 20 elementos dentários), foi encontrado em 92,7\% dos indivíduos. Os autores salientam que problemas bucais em idosos podem representar efeitos cumulativos de uma história pregressa de cuidados deficientes e assistência mutiladora. 
Quanto aos níveis de fragilidade, um percentual de 47,7\% de participantes do atual estudo foi classificado como pré-frágeis e 13,3\% como frágeis. Esses dados estão de acordo com aqueles apresentados por Melo Filho et al. (2020) nos quais a maioria dos idosos mostrou-se pré-frágil $(65,3 \%)$ e frágil $(15,8 \%)$, assim como com resultados de pesquisa de Leite et al. (2019), que avaliou 28 residentes em um condomínio exclusivo para idosos no interior paulista e identificou, 42,9\% de idosos pré-frágeis. Ainda, no estudo FIBRA de Neri et al. (2013), por meio do qual foram avaliados 3478 idosos integrantes de amostras probabilísticas de sete cidades brasileiras foram identificados, a semelhança dos dados obtidos no presente estudo, $51.8 \%$ de idosos pré-frágeis. No estudo de Leme et al. (2019) sobre informações clínicas, de saúde e sobrevida de 133 idosos assistidos no Ambulatório de Geriatria do Hospital das Clínicas da Universidade Estadual de Campinas, 56,1\%, também foram classificados como pré-frágeis. Depreende-se que em todos os estudos referidos foram identificados valores semelhantes aos encontrados na atual pesquisa. Salienta-se que estudos que se debruçam sobre a identificação de fragilidade e especialmente de condições que possam levar a fragilidade são extremamente oportunos. Conforme o Ministério da Saúde (2006) fragilidade é considerada uma síndrome fortemente biológica cujos sinais e sintomas poderiam ser precocemente identificados, e desse modo, passível de alteração em seus desfechos.

As doenças crônicas mais prevalentes na presente pesquisa foram hipertensão arterial sistêmica (HAS) (81\%), osteoartrose (47,9\%), diabetes mellitus (43\%), dor crônica $(23,1 \%)$ e depressão $(21,1 \%)$. Ressalta-se que os achados deste estudo superam os valores encontrados na pesquisa de Leme et al. (2019) no que se refere a HAS e diabetes, sendo esses $66,2 \%$ e $21,1 \%$ respectivamente.

Parte dos idosos da presente pesquisa referiu dor crônica $(23,1 \%)$. Embora não tenha sido mencionada pela maioria, considera-se um número relevante por se tratar de um sintoma limitante. Em estudo de Lini et al. (2016) acerca da prevalência de dor crônica autorreferida e suas repercussões, foram avaliados 416 residentes em municípios do Sul do Brasil, onde 54.4\% referiram dor crônica, valor acima do encontrado no presente estudo. O autor reforça que a dor é um sintoma preocupante no idoso, pois pode comprometer sua segurança, independência e autonomia.

No que se refere à distribuição de idosos quanto às dificuldades para as ABVD, nota-se que predominam as dificuldades na atividade de locomoção, mencionada por 19,5\% idosos, enquanto comunicação e transferências posturais foram atividades com 
menor porcentagem de dificuldades referidas. Dificuldades de natureza física foram mencionadas com maior frequência pelos idosos, e para superarem dificuldades dessa natureza eles adotam especialmente mudanças comportamentais como práticas de autocuidado. Dados um pouco distintos foram encontrados na pesquisa de Nunes et al. (2018) onde a dificuldade na atividade de vestir foi mencionada com maior frequência $(12,2 \%)$, locomoção foi mencionada apenas por 5,7\% dos idosos e a atividade de comer foi a menos mencionada. No que se refere às práticas de autocuidado, os dados do estudo atual corroboram com dados obtidos por Almeida et al. (2012) que afirma que quando os idosos adotam práticas de autocuidado comumente lançam mão de mudanças comportamentais para superar dificuldades. A autora refere que adoção de mudanças na forma de realizar atividades tem sido apontada como preferível ao uso de equipamentos, pois novos modos de desempenhar atividades dão maior flexibilidade à pessoa, enquanto equipamentos geram problemas de custo, cuidados e aceitação por parte do usuário. Almeida et al. (2012) reflete que embora as modificações ambientais também sejam formas possíveis de compensar dificuldades funcionais e algumas sejam pouco custosas, na sua pesquisa também foram pouco utilizadas pelos participantes. Esse dado parece relacionar-se a dificuldade de idosos em identificar a influência de fatores ambientais sobre a funcionalidade. Quase a totalidade dos idosos pesquisados por Almeida et al. (2012) referiu fatores intrínsecos, especialmente prejuízos físicos e sensoriais para dificuldades básicas de vida diária, o que não surpreende já que a competência para elas está fortemente relacionada aos recursos relativos à saúde.

Observou-se que as dificuldades nas AIVD, especificamente nas tarefas domésticas predominaram no presente estudo com $64 \%$ de idosos referindo dificuldades para essas atividades, seguida por dificuldades para compras $(46,1 \%)$, uso de meios de transporte $(23,4 \%)$, controle do orçamento $(21,3 \%)$ e lavagem de roupas $(19,8 \%)$. Dificuldades de natureza física, também foram mais frequentemente mencionadas e, quando adotam práticas de autocuidados para seu enfrentamento, os entrevistados recorrem especialmente às mudanças comportamentais, porém parte importante dos idosos realizam essas atividades sem compensar suas dificuldades ou necessitam de assistência física. Comparando tais dados com os obtidos na pesquisa de Nunes et al. (2018), as dificuldades em realizar tarefas domésticas pesadas foram as mais referidas pelos idosos $(27,6 \%)$, seguida por cuidar das finanças $(19,6 \%)$ e utilizar transporte público $(17,6 \%)$. Dificuldades relativas à atividade de compra foram mencionadas por $13,4 \%$ dos idosos. 
No que se refere às práticas de autocuidado, Almeida et al. (2012) mencionam que os idosos, embora adotem pouco as práticas de autocuidado, quando o fazem comumente recorrem a mudanças comportamentais para superar tais dificuldades, informação confirmada com os achados desde estudo. Os dados referentes às dificuldades físicas se assemelham aos obtidos na pesquisa de Almeida et al. (2012) onde a maioria dos participantes identificam fundamentalmente fatores intrínsecos relacionados aos aspectos físicos para explicarem suas dificuldades nas AIVD. A mesma autora reflete, entretanto, acerca da complexidade para a realização destas atividades nas quais há interação entre fatores intrínsecos e extrínsecos. No mesmo estudo a autora refere que parte considerável (35\%) dos idosos por ela pesquisados requer ajuda para a realização dessas atividades.

$\mathrm{Na}$ pesquisa de Nunes et al. (2018), que objetivou identificar e hierarquizar as dificuldades referidas no desempenho das atividades de vida diária de idosos, foram utilizadas as bases de dados do estudo SABE (Saúde e Bem-Estar no Envelhecimento) dos anos de 2000, 2006 e 2010 e os resultados foram semelhantes aos obtidos na presente pesquisa. As dificuldades na realização das AIVD (utilizar transportes, realizar tarefas domésticas, fazer compras e cuidar de finanças, respectivamente), nas três ondas do estudo SABE foram mais prevalentes que as dificuldades nas ABVD. Tais resultados corroboram com o escalonamento de Guttman mencionado (Ramos et al., 1993). A escala de Guttman pressupõe hierarquização do comprometimento funcional ordenando as respostas segundo a frequência de aparecimento. Assim, no que se referem às atividades de vida diária, geralmente é observada maior frequência de dificuldades para as AIVD do que para as ABVD, pois são mais complexas e requerem para seu desempenho adequado múltiplos sistemas interligados funcionando de maneira satisfatória. Com o avançar do tempo e persistência de dificuldades funcionais essas poderão progressivamente comprometer o desempenho das ABVD. Na pesquisa de pesquisa de Carmona-Torres et al. (2019) que objetivou conhecer a prevalência, os fatores associados e as tendências temporais das dificuldades para as atividades básicas e instrumentais da vida diária de mais de 25000 idosos na Espanha, encontrou-se valores semelhante aos do presente estudo no tocante às dificuldades referidas nas AIVD, onde a atividade de realização das tarefas domésticas foi a mais citada.

No tocante às atividades de lazer, considera-se pertinente discuti-las tanto na perspectiva de sua inclusão no universo ocupacional dos idosos entrevistados, quanto em relação à capacidade funcional. Observa-se que a maioria dos entrevistados refere prática 
de atividade física e religiosa ( $73 \%$ e $71,9 \%$ respectivamente) e uma quantidade pequena de idosos refere atividades de lazer com predomínio de outros interesses $(0,8 \%$ a $25 \%)$. Quanto à capacidade funcional, um número ainda menor refere dificuldade $(0,8$ a 3,9\%) para sua realização, mas quando o fazem, mencionam especialmente dificuldade de natureza física $(3,9 \%)$ e adotam mudanças comportamentais para sua compensação (1,6\%), reproduzindo comportamento observado em relação às ABVD e AIVD.

Embora se constate pouca diversificação de interesses entre idosos no que se refere a prática do lazer, mostra-se positivo seu envolvimento em atividades físicas e religiosas. Segundo Brandão et al. (2019) que realizaram estudo transversal com 310 idosos na Bahia, com o objetivo de determinar o poder preditivo do comportamento sedentário e estabelecer seus pontos de corte como discriminadores da incapacidade funcional em idosos, concluiu que a prática de atividade física para evitar os comportamentos sedentários é importante indicador de saúde na população idosa. A pesquisa Komatsu et al. (2019) demonstrou, por meio de testes estatísticos, que o engajamento em atividades físicas e culturais pode efetivamente prevenir o declínio funcional nas atividades de vida diária, evidenciando a necessidade de políticas públicas para promover atividade de lazer, com intuito de prolongar a expectativa de vida saudável. Os autores ainda reforçam que a prática de atividades físicas está associada à melhora da força muscular, volume muscular e função física, diminuindo o risco de obesidade, diabetes, dislipidemias, hipertensão e doenças cardiovasculares.

Quanto à atividade religiosa Costa and Humboldt (2020) referem que a população idosa vivencia diversos tipos de perdas e alterações em sua vida, onde a espiritualidade pode ser uma forma de encontrar força para vencer as adversidades. Na sua pesquisa sobre fé e espiritualidade para lidar com as doenças crônicas, todos os inquiridos responderam que acreditam em Deus e que a fé e crença em Deus os ajudaram e ajudam a enfrentar as doenças.

Em estudo conduzido por Almeida et al. (2016), idosos que participam de lazer também referem predominantemente prática de atividades físicas e religiosas, como caminhadas e ir à missa, citam dificuldades físicas para sua realização, seguidas por dificuldades sensoriais. Os dados do referido estudo diferem em relação a presente pesquisa quanto à forma de compensação de dificuldades. Assim, embora em ambos os estudos, predominem adoção de práticas do autocuidado, no estudo de Almeida et al. (2016) os idosos adotam fundamentalmente dispositivos de mobilidade seguidos por 
mudanças comportamentais e ambientais.

O estudo atual previu também a identificação de atividades desejadas, dificuldades supostas para sua não realização e formas imaginadas de virem a superar essas dificuldades. Importante parcela dos idosos referiu como atividade desejada estudar $(46,1 \%)$, esses idosos mencionam fundamentalmente falta de oportunidades e de recursos financeiros durante a vida para realizarem essa atividade. Conforme referido anteriormente pouco valor era atribuído à educação formal no passado e condições socioeconômicas precárias dificultavam ainda mais o acesso à educação (Del Duca et al., 2012).

No tocante as ABVD e AIVD, buscou-se também traçar perfil dos idosos entrevistados quanto à presença, número e grau de dificuldades. As dificuldades para as ABVD foram mencionadas por $25 \%$ dos idosos, onde a maioria referiu de 1 a 2 atividades para as quais tinham dificuldades, sendo que estas se encontram mais frequentemente compensadas $(10,9 \%)$ em relação aos que realizam com dificuldade $(8,6 \%)$ ou requerem ajuda (5,5\%). Em estudo realizado por Andrade et al. (2018) com o objetivo de avaliar a magnitude das desigualdades relacionadas às ABVD entre idosos brasileiros residentes na comunidade e determinar a contribuição das condições demográficas, socioeconômicas e de saúde para essa desigualdade, os pesquisadores utilizaram dados do Estudo Longitudinal Brasileiro de Envelhecimento de 2015 - ELSI-Brasil (2015) com 9412 participantes, os resultados demonstraram que as incapacidades nas atividades de vida diária afetam aproximadamente $16 \%$ dos idosos brasileiros, valor abaixo do encontrado na presente pesquisa. Na pesquisa de Almeida et al. (2012) entretanto um percentual bem maior de idosos apresentam dificuldades $(52,1 \%)$ e requerem ajuda $(15,2 \%)$, em contrapartida apenas $12.1 \%$ compensam todas as suas dificuldades com práticas de autocuidado. A maior prevalência de incapacidades no estudo de Almeida et al. (2012), em relação aos dados obtidos na presente pesquisa, possivelmente está relacionada à grande proporção de participantes acima de 75 anos no estudo referido.

Quanto às AIVD, a grande maioria dos idosos referiu dificuldades $(84,8 \%)$, possui 1 a 2 atividades com dificuldades $(52,3 \%)$, e requerem ajuda $(53,9 \%)$ para a realização destas atividades, apenas $8,6 \%$ dos idosos compensam suas dificuldades com práticas de autocuidado. Na pesquisa de Almeida et al. (2012), apesar de haver uma proporção bem menor de idosos com dificuldades nas $\operatorname{AIVD}(48,4 \%)$ e, bem maior em relação aos idosos que referiram de 1 a 2 dificuldades (80,5\%), ambos os estudos se assemelham na distância 
entre os demais graus de dificuldade, visto que a proporção de idosos que compensam dificuldades no estudo de Almeida et al (2012) foi menor (5,3\%) do que aqueles que não compensam dificuldades $(7,9 \%)$ ou requerem ajuda $(72,8 \%)$.

Com relação às possíveis associações estatísticas entre presença, número e grau de dificuldades para ABVD e características - demográficas e socioeconômicas, referentes à autopercepção de saúde, clínicas e nível de fragilidade - identificou-se que as condições ser do sexo masculino, ser classificado como frágil, ter autopercepção de saúde pior, apresentar condições crônicas, diabetes, AVC, depressão e dor crônica mostraram-se associadas ao grau, número ou presença de dificuldades nessas atividades.

De modo semelhante, no estudo de Aguiar et al. (2019) com 360 idosos atendidos por um centro de referência no norte de Minas Gerais, a presença de incapacidade funcional para as ABVD foi maior no sexo masculino $(\mathrm{p}=0,03)$. Ressalta-se que em função de questões culturais ligadas ao gênero, muitos homens não realizam ou solicitam auxílio para executar as atividades básicas. Portanto, a maior incapacidade funcional no sexo masculino pode se relacionar às questões socioculturais e não somente ao declínio funcional. Ainda, podem-se elencar como prováveis fatores que contribuem para a incapacidade funcional nos homens, a maior exposição a comportamentos de risco em trabalhos que exigem maior esforço, tabagismo, ingesta rotineira de bebidas alcóolicas e, consequentemente, ocorrência de adoecimentos crônicos (Almeida et al., 2016).

Assim como no presente estudo, a fragilidade também esteve associada a presença de dificuldades na pesquisa conduzida por Aguiar et al. (2019) $(\mathrm{p}=0,00)$. A presença da incapacidade funcional para as atividades da vida diária foi maior entre os considerados frágeis. Diante deste quadro, emerge a reflexão sobre as redes de apoio formais e informais destinadas à população idosa, frente à necessidade de cuidados e de preservação de sua autonomia e bem-estar, visto que os sinais e sintomas relacionados a fragilidade poderiam ser precocemente identificados e seus desfechos alterados (Ministério da Saúde, 2006).

A autopercepção de saúde regular, ruim ou muito ruim, demonstrou valores significativos no grau, número ou presença de dificuldades nas ABVD no presente estudo, assim como na pesquisa de Storeng et al. (2018) que investigou fatores associados à necessidade de assistência nas atividades básicas e instrumentais de vida diária em idosos noruegueses. Os autores reconheceram na percepção subjetiva de saúde um importante fator de risco para a necessidade de assistência em uma ou mais atividades básicas. 
Quanto às condições crônicas, o estudo de Andrade et al. (2018) reafirmou os dados encontrados na presente pesquisa, pois foi observado que as condições crônicas estão estatisticamente associadas às dificuldades em ABVD. No seu estudo foram relatadas condições crônicas no grupo de indivíduos mais ricos, os quais têm maior possibilidade de receberem diagnósticos e cuidados de saúde, com consequente redução de risco para dificuldades na sua rotina.

Ainda em consonância com a presente pesquisa, o estudo de Araújo et al. (2019) com 159 idosos objetivando estimar o nível de capacidade funcional, doenças autorreferidas e fatores associados entre idosos comunitários, demonstrou que as doenças crônicas podem influenciar negativamente a realização das ABVD e para estas, ter diabetes foi o fator mais importante, com 7.30 vezes a probabilidade de ser dependente.

No estudo de Matos et al. (2018) que pesquisou fatores de risco para a redução da capacidade funcional junto a 202 idosos, identificou-se maior presença de dependência em idosos com diabetes $(\mathrm{p}=0,130)$, assim como no presente estudo onde a diabetes demonstrou valores significativos na presença das dificuldades nas ABVD.

Investigação de Aguiar et al. (2019) com 360 idosos, identificou presença de incapacidade funcional para as ABVD maior entre os idosos que sofreram AVC, assim como no atual estudo. A incapacidade funcional relacionada ao AVC pode ser decorrente do fato de sua grande possibilidade de gerar consequências motoras e sensoriais no indivíduo, o que resulta em uma maior dificuldade para deambular de forma independente e realizar tarefas básicas de autocuidado (Castro et al., 2016).

Os dados encontrados por Storeng et al. (2018) corroboram com os obtidos pela presente pesquisa, no que se refere a relação entre depressão e dificuldades nas ABVD. No seu estudo de coorte prospectivo com 5050 idosos noruegueses, os autores verificaram que a depressão foi um dos fatores de risco mais fortes para a necessidade de assistência em uma ou mais atividades básicas da vida diária.

Ainda no tocante a associação entre depressão e dificuldades para ABVD, o estudo de Koç and Sağlam (2019) realizado na Turquia, encontrou associação negativa e estatisticamente significante entre atividades da vida diária, autocuidado e depressão. Os escores de depressão dos idosos aumentaram à medida que suas atividades de vida diária e os escores de capacidade de autocuidado diminuíram. Os autores propõem que rastreios, acompanhamento e encaminhamento de idosos com risco de depressão sejam rotina no atendimento a essa população, fortalecendo os serviços de aconselhamento e orientação 
psicológica.

A dor crônica também demonstrou valores significativamente associados ao grau, número ou presença de dificuldades nas ABVD na presente pesquisa. Essa informação também foi observada na investigação de Carmona-Torres et al. (2019) que encontrou associação entre dificuldades em ABVD e níveis elevados de dor, que podem preceder tais dificuldades, estando portanto fortemente relacionadas entre si.

Quando as variáveis são analisadas no modelo múltiplo, idosos do sexo masculino apresentam chance de 6,06 vezes maiores de apresentar algum tipo de dificuldade para ABVD quando comparadas aos idosos do sexo feminino; idosos com fragilidade, 16,59 vezes, quando comparadas a pessoas saudáveis; idosos com diabetes, 4,65 vezes mais que idosos sem diabetes e por fim idosos com depressão apresentam 3,62 vezes mais chances de apresentar algum tipo de dificuldade quando comparado às pessoas sem depressão, independente das demais características avaliadas.

Com relação às possíveis associações estatísticas entre presença, número e grau de dificuldades para AIVD e características - demográficas e socioeconômicas, referentes à autopercepção de saúde, condições clínicas e nível de fragilidade - identificaram-se associações entre essas dificuldades funcionais e ser do sexo feminino, ter 80+ anos, baixa escolaridade, fragilidade, autopercepção de saúde pior, apresentar condições crônicas, osteoartrose, anemia e depressão.

No presente estudo o sexo feminino influenciou estatisticamente em relação ao número de dificuldades referidas para AIVD, assim como na investigação conduzida por Alexandre et al. (2014) junto a 1.034 idosos, que objetivou justamente analisar diferenças de gênero na incidência e determinação de incapacidade em atividades instrumentais de vida diária. Em consonância, revisão sistemática com metanálise conduzida por Campos et al. (2016) teve como objetivo descrever a prevalência de incapacidade funcional por gênero entre idosos brasileiros identificou que a proporção de mulheres com incapacidade funcional é 1,51 vezes maior que a de homens ( $\mathrm{p}<0,001)$, com intervalo de confiança entre 1,43 e 1,59, em conformidade com estudo de Matos et al. (2018) no qual maior proporção de mulheres (54.8\%) referiu algum tipo de dependência

No presente estudo, maior proporção de idosos com 80+ anos requerem ajuda para AIVD do que entrevistados de outras faixas etárias, sendo essa diferença estatisticamente significativa. Dado semelhante também foi encontrado na pesquisa de Aguiar et al. (2019) onde a presença de incapacidade funcional para as AIVD foi maior entre os idosos mais 
longevos. Tal associação pode estar relacionada ao fato de que com o decorrer dos anos a capacidade funcional pode sofrer declínio, visto que a capacidade de executar uma tarefa exige a agregação dos diferentes sistemas fisiológicos Barbosa et al. (2014). Salienta-se que com o decorrer dos anos o idoso passa a ser vulnerável a vários tipos de dependências (Ceccon et al., 2021).

O nível de fragilidade foi associado de modo significativo com a presença dificuldades nas AIVD, assim como no estudo de Aguiar et al. (2019), onde a fragilidade foi determinante para a incapacidade funcional tanto para as ABVD quanto para as AIVD. O autor considera que uma provável justificativa seria o fato de o idoso frágil manifestar maiores limitações para exercer tarefas diárias, havendo assim, um declínio inicial para atividades mais complexas, que exigem uma maior habilidade para seu desenvolvimento e posteriormente, manifestação de declínio para realização de atividades de autocuidado (Lenardt et al., 2016).

A autopercepção de saúde pior como já comentado, mostrou-se associada significativamente à presença dificuldades nas AIVD, assim como no estudo Storeng et al. (2018) que demonstrou que tal aspecto deve ser considerado na assistência em uma ou mais atividades básicas e instrumentais de vida diária, sendo a melhora na percepção de saúde uma meta para fins de prevenção. Segundo Zanesco et al. (2020) a autopercepção em relação à saúde é modulada por inúmeras questões, incluindo as dimensões biológica, psicológica e social, sendo muitas vezes ignorada por profissionais e pesquisadores.

De acordo com as análises realizadas na presente pesquisa, as condições crônicas estão associadas tanto ao nível quanto ao número de dificuldades nas AIVD. No estudo de Melo et al. (2020) a prevalência de multimorbidade, ou seja, a presença de duas ou mais doenças crônicas, foi de 53,1\% em idosos brasileiros; considerando a prevalência dessas condições e sua associação a incapacidades, discute-se medidas preventivas e de enfrentamento no âmbito da saúde pública. Na pesquisa de Koç and Sağlam (2019) constatou-se que quase todas as atividades da vida diária foram afetadas em idosos que referiram doenças crônicas, sendo que um terço dos idosos apresentava dependência para a realização dessas atividades.

No que se refere à osteoartrose, estudos que tentam verificar sua associação à presença de dificuldades para a realização das AIVD, são escassos, porém Clynes et al. (2019) relacionaram o diagnóstico clínico e radiológico de AO, especificamente de joelho ou quadril, e as atividades de vida diária em idosos, verificando que a osteoartrose está 
fortemente associada a tais dificuldades em ambos os sexos. O diagnóstico clínico de OA de quadril ou joelho foi associado às dificuldades relatadas de mobilidade, capacidade de autocuidado e realização de atividades habituais, podendo influenciar em problemas de mobilidade dentro dos cômodos da casa e para acesso a instalações públicas.

No presente estudo a anemia influenciou estatisticamente o número de dificuldades, ou seja, as pessoas com anemia apresentaram maior número de dificuldades. O estudo de Braz et al. (2019) objetivou avaliar a associação entre anemia e algumas atividades de vida diária junto a 1.256 indivíduos de 60 anos ou mais participantes do Estudo SABE (Saúde, Bem-estar e Envelhecimento). Os autores encontraram maior prevalência de anemia em indivíduos com dificuldades de mastigação, deglutição, com dificuldade de alimentar-se sozinho e de fazer compras de alimentos. Devido a esses achados, os autores discutem que as questões de saúde oral (mastigação, dentição e deglutição) estão ligadas diretamente a presença de anemia e qualidade de vida dos idosos, necessitando de uma abordagem multidisciplinar.

A depressão mostrou-se associada ao grau, número ou presença de dificuldades nas AIVD, assim identificou-se na pesquisa de Aguiar et al. (2019) onde a presença de incapacidade funcional para as AIVD foi maior entre os idosos com sintomas depressivos. Os sintomas depressivos associados à incapacidade funcional podem estar relacionados ao fato de que as atividades, principalmente as instrumentais, exigem maior organização e articulação na execução das tarefas, o que envolve também a interação social (Trindade et al., 2013). Dados que corroboram com a pesquisa de Storeng et al. (2018), na qual a depressão foi um dos fatores de risco mais fortes para a necessidade de assistência em uma ou mais atividades básicas ou instrumentais da vida diária.

Quando as variáveis são analisadas no modelo múltiplo apenas OA influenciou estatisticamente em qualquer tipo de dificuldade para $\operatorname{AIVD}(\mathrm{p}=0,042)$ independente das demais características, sendo que os idosos com OA apresentam chance 4,01 vezes de apresentar algum tipo de dificuldade quando comparado a idosos sem tal patologia, sobrepondo-se a qualquer outra característica da pessoa. No estudo de Solis Cartas et al. (2018) que teve como objetivo avaliar a percepção da qualidade de vida em pacientes com osteoartrose e sua correlação com a capacidade funcional, as dimensões mais afetadas foram dor, forma física e atividades da vida diária, para as quais houve predomínio da incapacidade moderada. Em estudo realizado por French et al. (2016) $58,5 \%$ dos idosos com osteoartrose relataram dificuldades nas suas atividades de vida 
diária, e 35,5\% referiram dificuldades em algumas atividades sociais. Em consonância, um estudo buscou relacionar diagnóstico clínico e radiológico de OA ao desempenho nas atividades de vida diária em idosos e verificou que a OA está fortemente associada as dificuldades em ambos os sexos, no que se refere à mobilidade, capacidade de autocuidado e realização de atividades diárias (Clynes et al., 2019).

Em relação à escolaridade, embora não tenha se mantido como fator de risco para dificuldades nas AIVD após controle das demais variáveis, observa-se diminuição da chance de dificuldades nessas atividades, conforme aumenta a escolaridade. Esse dado é reforçado por estudos, como os de Aguiar et al. (2019), o qual constatou que os idosos que não sabiam ler e possuíam poucos anos de escolaridade apresentaram incapacidade funcional para as AIVD e, em pesquisa de Carmona-Torres et al. (2019) que encontrou associação entre dificuldades em ABVD e baixa escolaridade. Em consonância, é possível afirmar que atividades instrumentais complexas demandam mais do idoso, impondo um grau de dificuldade maior para sua completa execução. De modo complementar, identifica-se que idosos com nível educacional mais elevado são menos prováveis de se exporem aos fatores de risco para doenças e de se submeterem a condições de trabalho inadequadas (Pereira et al., 2017).

O modelo de regressão logística múltipla - que buscou analisar efeito de cada uma das variáveis associadas às dificuldades, mantendo-se sob controle todas as demais sugere embora sem valores significativos, que quanto maior a idade, pior o nível de fragilidade e pior a autopercepção de saúde, maiores poderiam ser as chances de desenvolver dependência nas AIVD.

No estudo buscou-se ainda verificar especificamente associação entre características avaliadas - sociodemográficas e clínicas, referentes a autopercepção de saúde e nível de fragilidade - e adoção de práticas de autocuidado para compensar dificuldades (comportamento previsto e posicionado no segundo ponto das escalas de "graus dificuldade para as ABVD e AIVD” e codificada como DC), salienta-se, entretanto, que não esteve associado a nenhuma das características avaliadas em relação às ABVD ( $\mathrm{p}>0,05)$; quanto às AIVD, exclusivamente idosos com osteoartrose apresentaram estatisticamente menor frequência de compensação de dificuldades para essas atividades $(\mathrm{p}=0,016)$.

Esse dado, em conjunto com as demais associações encontradas entre características avaliadas e dificuldades funcionais, impõe necessidade de qualificar o 
cuidado aos idosos na região do Itaim Paulista, em rede setorial e intersetorial. Considerase que o cuidado nessa perspectiva e preferencialmente a partir da atenção primária em saúde deva buscar reduzir efeitos de alguns indicadores de vulnerabilidade e de alguns componentes de fragilidade, encontrados na pesquisa, como escassez de recursos sociais e econômicos, de oportunidades educacionais e de lazer, detectar e controlar doenças crônicas, melhorar autopercepção de saúde, prover ações de promoção da saúde e reabilitação visando manter e melhora a capacidade funcional; desenvolver, reforçar e ampliar práticas de autocuidado.

Assim, faz-se necessário reforçar, ampliar e integrar ações não somente no âmbito da saúde, mas também da assistência social, cultura, transporte, trabalho e previdência social, entre outros setores, a fim de prevenir e equacionar quadros mais complexos.

Como limitações do estudo é possível apontar coleta de dados junto a uma amostra de conveniência, composta exclusivamente por usuários de unidades básicas de um mesmo território, que se encontram em situação bastante semelhante do ponto de visto socioeconômico e que dispõem dos mesmos recursos sociais, culturais e de saúde. Se, por um lado, esses critérios de participação no estudo permitem planejar intervenções futuras que levem em consideração características semelhantes de ponto de vista socioeconômico e de acesso a equipamentos de saúde, sociais e culturais, por outro lado, dificultam tecer comparações entre população distintas, ou seja, tecer comparações entre capacidade funcional e práticas de autocuidado de idosos moradores de território com muitos indicadores de vulnerabilidade em relação a idosos que vivenciam realidade socioeconômica diversa.

Vale ressaltar também a reduzida capacidade, que se revelou nas análises, de algumas variáveis em discriminar aspectos das dificuldades funcionais. Assim, ainda que as distribuições das dificuldades para ABVD entre as "faixas etárias" e das AVD em geral entre "morar sozinho" ou "com alguém" tenham se mostrado semelhantes, os resultados foram apresentados, pois se revestem de significado. No primeiro exemplo, evidencia-se que os idosos entrevistados, mesmo os mais longevos, ainda apresentam poucas dificuldades nas ABVD, porém mostram importantes comprometimentos nas AIVD, sugerindo medidas relevantes e urgentes voltadas a prevenção do agravamento de dificuldades. Já a distribuição homogênea entre idosos que moram sozinhos ou acompanhados em relação às dificuldades funcionais, nos alerta para necessidade de acompanhar sua capacidade funcional visto que morar só não se configura, ao menos no 
presente estudo, como fator de proteção às dificuldades. 


\section{CONCLUSÃO}

O estudo permitiu avaliar capacidade funcional, indicadores de vulnerabilidade social e de fragilidade de idosos moradores da região do Itaim Paulista e usuários de serviços no âmbito da atenção primária em saúde na região, bem como identificar associações entre esses indicadores e dificuldades funcionais.

As dificuldades funcionais foram descritas para AVD e, no que se refere especificamente às ABVD e AIVD, essas foram descritas quanto à presença de dificuldades, número de atividades para as quais apresentam dificuldades e grau de dificuldade, incluindo adoção ou não de práticas de autocuidado. A seguir se procederam às análises estatísticas que permitiram estabelecer associações isoladas e combinadas entre essas dificuldades e variáveis diversas, muitas delas indicativas de vulnerabilidade social e fragilidade.

Através da pesquisa constatou-se fundamentalmente que a maioria dos idosos apresentam dificuldades nas AIVD, uma proporção bem menor de idosos apresenta dificuldade nas ABVD e que pequena parcela adota práticas de autocuidado efetivas nas suas atividades cotidianas.

A caracterização dos idosos quanto aos dados sociodemográficos, autopercepção de saúde, condições crônicas, nível de fragilidade e acerca do seu universo ocupacional, foi também de extrema importância, dada a escassez de estudos científicos junto à população idosa da região em torno das variáveis aqui estudadas.

Com base na análise estatística foi possível afirmar que variáveis como presença de doenças crônicas, com destaque para diabetes, depressão, osteoartrose, dor crônica; fragilidade e autopercepção negativa de saúde estiveram associadas às dificuldades nas ABVD e AIVD. Salienta-se que essas variáveis são passíveis de manejo por meio de trabalho integrado em rede, ou seja, essas associações reforçam investimento nessa direção.

"Baixa escolaridade" e "não ter com quem contar" também se associaram às dificuldades funcionais, indicam vulnerabilidade de alguns idosos e convocam ações intersetoriais. Assim, além das ações relacionadas à saúde, deve-se buscar o fortalecimento do diálogo, o planejamento e execução conjuntos de ações com a assistência social, esfera previdenciária e de mobilidade urbana, visto a complexidade das demandas da população estudada. 
Desta forma, considera-se que os resultados do presente estudo devam contribuir para o planejamento de ações no território, especialmente nas perspectivas interprofissional e intersetorial, para manutenção ou melhora da capacidade funcional e fomento das práticas do autocuidado para idosos, a partir da atenção primária em saúde. 


\section{REFERÊNCIAS BIBLIOGRÁFICAS}

Aguiar BM, Silva PO, Vieira MA, Costa FM da, Carneiro JA. Avaliação da incapacidade funcional e fatores associados em idosos. Rev Bras Geriatr E Gerontol 2019;22. https://doi.org/10.1590/1981-22562019022.180163.

Aires M, Fuhrmann AC, Mocellin D, Pizzol FLFD, Sponchiado LF, Marchezan CR, et al. Burden of informal caregivers of dependent elderlies in the community in small cities. Rev Gaúcha Enferm 2020;41. https://doi.org/10.1590/1983-1447.2020.20190156.

Alexandre T da S, Corona LP, Nunes DP, Santos JLF, Duarte YA de O, Lebrão ML. Disability in instrumental activities of daily living among older adults: gender differences. Rev Saúde Pública 2014;48:379-89. https://doi.org/10.1590/S00348910.2014048004754.

Almeida MHM de. Elaboração e validação do instrumento CICAc: classificação de idosos quanto à capacidade para o autocuidado. Rev Ter Ocupacional Universidade São Paulo 2004;15:112-20. https://doi.org/10.11606/issn.2238-6149.v15i3p112-120.

Almeida MHM de, Litvoc J, Perez MP. Dificuldades para atividades básicas e instrumentais de vida diária, referidas por usuários de um centro de saúde escola do município de São Paulo. Rev Bras Geriatr E Gerontol 2012;15:187-200. https://doi.org/10.1590/S1809-98232012000200002.

Almeida TZS de, Santos CA dos, Rocha SV, Pedreira RBS, Junior EPP. Prevalência e fatores associados à incapacidade funcional em idosos residentes na zona rural. Rev Ciênc Médicas E Biológicas 2016;15:199-203. https://doi.org/10.9771/cmbio.v15i2.16996.

Andrade FB de, Duarte YA de O, Souza Junior PRB de, Torres JL, Lima-Costa MF, Andrade FCD, et al. Inequalities in basic activities of daily living among older adults: ELSI-Brazil, 2015. Rev Saúde Pública 2018;52. https://doi.org/10.11606/s15188787.2018052000617.

Araújo GKN de, Souto RQ, Alves FAP, Sousa RCR de, Ceballos AG da C de, Santos R da $\mathrm{C}$, et al. Capacidade funcional e fatores associados em idosos residentes em comunidade. Acta Paul Enferm 2019;32:312-8. https://doi.org/10.1590/19820194201900043.

Araújo RS, Nascimento ÉR do, Barros R de S, Ritter SRF, Abreu AMS, Garcia PA, et al. Can clinical and physical-functional factors predict falls in cognitively impaired older adults? Rev Bras Geriatr E Gerontol 2019;22. https://doi.org/10.1590/198122562019022.190211.

Ayres JR de CM, Calazans GJ, Saletti Filho HC, Franca Junior I. Risco, vulnerabilidade e práticas de prevenção e promoção da saúde. Tratado Saúde Coletiva 2009. 
Barbosa BR, Almeida JM de, Barbosa MR, Rossi-Barbosa LAR. Avaliação da capacidade funcional dos idosos e fatores associados à incapacidade. Ciênc Amp Saúde Coletiva 2014;19:3317-25. https://doi.org/10.1590/1413-81232014198.06322013.

Brandão TL, Lago KN, Rocha SV. Sedentary behavior and functional disability in older adults with low economic status: Monidi Study. Rev Bras Cineantropometria Amp Desempenho Hum 2019;21. https://doi.org/10.5007/1980-0037.2019v21e55944.

Brasil. Brasil. Ministério da Saúde. Portaria de Consolidação no 3, de 28 de setembro de 2017. Consolidação das normas sobre as redes do Sistema Único de Saúde. Brasília (DF); 2017.

Brasil. Brasil. Ministério da Saúde. Diretrizes para o Cuidado das Pessoas Idosas no SUS: proposta de modelo de Atenção Integral. Brasília: Ministério da Saúde; 2014. [acesso em 14 out. 2019]. Disponível em: http://bvsms.saude.gov.br/bvs/publicacoes/diretrizes_cuidado_pessoa_idosa_sus.pdf.

Brasil. Ministério da Saúde. Envelhecimento e Saúde da Pessoa Idosa. Cadernos da Atenção Básica;(19). Brasília: Ministério da Saúde; 2006.

Brasil. Ministério da Saúde. Portaria no 2.528, de 19 de outubro de 2006. Aprova a Política Nacional de Saúde da Pessoa Idosa. Brasília (DF); 2006 a. [acesso em 23 out. 2019]. Disponível em: http://bvsms.saude.gov.br/bvs/saudelegis/gm/2006/prt2528_19_10_2006.html.

Brasil. Ministério da Saude. Orientações técnicas para a implementação de Linha de Cuidado para Atenção Integral à Saúde da Pessoa Idosa no Sistema Único de Saúde SUS [recurso eletrônico] 2018:95.

Braz VL, Duarte YA de O, Corona LP. A associação entre anemia e alguns aspectos da funcionalidade em idosos. Ciênc Amp Saúde Coletiva 2019;24:3257-64. https://doi.org/10.1590/1413-81232018249.21142017.

Buss PM, Pellegrini Filho A. A saúde e seus determinantes sociais. Physis Rev Saúde Coletiva 2007; 17:77-93.

Buurman BM, van Munster BC, Korevaar JC, de Haan RJ, de Rooij SE. Variability in measuring (instrumental) activities of daily living functioning and functional decline in hospitalized older medical patients: a systematic review. J Clin Epidemiol 2011;64:619_ 27. https://doi.org/10.1016/j.jclinepi.2010.07.005.

Calderón-Larrañaga A, Vetrano DL, Welmer A-K, Grande G, Fratiglioni L, Dekhtyar S. Psychological correlates of multimorbidity and disability accumulation in older adults. Age Ageing 2019;48:789-96. https://doi.org/10.1093/ageing/afz117.

Camarano AA. O novo paradigma demográfico. Ciênc Amp Saúde Coletiva 2013;18:3446-3446. https://doi.org/10.1590/S1413-81232013001200001. 
Campos ACV, Almeida MHM de, Campos GV, Bogutchi TF. Prevalência de incapacidade funcional por gênero em idosos brasileiros: uma revisão sistemática com metanálise. Rev Bras Geriatr E Gerontol 2016;19:545-59. https://doi.org/10.1590/180998232016019.150086 .

Carmona-Torres JM, Rodríguez-Borrego MA, Laredo-Aguilera JA, López-Soto PJ, Santacruz-Salas E, Cobo-Cuenca AI. Disability for basic and instrumental activities of daily living in older individuals. PLoS ONE 2019;14. https://doi.org/10.1371/journal.pone.0220157.

Castro DC, Nunes DP, Pagotto V, Pereira LV, Bachion MM, Nakatani AYK. Incapacidade funcional para atividades básicas de vida diária de idosos: estudo populacional/Functional disability for basic activities of daily lives of the elderly: a population study <b>. Ciênc Cuid E Saúde 2016;15:109-17. https://doi.org/10.4025/cienccuidsaude.v15i1.27569.

Ceccon RF, Vieira LJE de S, Brasil CCP, Soares KG, Portes V de M, Garcia Júnior CAS, et al. Envelhecimento e dependência no Brasil: características sociodemográficas e assistenciais de idosos e cuidadores. Ciênc Saúde Coletiva 2021;26:17-26. https://doi.org/10.1590/1413-81232020261.30352020.

CEM-CEBRAP. SAS-PMSP. Mapa da vulnerabilidade social da população da cidade de São Paulo. São Paulo: Sesc-SP, 2004. 2004.

Chaimowicz F. A saúde dos idosos brasileiros às vésperas do século XXI: problemas, projeções e alternativas. Rev Saúde Pública 1997;31:184-200. https://doi.org/10.1590/S0034-89101997000200014.

Chen L, Zhou R. Does self-reported hearing difficulty decrease older adults' cognitive and physical functioning? The mediating role of social isolation. Maturitas 2020;141:538. https://doi.org/10.1016/j.maturitas.2020.06.011.

Clares JWB, Freitas MC de, Borges CL. Fatores sociais e clínicos que causam limitação da mobilidade de idosos. Acta Paul Enferm 2014;27:237-42. https://doi.org/10.1590/1982-0194201400040.

Clynes MA, Jameson KA, Edwards MH, Cooper C, Dennison EM. Impact of osteoarthritis on activities of daily living: does joint site matter? Aging Clin Exp Res 2019;31:1049-56. https://doi.org/10.1007/s40520-019-01163-0.

Costa A, Humboldt S von. A espiritualidade e as doenças crónicas nos idosos - estudo exploratório em idosos. Psicol Saúde Amp Doenças 2020;21:69-74. https://doi.org/10.15309/20psd210111.

Del Duca GF, Silva SG da, Thumé E, Santos IS, Hallal PC. Indicadores da institucionalização de idosos: estudo de casos e controles. Rev Saúde Pública 2012;46:147-53. https://doi.org/10.1590/S0034-89102012000100018. 
Duran-Badillo T, Salazar-González BC, Cruz-Quevedo JE, Sánchez-Alejo EJ, GutierrezSanchez G, Hernández-Cortés PL, et al. Sensory and cognitive functions, gait ability and functionality of older adults. Rev Lat Am Enfermagem 2020;28. https://doi.org/10.1590/1518-8345.3499.3282.

ELSI-Brasil - Estudo longitudinal da saúde dos idosos brasileiros 2015. http://elsi.cpqrr.fiocruz.br/ (accessed March 15, 2021).

French HP, Galvin R, Horgan NF, Kenny RA. Prevalence and burden of osteoarthritis amongst older people in Ireland: findings from The Irish LongituDinal Study on Ageing (TILDA). Eur J Public Health 2016;26:192-8. https://doi.org/10.1093/eurpub/ckv109.

Fried LP, Tangen CM, Walston J, Newman AB, Hirsch C, Gottdiener J, et al. Frailty in Older AdultsEvidence for a Phenotype. J Gerontol Ser A 2001;56:M146-57. https://doi.org/10.1093/gerona/56.3.M146.

Geib Lorena Teresinha Consalter. Determinantes sociais da saúde do idoso. Ciênc. saúde coletiva [Internet]. 2012 Jan [cited 2021 Mar 20] ; 17( 1 ): 123-133. Available from: http://www.scielo.br/scielo.php?script=sci_arttext\&pid=S1413-

81232012000100015\&lng=en. http://dx.doi.org/10.1590/S1413-81232012000100015.

Giacomin KC, Duarte YAO, Camarano AA, Nunes DP, Fernandes D, Giacomin KC, et al. Care and functional disabilities in daily activities - ELSI-Brazil. Rev Saúde Pública 2018;52. https://doi.org/10.11606/s1518-8787.2018052000650.

Gordilho A, Universidade Aberta da Terceira Idade, editors. Desafios a serem enfrentados no terceiro milênio pelo setor saúde na atenção integral ao idoso. Rio de Janeiro: UnATI, UERJ; 2000.

Gross CB, Kolankiewicz ACB, Schmidt CR, Berlezi EM. Níveis de fragilidade de idosos e sua associação com as características sociodemográficas. Acta Paul Enferm 2018;31:209-16. https://doi.org/10.1590/1982-0194201800030.

Hildon Z, Montgomery SM, Blane D, Wiggins RD, Netuveli G. Examining resilience of quality of life in the face of health-related and psychosocial adversity at older ages: what is "right" about the way we age? The Gerontologist 2010;50:36-47. https://doi.org/10.1093/geront/gnp067.

Hosmer Jr DW, Lemeshow S, Sturdivant RX. Applied logistic regression. vol. 398. John Wiley \& Sons; 2013.

IBGE. Número de idosos cresce 18\% em 5 anos e ultrapassa 30 milhões em 2017. https://agenciadenoticias.ibge.gov.br/agencia-noticias/2012-agencia-denoticias/noticias/20980-numero-de-idosos-cresce-18-em-5-anos-e-ultrapassa-30milhoes-em-2017 (accessed March 15, 2021).

IBGE. Instituto Brasileiro de Geografia e Estatística. Tábua completa de mortalidade para o Brasil 2018: Breve análise da evolução da mortalidade no Brasil. Rio de Janeiro: IBGE; 2019. 
IBGE | censo 2010 | resultados | notícias | IBGE: população brasileira envelhece em ritmo acelerado. n.d. https://censo2010.ibge.gov.br/noticiascenso.html?busca $=1 \& \mathrm{id}=1 \& \mathrm{idnoticia}=1272 \& \mathrm{t}=\mathrm{ibge}$-populacao-brasileira-envelheceritmo-ac\&view=noticia (accessed March 15, 2021).

Kirkwood BR, Sterne JA. Essential medical statistics. John Wiley \& Sons; 2010.

Koç Z, Sağlam Z. DETERMINATION OF THE EFFECTS OF DAILY LIFE ACTIVITIES AND SELF-CARE CAPACITY ON DEPRESSION OF THE ELDERLY IN NORTHERN TURKEY. Acta Clin Croat 2019;58:516-22. https://doi.org/10.20471/acc.2019.58.03.16.

Komatsu M, Obayashi K, Tomioka K, Morikawa M, Jojima N, Okamoto N, et al. The interaction effect between physical and cultural leisure activities on the subsequent decline of instrumental ADL: the Fujiwara-kyo study. Environ Health Prev Med 2019;24:71. https://doi.org/10.1186/s12199-019-0826-4.

Kowarick L. Viver em risco: sobre a vulnerabilidade socioeconômica e civil 2009.

Leite JC, Jesus ITM de, Orlandi FS, Zazzetta MS. Fragilidade, cognição, depressão e funcionalidade de idosos em condomínio habitacional. Estud Interdiscip Envelhec 2019:75-90.

Leme DE da C, Thomaz RP, Borim FSA, Brenelli SL, Oliveira DV de, Fattori A. Estudo do impacto da fragilidade, multimorbidade e incapacidade funcional na sobrevida de idosos ambulatoriais. Ciênc Amp Saúde Coletiva 2019;24:137-46. https://doi.org/10.1590/1413-81232018241.04952017.

Lenardt MH, Carneiro NHK, Binotto MA, Willig MH, Lourenço TM, Albino J. Fragilidade e qualidade de vida de idosos usuários da atenção básica de saúde. Rev Bras Enferm 2016;69. https://doi.org/10.1590/0034-7167.2016690309i.

Lima LJC de, Manicardi RM, Azevedo LM, Camargo MFM, Filho AN. Capacitação em avaliação multidimensional da pessoa idosa na atenção básica (AMPI-AB) na Coordenadoria Regional de Saúde Oeste: caminho para a integralidade no atendimento de idosos na atenção básica. São Paulo; SMS; abr. 2016. [2] p.

Lini EV, Tomicki C, Giacomazzi RB, Dellani MP, Doring M, Portella MR. Prevalence of self-referred chronic pain and intercurrences in the health of the elderly. Rev Dor 2016;17:279-82. https://doi.org/10.5935/1806-0013.20160089.

Luiz LC, Rebelatto JR, Coimbra AMV, Ricci NA. Associação entre déficit visual e aspectos clínico-funcionais em idosos da comunidade. Braz J Phys Ther 2009;13:44450. https://doi.org/10.1590/S1413-35552009005000049.

Magni C, Freiberger F, Tonn K. Avaliação do grau de satisfação entre os usuários de amplificação de tecnologia analógica e digital. Rev Bras Otorrinolaringol 2005;71:6507. https://doi.org/10.1590/S0034-72992005000500017. 
Maia LC, Moraes EN de, Costa S de M, Caldeira AP, Maia LC, Moraes EN de, et al. Fragilidade em idosos assistidos por equipes da atenção primária. Ciênc Amp Saúde Coletiva 2020;25:5041-50. https://doi.org/10.1590/1413-812320202512.04962019.

Mann WC, Hurren D, Tomita M. Assistive devices used by home-based elderly persons with arthritis. Am J Occup Ther Off Publ Am Occup Ther Assoc 1995;49:810-20. https://doi.org/10.5014/ajot.49.8.810.

Matos FS, Jesus CS de, Carneiro JAO, Coqueiro R da S, Fernandes MH, Brito TA. Redução da capacidade funcional de idosos residentes em comunidade: estudo longitudinal. Ciênc Amp Saúde Coletiva 2018;23:3393-401. https://doi.org/10.1590/1413-812320182310.23382016.

Melo Filho J, Moreira NB, Vojciechowski AS, Biesek S, Bento PCB, Gomes ARS, et al. Frailty prevalence and related factors in older adults from southern Brazil: A cross$\begin{array}{llll}\text { sectional observational } & \text { study. } & \text { Clinics } & \text { 2020;75. }\end{array}$ https://doi.org/10.6061/clinics/2020/e1694.

Melo NCV de, Teixeira KMD, Barbosa TL, Montoya ÁJA, Silveira MB. Arranjo domiciliar de idosos no Brasil: análises a partir da Pesquisa Nacional por Amostra de Domicílios (2009). Rev Bras Geriatr E Gerontol 2016;19:139-51. https://doi.org/10.1590/1809-9823.2016.15011.

Negrini ELD, Nascimento CF do, Silva A da, Antunes JLF, Negrini ELD, Nascimento $\mathrm{CF}$ do, et al. Elderly persons who live alone in Brazil and their lifestyle. Rev Bras Geriatr E Gerontol 2018;21:523-31. https://doi.org/10.1590/1981-22562018021.180101.

Neri AL, Yassuda MS, Araújo LF de, Eulálio M do C, Cabral BE, Siqueira MEC de, et al. Metodologia e perfil sociodemográfico, cognitivo e de fragilidade de idosos comunitários de sete cidades brasileiras: Estudo FIBRA. Cad Saúde Pública 2013;29:778-92. https://doi.org/10.1590/S0102-311X2013000400015.

Nichiata LYI, Bertolozzi MR, Takahashi RF, Fracolli LA. A utilização do conceito" vulnerabilidade" pela enfermagem. Rev Lat Am Enfermagem 2008;16:923-8.

Norburn JEK, Bernard SL, Konrad TR, Woomert A, DeFriese GH, Kalsbeek WD, et al. Self-Care and Assistance from others in Coping with Functional Status Limitations among a National Sample of Older Adults. J Gerontol Ser B 1995;50B:S101-9. https://doi.org/10.1093/geronb/50B.2.S101.

Nunes DP, Brito TRP de, Giacomin KC, Duarte YA de O, Lebrão ML. Padrão do desempenho nas atividades de vida diária em idosos no município de São Paulo, nos anos 2000, 2006 e 2010. Rev Bras Epidemiol 2018;21:e180019. https://doi.org/10.1590/1980549720180019.supl.2.

OMS. Organização Mundial da Saúde - OMS. Secretaria de Estado da Saúde. Relatório global da OMS sobre prevenção de quedas na velhice. São Paulo: OMS, 2010. Available 
from: http://www. saude.sp.gov.br/resources/ccd/publicacoes/publicacoes-ccd/saudeepopulacao/manual_oms_-_site.pdf 2010.

OMS. ORGANIZAÇÃO MUNDIAL DA SAÚDE (OMS). Envelhecimento ativo:uma política de saúde. Brasília: Organização Pan-Americana de Saúde, 2005.

OPAS/OMS - $\quad$ Recommendations: $1994 . \quad$ n.d. https://www.paho.org/hq/index.php?option=com_docman\&view=list\&slug=recommen dations-for-1994-4251\&Itemid=270\&lang=pt (accessed March 15, 2021).

Orem DE, Taylor SG, Renpenning KM. Nursing: concepts of practice. St. Louis: Mosby; 2001.

Pereira LC, Figueiredo M do LF, Beleza CMF, Andrade EMLR, Silva MJ da, Pereira AFM, et al. Predictors for the functional incapacity of the elderly in primary health care. Rev Bras Enferm 2017;70:112-8. https://doi.org/10.1590/0034-7167-2016-0046.

Pimentel J de O, Loch MR. "Melhor idade"? Será mesmo? A velhice segundo idosas participantes de um grupo de atividade física. Rev Bras Ativ Fís Saúde 2020:1-7.

São Paulo (Município). Linha de cuidado e saúde da pessoa idosa, 26 jun. 2014. Secretaria da Saúde [Guterres C, Santana D]; 2014. [acesso em 20 out. 2019]. Disponível em: http://www.prefeitura.sp.gov.br/cidade/secretarias/saude/cogep/coord_centro_oeste/noti cias/?

São Paulo (Município). Histórico | Subprefeitura Itaim Paulista | Prefeitura da Cidade de São Paulo 2019. [acesso em 15 mar. 2020]. https://www.prefeitura.sp.gov.br/cidade/secretarias/saude/epidemiologia_e_informacao/ informacoes_assistenciais/index.php?p=30566.

São Paulo (Município). Estabelecimentos e Serviços de Saúde | Secretaria Municipal da Saúde | Prefeitura da Cidade de São Paulo 2020. [acesso em 15 mar. 2020]. Disponível em: Disponível em: https://www.prefeitura.sp.gov.br/cidade/secretarias/subprefeituras/itaim_paulista/histori $\mathrm{co} /$.

Ramos LR. Fatores determinantes do envelhecimento saudável em idosos residentes em centro urbano: Projeto Epidoso, São Paulo. Cad Saúde Pública 2003;19:793-7. https://doi.org/10.1590/S0102-311X2003000300011.

Ramos LR, Perracini M, Rosa TE, Kalache A. Significance and management of disability among urban elderly residents in Brazil. J Cross-Cult Gerontol 1993;8:313-23. https://doi.org/10.1007/BF00972560. 
Rocha J de P, Oliveira GG, Neris JCD, Bós AMG, Bós ÂJG. Impacto clínico, socioeconômico e da autopercepção de saúde na funcionalidade de idosos. Geriatr Gerontol Aging Impr 2017:124-32.

Saraiva MD, Venys AL, Abdalla FLP, Fernandes MS, Pisoli PH, Sousa DM da RV, et al. AMPI-AB validity and reliability: a multidimensional tool in resource-limited primary care settings. BMC Geriatr 2020;20:124. https://doi.org/10.1186/s12877-020-01508-9.

Scherer MD dos A, Pires DEP de, Jean R. A construção da interdisciplinaridade no trabalho da Equipe de Saúde da Família. Ciênc Amp Saúde Coletiva 2013;18:3203-12. https://doi.org/10.1590/S1413-81232013001100011.

Sevalho G. O conceito de vulnerabilidade e a educação em saúde fundamentada em Paulo Freire. Interface - Comun Saúde Educ 2018;22:177-88. https://doi.org/10.1590/180757622016.0822 .

Silva DA da, Freitas YNL de, Oliveira TC de, Silva RL da, Pegado CP de C, Lima KC de, et al. Oral health conditions and activities of daily living in an elderly population in Brazil. Rev Bras Geriatr E Gerontol 2016;19:917-29. https://doi.org/10.1590/198122562016019.160031.

Silva LG de C, Oliveira FS de, Martins Í da S, Martins FES, Garcia TFM, Sousa ACPA, et al. Evaluation of the functionality and mobility of community-dwelling older adults in primary health care. Rev Bras Geriatr E Gerontol 2019;22. https://doi.org/10.1590/198122562019022.190086.

Silveira DR, Giacomin KC, Dias RC, Firmo JOA, Silveira DR, Giacomin KC, et al. The perception of the elderly about suffering related to frailty. Rev Bras Geriatr E Gerontol 2018;21:215-22. https://doi.org/10.1590/1981-22562018021.170126.

Sluzki. A rede social na pratica sistemica: alternativas terapeutucas - 1aED.(1997) Carlos E. Sluzki - Livro. 1997.

Soares MFN, Maia LC, Costa S de M, Caldeira AP, Soares MFN, Maia LC, et al. Functional Dependence among older adults receiving care from Family Health Strategy teams. Rev Bras Geriatr E Gerontol 2019;22. https://doi.org/10.1590/198122562019022.190147.

Solis Cartas U, Calvopiña Bejarano SJ, Martínez Larrarte JP, Paguay Moreno ÁR, Saquipay Duchitanga GI. Percepción de calidad de vida en pacientes con osteoartritis. Características sociodemográficas y clínicas. Estudio de 5 años. Rev Colomb Reumatol 2018;25:177-83. https://doi.org/10.1016/j.rcreu.2018.05.002.

SPBairros. Itaim Paulista | São Paulo Bairros 2020. https://www.spbairros.com.br/itaimpaulista/ (accessed March 15, 2021).

Storeng SH, Sund ER, Krokstad S. Factors associated with basic and instrumental activities of daily living in elderly participants of a population-based survey: the Nord- 
Trøndelag Health Study, Norway. BMJ Open 2018;8:e018942. https://doi.org/10.1136/bmjopen-2017-018942.

Trindade APNT da, Barboza MA, Oliveira FB de, Borges APO. Repercussão do declínio cognitivo na capacidade funcional em idosos institucionalizados e não institucionalizados. Fisioter Em Mov 2013;26:281-9. https://doi.org/10.1590/S010351502013000200005.

Zanesco C, Bordin D, Santos CB dos, Fadel CB. Dificuldade funcional em idosos brasileiros: um estudo com base na Pesquisa Nacional de Saúde (PNS - 2013). Ciênc Saúde Coletiva 2020;25:1103-18. https://doi.org/10.1590/141381232020253.19702018 . 


\section{ANEXO I - TERMO DE CONSENTIMENTO LIVRE E ESCLARECIDO}

TERMO DE CONSENTIMENTO LIVRE E ESCLARECIDO

FACULDADE DE MEDICINA DA UNIVERSIDADE DE SÃO PAULO

\section{DADOS DOS SUJEITOS DA PESQUISA}

SEXO: $\mathrm{M} \square \mathrm{F} \square$

DATA NASCIMENTO:

\section{DADOS SOBRE A PESQUISA}

TÍTULO DA PESQUISA: Capacidade funcional e práticas de autocuidado de idosos: norteadores para atenção integral a idosos a partir da atenção primária a saúde PESQUISADORA RESPONSÁVEL: Maria Helena Morgani de Almeida CARGO/FUNÇÃO: Docente do Curso de Terapia Ocupacional da USP INSCRIÇÃO CONSELHO REGIONAL CREFITO 3 - 1627 TO PESQUISADORA EXECUTANTE: Priscila Tavares Franco e Semprebom CARGO/FUNÇÃO: Terapeuta Ocupacional da Unidade Básica de Saúde jardim Camargo Novo/Itaim Paulista/SP INSCRIÇÃO CONSELHO REGIONAL CREFITO 3- 9312

UNIDADE DO HCFMUSP: Departamento de Fisioterapia, Fonoaudiologia e Terapia Ocupacional da Faculdade de Medicina da Universidade de São Paulo

2. AVALIAÇÃO DO RISCO DA PESQUISA:

$\begin{array}{rlll}\text { RISCO MÍNIMO } & \mathrm{X} & \text { RISCO MÉDIO } \\ \text { RISCO BAIXO } & \square & \text { RISCO MAIOR }\end{array}$

3. DURAÇÃO DA PESQUISA: 01/03/18 a 31/10/20 


\title{
TERMO DE CONSENTIMENTO LIVRE E ESCLARECIDO
}

\author{
FACULDADE DE MEDICINA DA UNIVERSIDADE DE SÃO PAULO
}

Considerando que a capacidade para atividades do dia-a-dia contribui para saúde e qualidade de vida da população idosa, nós, Profa. Dra. Maria Helena Morgani de Almeida e a Terapeuta ocupacional Priscila Tavares Franco e Semprebom, pesquisadoras do estudo: "Capacidade funcional e práticas de autocuidado de idosos: norteadores para atenção integral a idosos a partir da atenção primária a saúde", temos como objetivos: avaliar dificuldades de idosos para atividades do dia-a-dia; identificar condições sociais e de saúde que possam estar relacionadas a essas dificuldades; conhecer, reforçar e propor novas maneiras de reduzir essas dificuldades.

Assim, convidamos o (a) Sr. (a) a participar voluntariamente deste estudo por ter mais de 60 anos e ser usuário da UBS Jd. Camargo Novo ou UBS Júlio de Golveia.

Para que o (a) $\mathrm{Sr}$ (a) colabore com a pesquisa será necessário que nos conceda uma entrevista de aproximadamente 1 hora na unidade básica de saúde de sua referência. A entrevista será agendada em horário mais confortável para o Sr. (a) de acordo com sua disponibilidade. Em caso de impossibilidade, as entrevistas poderão ser conduzidas com seu cuidador ou familiar mais próximo desde que o (a) $\mathrm{Sr}$ (a) nos autorize a entrevistá-los.

Os riscos de sua participação na entrevista são mínimos e referem-se ao receio que possa ter em relação à exposição de ideias e, possíveis desconfortos ou constrangimentos em relação às perguntas que realizarmos. Esses sentimentos podem ser reduzidos ou superados por meio de esclarecimentos, orientação das pesquisadoras e garantia quanto ao sigilo e ao anonimato das informações que o (a) $\mathrm{Sr}$ (a) venha nos oferecer.

Esperamos que esse estudo traga benefícios diretos ao $\mathrm{Sr}$ (a), considerando que as informações coletadas nas entrevistas serão analisadas e, com base nelas, as pesquisadoras deverão realizar intervenções voltadas a reduzir dificuldades para atividades do dia-a-dia. Os resultados do estudo também nos ajudarão a identificar condições sociais e de saúde que podem estar relacionadas a essas dificuldades, apoiando o planejamento de ações para os demais idosos usuários das unidades básicas envolvidas no estudo.

Divulgaremos os principais resultados da pesquisa em eventos e publicações científicas e reafirmamos também nosso compromisso com o sigilo da identidade dos participantes. Assim manteremos em sigilo seu nome e as demais informações que lhe identificam na pesquisa. Não serão utilizados seus dados pessoais como RG, nome, endereço. Em qualquer etapa do estudo, o (a) Sr. (a) terá acesso aos profissionais responsáveis pela pesquisa para esclarecimento sobre objetivos, procedimentos, resultados parciais, riscos e benefícios relacionados à pesquisa e, inclusive para tirar eventuais dúvidas. O Sr. (a) poderá dispor do tempo que achar necessário para refletir acerca da decisão em participar ou não do estudo, caso julgue desconfortável poderá não responder alguma questão que o constranja ou retirar o consentimento em qualquer momento da pesquisa.

O principal investigador é a Profa. Dra. Maria Helena Morgani de Almeida que pode ser encontrada no endereço Rua Cipotânea, 51. Cidade Universitária. Butantã. CEP. 05083-160. São Paulo, SP, telefone (s) 30918439. Se o (a) Sr. (a) tiver alguma consideração ou dúvida sobre a ética da pesquisa, entre em contato com o Comitê de Ética em Pesquisa da Faculdade de Medicina da Universidade de São Paulo (CEPFMUSP): Av. Dr. Arnaldo, 251 - Cerqueira César- São Paulo - SP -21 $1^{\circ}$ andar - sala 36- CEP: 01246000 Tel.: 3893-4401/4407 E-mail: cep.fm@usp.br., ou entrar em contato com CEP/SMS para tirar dúvidas e fazer denúncias quanto à questões éticas smscep@ gmail.com / 11-33972464.

É garantida a sua liberdade da retirada de consentimento a qualquer momento e deixar de participar do estudo, sem qualquer prejuízo quanto ao seu atendimento pela sua unidade básica de saúde de referência. As informações obtidas serão analisadas em conjunto com aquelas obtidas com outros sujeitos de pesquisa, não sendo divulgada sua identificação. O Sr. (a) terá direito de ser mantido atualizado sobre os resultados da pesquisa. Sua participação no estudo é voluntária. Não há despesas pessoais para o (a) Sr. (a) em qualquer fase do estudo. Também não há compensação financeira relacionada à sua participação. Se 
existir qualquer despesa adicional, ela será absorvida pelo orçamento da pesquisa. Comprometemo-nos a utilizar os dados e o material coletado somente para esta pesquisa.

Após ter sido devidamente esclarecido, concordo em participar do estudo e poderei retirar o meu consentimento a qualquer momento, antes ou durante o mesmo, sem penalidades ou prejuízo.

Assinatura do sujeito da pesquisa
(Somente para o responsável do projeto)
Declaro que obtive de forma apropriada e voluntária o Consentimento Livre e Esclarecido deste paciente
ou representante legal para a participação neste estudo.

Assinatura da responsável pelo projeto $\quad$ Data_ / /

Pesquisador Responsável/Orientador: $\operatorname{Prof}^{\mathrm{a}} \mathrm{Dr}^{\mathrm{a}}$ Maria Helena Morgani de Almeida Pesquisador Executante: Priscila Tavares Franco e Semprebom

Curso de Terapia Ocupacional da Faculdade de Medicina da USP

Rua Cipotânea, 51. Cidade Universitária. Butantã.

CEP. 05083-160. São Paulo, SP.

Tel: (011) 3091-7457 /3091-8439 (Maria Helena Morgani de Almeida)

(011) 99654-8928 (Priscila)

e-mail: hmorgani@usp.br; pritavares_to@yahoo.com.br 


\section{ANEXO II - AVALIAÇÃO MULTIDIMENSIONAL DA PESSOA IDODA NA ATENÇÃO BÁSICA - AMPI-AB}

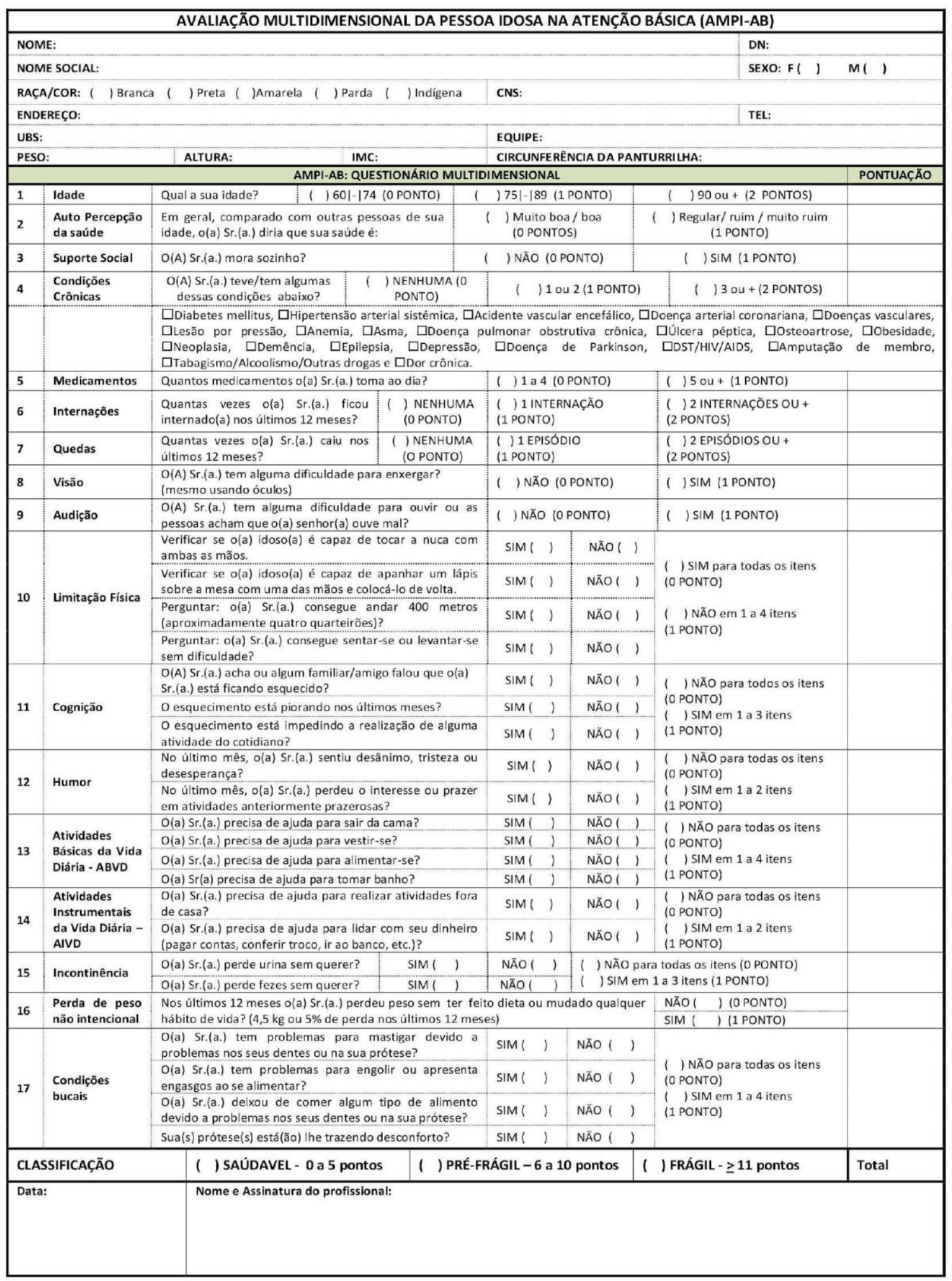




\section{ANEXO III - INSTRUMENTO DE CLASSIFICAÇÃO DE IDOSOS QUANTO À CAPACIDADE PARA O AUTOCUIDADO - CICAC}

Instrumento C.I.C.Ac

Orientações gerais para aplicação

A versão simplificada do Instrumento CICAc foi elaborada com alternativa a $3^{\text {a }}$ versão grupal do Instrumento para aplicação especialmente em UBSs, por apresentar as seguintes características:

Demanda menor tempo de aplicação facilitando sua incorporação à rotina da UBS (a $3^{\mathrm{a}}$ versão grupal do Instrumento requer cerca de uma hora de aplicação ou sua aplicação por áreas de investigação $\mathrm{em}$ momentos distintos)

- Aplicação e registro de informações facilitado, uma vez que um menor número de alternativas deverá ser oferecida aos idosos, bem como um menor número de alternativas deverá ser selecionada pelo entrevistador para registro

Possibilidade de caracterizar idosos segundo um menor número de características ocupacionais e funcionais

A versão simplificada do instrumento CICAc, compreende o agrupamento de itens/respostas presentes na $3^{\text {a }}$ versão grupal, especificamente nas áreas Universo Ocupacional e Capacidade Funcional. Esses agrupamentos baseiam em reflexões teóricas e nos resultados de pesquisa de validação do Instrumento e, serão apresentados a seguir.

Agrupamento de respostas às questões 13 e 14. Instrumento CICAC $3^{a}$ versão grupal.

\begin{tabular}{|c|c|}
\hline 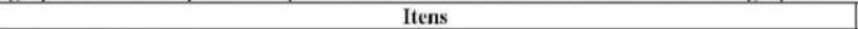 & Agrupamento de itens \\
\hline Atividades de Lazer & $\begin{array}{l}\text { Lazer com predominio de } \\
\text { interesse... }\end{array}$ \\
\hline Caminhar/ Dançar/ Praticar esporte & físico \\
\hline Bordado/tricô/crochêf Cuidar de plantas/Costurar & manual \\
\hline Leituras /Participar de cursos & intelectual \\
\hline $\begin{array}{l}\text { Conversar com amigos/sair com amigos / Fazer visitas a familiares/Fazer visitas a doentes /Jogar } \\
\text { (jogos de salão) / Participar de grupos / Viajar / Passear }\end{array}$ & social \\
\hline Fazer oraçð̃es / Ir a missa ou reuniđ̃o religiosa/ & religioso \\
\hline Cantar/Ir ao cincma/tcatro /Pintar & artistico \\
\hline $\begin{array}{l}\text { Assistir televisão/Cuidar de pequenos animais/ Fazer pequenos consertos em casa/Ouvir } \\
\text { música/rádio }\end{array}$ & $\begin{array}{l}\text { Atividades de lazer com } \\
\text { interesses diversos }\end{array}$ \\
\hline \multicolumn{2}{|c|}{ Trabalho remunerado } \\
\hline Informal & Informal \\
\hline Cargo técnico ou administrativo/profissão liberal & $\begin{array}{l}\text { Cargo técnico } \\
\text { administrativo/profissão liberal }\end{array}$ \\
\hline Fimpregada doméstica & Fmpregada doméstica \\
\hline Operário & Outro \\
\hline Outro: especifique & \\
\hline \multicolumn{2}{|l|}{ Agrupamento de respostas à questâo 15.1. Instrumento CICAC $3^{a}$ versão grupal. } \\
\hline Itens & Agrupamento \\
\hline Trazem prazer & \multirow[t]{10}{*}{ Satisfação pessoal } \\
\hline Mantềm as pessoas ativas & \\
\hline Distracm & \\
\hline Ocupam o tempo & \\
\hline Mantém pessoa atualizada & \\
\hline Alimentam a vaidade & \\
\hline Diminuem a solidão e a carência afetiva & \\
\hline Trazcm satisfação cspiritual & \\
\hline Trazem oportunidade de descansar & \\
\hline Mantém a privacidade & \\
\hline Promovem senso de utilidade & \multirow[t]{2}{*}{ Responsabilidade social } \\
\hline desempenham comportamentos esperados & \\
\hline São benéficas à saúde fisica e ou mental & \multirow{3}{*}{$\begin{array}{l}\text { Prevenção de riscos a vida, ao } \\
\text { funcionamento c } \\
\text { desenvolvimento }\end{array}$} \\
\hline Estimulam o exercício da independência & \\
\hline Estão relacionadas com a sobrevivência & \\
\hline Outras razões: Especifique & Outras \\
\hline \multicolumn{2}{|l|}{ Agrupamento de respostas às questões 16.1 Instrumento CICAC $3^{a}$ versão grupal. } \\
\hline Itens & Agrupamento \\
\hline$\Lambda$ cima das capacidades do idoso & \multirow[t]{2}{*}{ Intrinsecas } \\
\hline Não atende as necessidades do idoso & \\
\hline Realizada em condiç̃es adversas & Extrinsecas \\
\hline Outras & Outras \\
\hline
\end{tabular}




Agrupamento de respostas das questôes 17,18,19: Instrumento CICAC $\mathbf{3}^{a}$ versao grupal.
\begin{tabular}{|l|l|}
\hline Tipos de dificuldade & Agrupamento \\
\hline $\begin{array}{l}\text { Tipos de dificuldade: Física, Sensorial, Cognitiva, Emocional e Restrições } \\
\text { clinicas }\end{array}$ & Fatores Biológicos e comportamentais \\
\hline $\begin{array}{l}\text { Tipos de dificuldade: Social, Econômica, Cultural (entre outros) e relativas ao } \\
\text { ambiente físico }\end{array}$ & Fatores do ambiente social e físico \\
\hline Outros tipos de dificuldade & Outros fatores \\
\hline Formas de compensaçao/Práticas de autocuidado & $\begin{array}{l}\text { Agrupamento } \\
\text { Não apresenta dificuldade }\end{array}$ \\
\hline $\begin{array}{l}\text { Compensa com Modificação Comportamental } \\
\text { Compensa com Dispositivo Auxiliar } \\
\text { Compensa com Modificação Ambiental }\end{array}$ & $\begin{array}{l}\text { apresenta dificuldade - compensa com uma ou } \\
\text { mais estratégias }\end{array}$ \\
\hline Faz com dificuldade & Apresenta e faz com dificuldade \\
\hline $\begin{array}{l}\text { Faz com ajuda - supervisão } \\
\text { Faz com ajuda - assistência fisica direta }\end{array}$ & Apresenta dificuldade - compensa com ajuda \\
\hline Deixa de fazer & Apresenta dificuldade - deixa de fazer \\
\hline
\end{tabular}

Agrupamento de respostas das questões 22.1. Instrumento CICAC $3^{a}$ versão grupal.
\begin{tabular}{|l|l|}
\hline Itens & agrupamentos \\
\hline PS: problemas de saúde & intrinsecos \\
A.VE: atitude negativa em relação ao envelhecimento & \\
PR: preocupação excessiva com atribuições/responsabilidades & \\
familiares & \\
\hline FA: falta de apoio familiar & Extrínsecos \\
DF: dificuldade financeira & \\
DRS: desconhecimento de recursos sociais & Outros \\
\hline outros: & \\
\hline
\end{tabular}

Agrupamento de respostas das questões 22.2. Instrumento CICAC 3 a versão grupal.

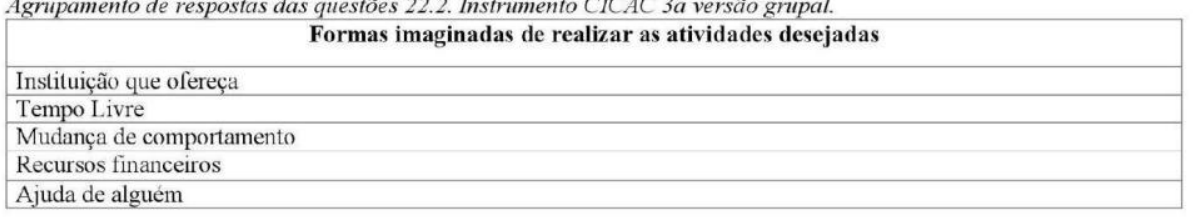

Vale destacar que, na presença de incapacidades não compensadas (atividades que o idoso faz com dificuldade, com ajuda ou tem deixado de fazer), sugere-se a aplicação de questões especificas da $3^{\mathbf{a}}$ versão grupal, voltada para o detalhamento das incapacidades: determinação de fatores associados e formas imaginadas para sua realização. Fsse detalhamento é especialmente importante quando houver perdas funcionais não compensadas para as atividades básicas e instrumentais de vida diária e atividades importantes para o idoso. 
Nome do entrevistado

Data de nascimento

$N^{o}$ do prontuário

Nome do entrevistador

Estado (ivil: () Solteiro

Data de entrevista

Area de investigação: Arranjo doméstico e familiar do idoso e potencial rede de suporte

Questão 1 -O sr mora com outras pessoas na mesma casa? Sim ( ) Não ( ) Com quem o sr mora?

Identificar todas as pessoas que moram, aiualmente, com o idoso

\begin{tabular}{|l|c|c|c|c|}
\hline \multirow{2}{*}{ Nome } & \multirow{2}{*}{\begin{tabular}{c} 
Grau de parentesco/ Tipo de \\
relacionamento \\
\cline { 3 - 4 }
\end{tabular}} & \multicolumn{2}{|c|}{ Sexo } & \multirow{2}{*}{ Idade } \\
\cline { 3 - 4 } & (cônjuge, irmão, filho, neto, amigo, etc) & Masculino & Feminino & \\
\hline & & & & \\
\hline & & & & \\
\hline
\end{tabular}

Questão 2 - O sr tem (outros) filhos? Sim ( ) Não ( )

Identificar todos os filhos vivos que não moram com o idoso

\begin{tabular}{|l|l|l|l|l|}
\hline \multirow{2}{*}{ Nome } & \multicolumn{2}{|c|}{ Sexo } & \multirow{2}{*}{ Idade } & \multirow{2}{*}{ Onde reside } \\
\cline { 2 - 3 } & Masculino & Feminino & & \\
\hline & & & & \\
\hline & & & & \\
\hline
\end{tabular}

Questão 3 - Com que freqüência o sr se relaciona com:

Preencher a coluna correspondente à freqüência segundo Legenda abaixo

\begin{tabular}{|c|c|c|}
\hline Tipo de relacionamento & Freqüência & \\
\hline \multicolumn{3}{|l|}{ Filhos } \\
\hline \multicolumn{3}{|l|}{ Vizinhos } \\
\hline \multicolumn{3}{|l|}{ Amigos } \\
\hline \multicolumn{3}{|l|}{ Associações/Grupos/Instituições } \\
\hline \multicolumn{3}{|l|}{ Outros Parentes } \\
\hline \multicolumn{3}{|l|}{ Legenda: Freqüência } \\
\hline Todos os dias & A cada 15 dias & 1 vez por ano \\
\hline Quase todos os dias & I vez por mês & A cada 2 anos \\
\hline 2 vezes por semana & I vez a cada 2 meses & Mais de dois anos \\
\hline 1 vez por semana & 1 vez a cada 6 meses & Nunca \\
\hline
\end{tabular}

Questão 4 - O sr está satisfeito com a freqüência com se relaciona com:

Assinale com um Xo grau de salisfação corresponde a cada um dos tipos de relacionamento

\begin{tabular}{|l|c|c|c|}
\hline \multirow{2}{*}{ Tipos de relacionamento } & \multicolumn{3}{c|}{ Grau de satisfação } \\
\cline { 2 - 4 } & Sim & Mais ou menos & Não \\
\hline Filhos & & & \\
\hline Vizinhos & & & \\
\hline Amigos & & & \\
\hline Associações/Grupos/Instituições & & & \\
\hline Outros Parcntes & & & \\
\hline
\end{tabular}

Questão 5 - Como o sr se sente com a relação que mantém com:

Assinale com um X o grau de satisfação correspondente a cada um dos tipos de relacionamento.

Se o idoso mora só assinale com X para a $I^{a}$ linha somente a coluna Mora só

\begin{tabular}{|l|c|c|c|c|c|}
\hline \multirow{2}{*}{ Tipos de relacionamento } & \multicolumn{5}{c|}{ Grau de satisfacão } \\
\cline { 2 - 6 } & $\begin{array}{c}\text { Muito } \\
\text { satisfeito }\end{array}$ & Satisfeito & Insatisfeito & $\begin{array}{c}\text { Muito } \\
\text { insatisfeito }\end{array}$ & Mora só \\
\hline As pcssoas da família que moram com o sr & & & & & \\
\hline Pessoas da família que não vivem com o sr & & & & & \\
\hline Os amigos & & & & & \\
\hline Os vizinhos & & & & & \\
\hline
\end{tabular}


Questão 6 - Tem alguém que cuida do sr quando o sr fica doente? Sim ( ) Não ( ).

Quem é ou quais são essa(s) pessoa(s)

Identifique todas as pessoas que cuidam do idoso em caso de doença

\begin{tabular}{|l|c|l|l|l|}
\hline \multirow{2}{*}{ Nome } & Tipo de relacionamento & \multicolumn{2}{|c|}{ Sexo } & \multirow{2}{*}{ Idade } \\
\cline { 3 - 4 } & (cônjuge, irmão, filho, neto, amigo, etc) & Masculino & Feminino & \\
\hline & & & & \\
\hline & & & & \\
\hline & & & & \\
\hline
\end{tabular}

Objetivo das questões $1,2,3,4,5, \mathrm{e} 6$ :

Descrever o arranjo doméstico e familiar do idoso e potencial rede de suporte

Area de investigação: perfil social

Questão 7 - O sr freqüentou escola? Até que ano estudon?

Assinale com um $X$ a escolaridade do entrevistado na coluna à direita

\begin{tabular}{|l|l|}
\hline Analfabeto & \\
\hline Sabe ler/escrever ou primário incompleto & \\
\hline Primário completo/ginásio incompleto & \\
\hline Ginásio complcto/colcgial incomplcto & \\
\hline Colegial completo/curso superior incompleto & \\
\hline Superior completo & \\
\hline
\end{tabular}

Questão 8 - Qual sua atividade profissional principal ? Preencha o campo abaixo:

Questão 9 - O sr exerce essa atividade profissional atualmente? () Sim ( ) Não

Se a resposta for negativa, aplicar a questão 10

Questão 10 - O sr tem trabalho remunerado atualmente? ( ) Sim ( ) Não. Qual ?

Após registrar o trabalho remunerado atual, procure transportá-lo para o Quadro 1, classificando-o segundo categorias definidas para Trabalho remunerado. As questões da área "Universo Ocupacional" deverão informar sobre o significado atribuido pelo idoso a esse trabalho e as suas outras atividades cotidianas

Questão 11 - Quais são seus recursos financeiros atualmente?

Assinale com um $X$ os recursos financeiros do entrevistado na coluna à direita (múltipla escolha)

- A aplicação financeira é considerada recurso somente se o entrevistado retirar dinheiro da aplicação para as suas despesas

\begin{tabular}{|l|l|}
\hline Salário & \\
\hline Aposcntadoria & \\
\hline Pensão & \\
\hline Renda mensal vitalícia & \\
\hline Aluguel & \\
\hline Atividades informais & \\
\hline Aplicação financeira & \\
\hline Recebe ajuda em dinheiro ou espécie & \\
\hline
\end{tabular}

Questão 12 - Com a sua situação econômica atual como o sr salisfaz suas necessidades de alimentação, moradia, saúde, etc?

Assinale com um $X$ a forma com o idoso satisfaz suas necessidades, na coluna à direila

\begin{tabular}{|l|l|}
\hline Muito bem & \\
\hline Bem & \\
\hline Mais ou menos & \\
\hline Mal & \\
\hline Muito mal & \\
\hline
\end{tabular}

Muito mal 


\section{Area de investigação : Universo ocupacional}

Questão 13 - $\mathrm{O}$ que o sr faz todos os dias, desde a hora que acorda até a hora que vai dormir? Procure contar todas as coisas que faz.

Utilize o Quadro 1 para registro das respostas (Objetivo: Conhecer as Atividades cotidianas rotineiras)

Questão 14 - T’em alguma coisa que o sr faz só de vez em quando ?

Utilize o Quadro 1 para registro das respostas (Objetivo: Conhecer as Atividades cotidianas não-rotineiras)

Questão 15 - Das coisas que o sr faz, quais o sr acha que são importantes para o sr ? 15.1. Por quê?

Utilize o Quadro 1 para registro das respostas à questão 15 e o Quadro 2 para registro de resposias à questão 15.1

Objetivo: Conhecer as atividades importantes e as necessidades a que elas correspondem

Questão 16 - Das coisas que o sr faz, quais gosta menos? 16.1 Por quê?

Utilize o Quadro 1 para registro das respostas à questão 16 e Quadro 3 para registro de respostas à questão 16.1

Objetivo: Conhecer as atividades não prazerosas e as necessidades a que elas não atendem

Quadro1: Quadro resumo para registro de respostas às questões $13,14,15$ e16

Identificar atividades que compõe a vida cotidiana do idoso, assinalando-as com $X$. São atribuídos códigos numéricos (1 a 31) às atividades para facilitar seu registro nos quadros seguintes.

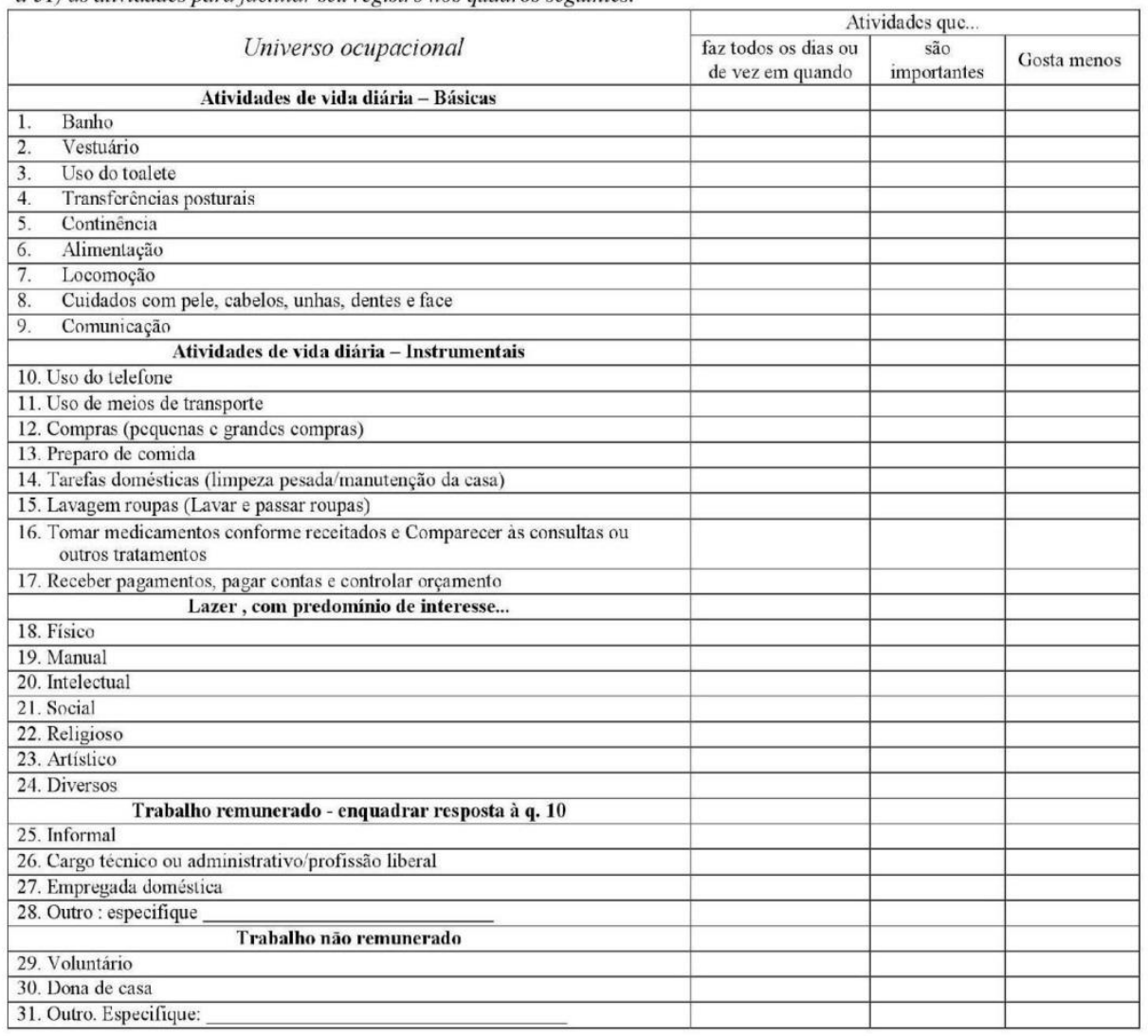


Quadro 2: Registro de respostas à questão 15.1: Porque o idoso acha determinadas atividades importantes. Preencha a coluna à direita com os códigos numéricos correspondentes às alividades. $O$ idoso pode atribuir importância a todas as suas atividades por uma ou mais razões, nesse caso ao invés de anotar os códigos, preencha a linha(s) correspondente(s) com a palavra todas.

\begin{tabular}{|l|l|}
\hline \multicolumn{1}{|c|}{ Porque são importantes } & Códigos numéricos das atividades \\
\hline Satisfação pessoal & \\
\hline Responsabilidade social & \\
\hline Prevenção de riscos a vida, ao funcionamento e desenvolvimento & \\
\hline Outras razões : Especifique & \\
\hline
\end{tabular}

Quadro 3: Registro de respostas à questão 16.1: Porque o idoso gosta menos de determinadas atividades. Preencha a coluna à direita com os códigos numéricos correspondentes às atividades. O idoso pode referir todas as suas atividades como não prazerosas por uma ou mais razões, nesse caso ao invés de anotar os códigos, preencha a linha(s) correspondente(s) com a palavra todas.

\begin{tabular}{|l|l|}
\hline \multicolumn{1}{|c|}{ Porque não gosta (razões) } & Códigos numéricos das atividades \\
\hline Intrinsecas & \\
\hline Fxtrinsecas & \\
\hline Outras razões: especifique & \\
\hline
\end{tabular}

\section{Área de investigação: Capacidade funcional}

Questão 17 - O sr tem dificuldade para fazer algumas das coisas que faz? Que tipo(s) de dificuldade? Utilize o Quadro 4 para registro de respostas

Objetivos: Conhecer as atividades cotidianas para as quais o idoso apresenta dificuldade(s) e alguns fatores relacionados às dificuldades

Questão 18 - O que o sr faz quanto à dificuldade X: Encontrou um jeito mais fácil de fazer, tem alguém que o ajuda, faz mesmo com dificuldade sem ajuda ou deixou de fazer?

Repita a pergunta 18 para cada dificuldade mencionada e utilize o Quadro 4 para registro de respostas

Questão 19 - Caso tenha encontrado um jeito mais fácil de fazer, como faz? Caso tenha alguém que o ajuda, quem o ajuda?

Repetir a pergunta 19 para cada uma das dificuldades mencionada e utilize o Quadro 4 para registro de respostas

Objetivo das questões 18 e 19: Conhecer as formas de compensação adotadas pelo idoso

Legenda para preenchimento do Quadro 4:

\begin{tabular}{|c|c|c|}
\hline Tipos de dificuldade & $\begin{array}{l}\text { Niveis de Independência/ } \\
\text { Práticas de autocuidado }\end{array}$ & $\begin{array}{l}\text { Códigos para tipos de } \\
\text { relacionamento (quando houver } \\
\text { alguém que ajude o idoso) }\end{array}$ \\
\hline F: Física & MC: Mudança Comportamental & 1: Pai, mãe, sogro(a), tio(a) \\
\hline S: Sensorial & MA: Mudança Ambiental & 2: Conjuge \\
\hline E: Emocional & DA: Dispositivo Auxiliar & 3: Irmãos, Primos, cunhados \\
\hline C: Cognitiva & FD: Faz mesmo com Dificuldades & 4: Filhos, enteados, sobrinhos \\
\hline EC: Econômica & SU: Supervisão & 5: Genro, nora \\
\hline R: Restrições clínicas & AS: Assistência Física & 6: Netos \\
\hline A: Ambiente físico & DF: Deixou de fazer & 7: Bisnetos \\
\hline O: Outros & & 8: Amigo, conhecido \\
\hline & & 9: Cuidador formal \\
\hline & & 10: Outros. Especifique: \\
\hline \multicolumn{3}{|l|}{ UO: Universo Ocupacional } \\
\hline \multicolumn{3}{|l|}{ FR: Frequência } \\
\hline
\end{tabular}


Quadro 4: Quadro resumo para registro das respostas à questões 17, 18 e 19

Identifique as atividades para as quais o idoso tenha dificuldades, assinale com $\mathrm{X}$ os tipos de dificuldade (múltipla escolha), se compensa ou não dificuldades e formas de compensação adotadas (múltipla escolha).

\begin{tabular}{|c|c|c|c|c|c|c|c|c|c|c|c|c|c|c|c|c|c|c|}
\hline & & $\begin{array}{c}\text { Tem } \\
\text { dificuldade } \\
\text { (G1A) }\end{array}$ & & & pod & le di & ificu & ldade & e (G) 1 & & & & $\begin{array}{r}\mathrm{Ni} \\
\text { Práti }\end{array}$ & $\begin{array}{l}\text { veis de } \\
\text { cas de }\end{array}$ & $\begin{array}{l}\text { indep } \\
\text { autoc }\end{array}$ & $\begin{array}{l}\text { endèn } \\
\text { uidado }\end{array}$ & G2) & \\
\hline & 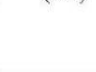 & & & & $\mathrm{B} / \mathrm{C}$ & & & & A & & 0 & Faz & $\begin{array}{l}\text { e jeito } \\
\mathrm{cil} / \mathbf{D C}\end{array}$ & mais & FD & $\begin{array}{r}\mathrm{Al}_{3} \\
\text { ajud }\end{array}$ & G3) & DF \\
\hline Atividades básicas de vida diária - Básicas & FR & & $\mathbf{F}$ & s & $\mathbf{E}$ & C & $\mathbf{R}$ & $\mathrm{EC}$ & So & A & o & Mc & Ma & Da & & SU & As & \\
\hline 1. Banho & & & & & & & & & & & & & & & & & & \\
\hline 2. Vestuário & & & & & & & & & & & & & & & & & & \\
\hline 3. Uso do toalete & & & & & & & & & & & & & & & 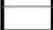 & & & 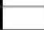 \\
\hline 4. Transferências posturais & & & & & & & & & & & & & & & & & & \\
\hline 5. Continência & & & & & & & & & & & & & & & & & & \\
\hline 6. Nlimentação & & & & & & & & & & & & & & & & & & \\
\hline 7. Locomoção & & & & & & & & & & & & & & & & & & \\
\hline 8. Cuidar pele,cabelos, unhas, dentes, face & & & & & & & & & & & & & & & & & & \\
\hline 9. Comunicaçã̃o & & & & & & & & & & & & & & & & & & \\
\hline Atividades de vida diária - Instrumentais & & & & & & & & & & & & & & & 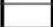 & & & \\
\hline 10. Uso do telefone & & & & & & & & & & & & & & & & & & \\
\hline 11. Uso de meios de transporte & & & & & & & & & & & & & & & 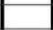 & & & \\
\hline 12. Compras (pequenas e grandes compras) & & & & & & & & & & & & & & & & & & \\
\hline 13. Preparo de comida & & & & & & & & & & & & & & & 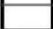 & & & \\
\hline $\begin{array}{l}\text { 14. Tarefas domésticas (limpeza } \\
\text { pesada/manutenção da casa) }\end{array}$ & & & & & & & & & & & & & & & & & & \\
\hline 15. Lavagem roupas (Lavar e passar roupas) & & & & & & & & & & & & & & & & & & \\
\hline $\begin{array}{l}\text { 16. Tomar medicamentos conforme receitados o } \\
\text { comparecer as consultas ou outros tratamentos }\end{array}$ & & & & & & & & & & & & & & & & & & \\
\hline $\begin{array}{l}\text { 17. Receber pagamentos, pagar contas e controlar } \\
\text { orçamento }\end{array}$ & & & & & & & & & & & & & & & & & & \\
\hline Lazer, com predomínio de interesse... & & & & & & & & & & & & & & & & & & \\
\hline 18. Físico & & & & & & & & & & & & & & & & & & \\
\hline 19. Manual & & & & & & & & & & & & & & & 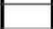 & & & \\
\hline 20. Intelectual & & & & & & & & & & & & & & & & & & \\
\hline 21. Social & & & & & & & & & & & & & & & 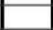 & & & \\
\hline 22. Religioso & & & & & & & & & & & & & & & & & & \\
\hline 23. Artisticos & & & & & & & & & & & & & & & & & & \\
\hline 24. Diversos & & & & & & & & & & & & & & & & & & \\
\hline Trabalho remunerado - enquad rar resposta it q. 10 & & & & & & & & & & & & & & & & & & \\
\hline 25. Informal & & & & & & & & & & & & & & & & & & \\
\hline $\begin{array}{l}\text { 26. Cargo técnico ou administrativo/profissão } \\
\text { liberal }\end{array}$ & & & & & & & & & & & & & & & & & & \\
\hline 27. Empregada doméstica & & & & & & & & & & & & & & & & & & \\
\hline 28. Outro: especifique & & & & & & & & & & & & & & & & & & \\
\hline $\begin{array}{l}\text { Trabalho não remunerado } \\
\end{array}$ & & & & & & & & & & & & & & & & & & \\
\hline 29. Voluntário & & & & & & & & & & & & & & & & & & \\
\hline 30. Dona de casa & & & & & & & & & & & & & & & & & & \\
\hline 31. Outro. Fspecifique: & & & & & & & & & & & & & & & & & & \\
\hline
\end{tabular}

Se o (a) idoso(a) faz com dificuldade, precisa de ajuda ou deixou de fazer alguma atividade, aplique as perguntas 20 e 21 (referentes ás praticas imaginadas de autocuidado)

20 - Pense nas coisas que o(a) sr(a) faz com dificuldade sem ajuda, faz com ajuda ou tenha deixado de fazer. O(a) sr(a) imagina algum jeito mais fácil de fazê-las?

1) Sim, para todas as atividades ( ) 2) Sim, para algumas atividades ( ) 3) Não ( ) 
Se a resposta for afirmativa para todas ou para algumas atividades, aplique a questão F4B e Utilize o quadro 5 para registro de todas as respostas

21 - Como poderia ser feito?

Quadro 5: Registro das respostas às questões 20 e 21

Nomeie as atividades para as quais o(a) idoso(a) imagina práticas de autocuidado. Assinale com X as práticas de autocuidado imaginadas (muiltipla escolha). Ajuda de alguém pode ser considerada prática de autocuidado para atividades que o(a) idoso(a) faz com dificuldade ou deixou de fazer.

\begin{tabular}{|c|c|c|c|c|c|}
\hline \multirow{2}{*}{$\begin{array}{c}\text { Atividades para as } \\
\text { quais apresenta } \\
\text { dificuldade } \\
\mathbf{q . 2 0}\end{array}$} & \multicolumn{5}{|c|}{$\begin{array}{c}\text { Práticas de autocuidado imaginadas } \\
\mathbf{q . 2 1}\end{array}$} \\
\cline { 2 - 6 } & $\begin{array}{c}\text { Mudança de } \\
\text { comportamento } \\
\text { (MC) }\end{array}$ & $\begin{array}{c}\text { Mudança } \\
\text { ambiental } \\
\text { (MA) }\end{array}$ & $\begin{array}{c}\text { Dispositivo } \\
\text { Auxiliar } \\
\text { (DA) }\end{array}$ & Ajuda de alguém & (AS) \\
\hline 1. & & & & & $\begin{array}{c}\text { Outra forma (especificar) } \\
\text { (O) }\end{array}$ \\
\hline 2. & & & & & \\
\hline 3. & & & & & \\
\hline
\end{tabular}

Questão 22 - Tem alguma coisa que o sr gostaria de ter feito em sua vida mas nunca fez ou fez há algum tempo atrás e gostaria de voltar a fazer?

Questão 22.1 - Por que não faz?

Questão 22. 2 - O sr imagina algum jeito de vir a fazê-las?

Utilize o Quadro 6 para registro das respostas à questão 22, 22.1 e 22.2

Objetivo das questões 22, 22.1 e 22.2: Conhecer as Atividades desejadas, Fatores de Inibição para essas atividades e Formas imaginadas para realizar as atividades desejadas

Quadro 6: Registro das Atividades desejadas (resposta à questâo 22), dos Por quês o idoso não faz (resposta à questẫo 22.1) e se imagina algum jeito de vir a fazê-las (resposta à questâo 22.2).

Registre as atividades desejadas (1a coluna), assinale a(s) coluna(s) correspondente(s) aos fatores de inibição consultando a lista de códigos abaixo (porque não faz) e as formas imaginadas de realização na coluna à direita.

\begin{tabular}{|c|c|c|c|c|c|c|c|c|c|}
\hline \multirow{2}{*}{$\begin{array}{c}\text { Atividades } \\
\text { desejadas }\end{array}$} & \multicolumn{3}{|c|}{ Porque não faz } & \multicolumn{5}{c|}{ Formas imaginadas para realizaçâo } \\
\cline { 2 - 8 } & Intrínsecos & Extrínsecos & Outros & $\begin{array}{c}\text { Instituição que } \\
\text { ofereça }\end{array}$ & $\begin{array}{c}\text { Tempo } \\
\text { livre }\end{array}$ & $\begin{array}{c}\text { Mudança de } \\
\text { comportamento }\end{array}$ & $\begin{array}{c}\text { Recursos } \\
\text { financeiros }\end{array}$ & $\begin{array}{c}\text { Ajuda de } \\
\text { alguém }\end{array}$ & Outras \\
\hline & & & & & & & & & \\
\hline
\end{tabular}

Objetivos:

Estratégia de intervenção em T.O: 
ANEXO IV - AUTORIZAÇÃO PARA CADASTRO DE PESQUISA

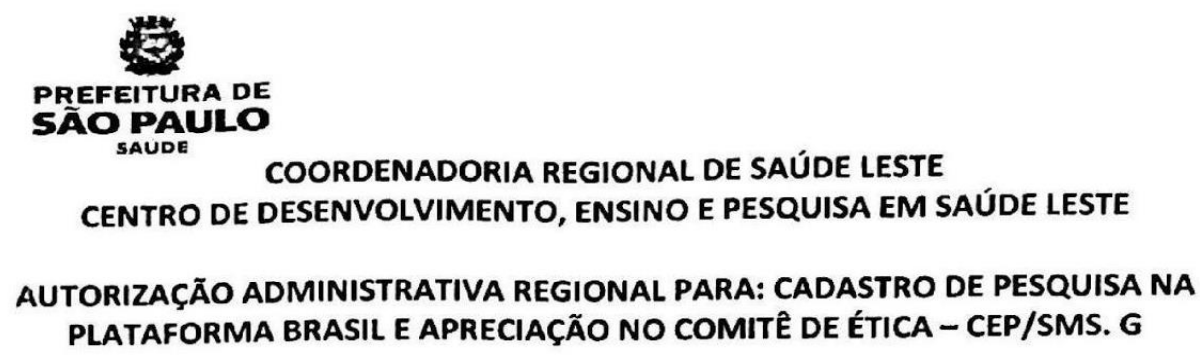

№ de ordem 2018.

Autorizo a realização da pesquisa abaixo descrita, condicionando a coleta de dados após aniálise eParecer aprovado do COMITÊ DE ÉTICA EM PESQUISA DA SECRETARIA MUNCIIPAL DA SAÚDE- CEP/SMS.G e Liberação formal desta Coordenadoria para início de coleta cle dados.

Título cla pesquisa: Capacidade funcional e práticas de autocuidado de idosos: norteadores para atenção integral $a$ idosos a partir da atençăo primária a saúde

Tipo dı pesquisa: Trata-se de pesquisa de natureza mista (qualitativa e quantitativa), descritiva e analítica a ser realizada por meio de entrevistas a idosos usuários de atenção primária em saúde

Pesquisador Responsável/Orientador: Maria Helena Morgani de Almeida

Pesquisador/Aluno: Priscila Tavares Franco e Semprebom

Institui!̣ão Proponente: Faculdade de Medicina da USP

E-mail/telefones: hmorgani@usp.br/ (11) 30918439

Unidacle(s) ou Serviço(s) de interesse: UBS Jd. Camargo Novo e UBS Dr. Júlio de Golveia/ Região do Itaim Paulista

$$
\text { São Paulo, } 17 \text { de agosto de } 2018 .
$$

Carimbo e Assinatura da Coordenadora Regional de Saúde 


\section{t: \\ PREFEITURA DE \\ SÃO PAULO \\ SAUDE \\ COORDENADORIA REGIONAL DE SAÚDE LESTE \\ CENTRO DE DESENVOLVIMENTO, ENSINO E PESQUISA EM SAÚDE LESTE}

№ de ordem 2018.

\section{AUTORIZAÇÃO ADMINISTRATIVA REGIONAL PARA CADASTRAMENTO DE PESQUISA NA} PLATAFORMA BRASIL PARA APRECIAÇÃO NO CEP/SMS/SP

Sr. (a) Pesquisador: Siga rigorosamente todas as orientações contidas no link http://www.prefeitura.sp.gov.br/cidade/secretarias/saude/comite de etica/index.php?p=5959

Obs. Não finalizar o cadastro na Plataforma Brasil com pendência de documentos, para não acarretar prejuizo no tramite de seu Projeto de Pesquisa.

Após a emissão do parecer do CEP/SMS, deverá nos encaminhar para os e-mails constantes no rodapé, os seguintes documentos:

- Cópia DIGITALIZADA do Parecer do CEP/SMS (Instituição co-participante) e da Universidade (Instituição proponente) quando for o caso;

- Projeto de Pesquisa Atualizado;

- Termo de Consentimento Livre e Esclarecido Atualizado;

- Confirmação das unidades de interesse;

Os documentos relacionados acima são imprescindíveis para que possamos providenciar a LIBERAÇÃO DO INÍCIO DA PESQUISA, em quaisquer modalidades: Por telefone, correspondência, e-mail, prontuários ou in loco (entrevistas), junto à (s) unidade(s) ou serviço(s) de interesse, para operacionalização da mesma.

E, após conclusão da pesquisa, o pesquisador deverá enviar o resultado da mesma para Escola Municipal de Saúde Regional Leste da Coordenadoria Regional de Saúde Leste. NOME: Maria Helena Morgani de Almeida RG: $10325212-5$

TíTULOS: Terapeuta Ocupacional, Mestre e Doutora em Saúde Pública, Profa. Dra. do Curso de Terapia Ocupacional da FMUSP

Ciente e de acordo em: 17/08/2018

Rua Pedro Avelino, 22 - Fones: 2956-8038 e 2017-2971 - São Miguel Paulista - São Paulo - SP. Email: cedepsleste@prefeitura.sp.gov.br 


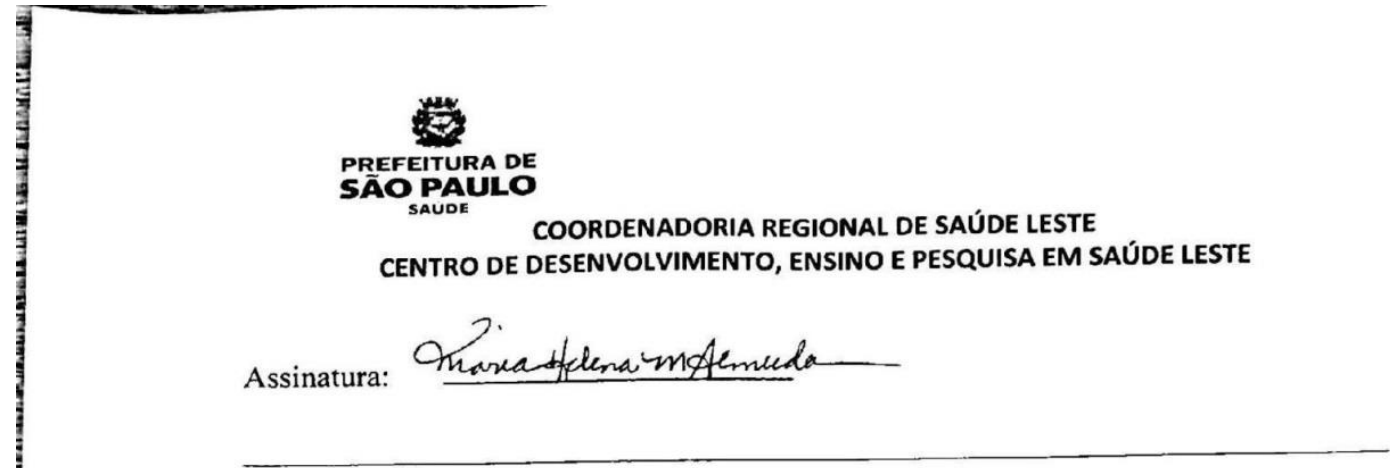

Ruāı Pedro Avelino, 22 - Fones: 2956-8038 e 2017-2971 - São Miguel Paulista - São Paulo - SP. Email: cedepsleste@prefeitura.sp.gov.br 
ANEXO V - PARECER CONSUBSTANCIADO DO CÔMITE DE ÉTICA EM PESQUISA DA FACULDADE DE MEDICINA DA UNIVERSIDADE DE SÃO

PAULO

\section{USP - FACULDADE DE MEDICINA DA UNIVERSIDADE DE SÃO PAULO - FMUSP}

\section{PARECER CONSUBSTANCIADO DO CEP}

\section{DADOS DO PROJETO DE PESQUISA}

Título da Pesquisa: Capacidade funcional e práticas de autocuidado de idosos: norteadores para atenção integral a idosos a partir da atenção primária a saúde

Pesquisador: Maria Helena Morgani de Almeida

Área Temática:

Versão: 2

CAAE: 97957718.8 .0000 .0065

Instituição Proponente: Faculdade de Medicina da Universidade de São Paulo

Patrocinador Principal: Financiamento Próprio

\section{DADOS DO PARECER}

Número do Parecer: 3.004 .846

Apresentação do Projeto:

Trata-se de um projeto interessante e relevante para a Saúde Pública. O projeto encontra-se bem fundamentado, com referências atualizadas e apropriadas ao objeto de estudo. A pesquisa é de caráter qualitativo e quantitativo

\section{Objetivo da Pesquisa:}

O objetivo da pesquisa é avaliar dificuldades funcionais e vulnerabilidade social de idosos no âmbito da atenção primária na região do Itaim Paulista e propor práticas de autocuidado e/ou encaminhamentos implicados para promoção da atenção integral a essa população.

\section{Avaliação dos Riscos e Benefícios:}

Avaliação de riscos adequada. Trata-se de uma pesquisa que envolve riscos mínimos.

Comentários e Considerações sobre a Pesquisa:

A pesquisa, de caráter quantitativo e qualitativo, encontra-se bem fundamentada em referências atualizadas e apropriadas ao objeto de estudo. Nesta segunda versão do projeto foram incluídas todas as sugestões do revisor: 1. foi incluído um cálculo de tamanho amostral para o componente quantitativo e 2. foram explicitados os riscos da pesquisa no corpo do projeto e no TCLE.

Considerações sobre os Termos de apresentação obrigatória: TCLE foi escrito de forma adequada.

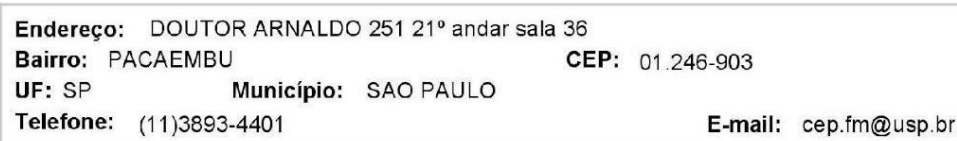




\section{USP - FACULDADE DE MEDICINA DA UNIVERSIDADE DE SÃO PAULO - FMUSP}

Continuaçăo do Parecer: 3.004 .846

\section{Recomendações:}

Os pesquisadores incluíram nesta versão do projeto todas as considerações realizadas no parecer anterior (2.927.968).

Não há outras sugestões/recomendações.

Conclusões ou Pendências e Lista de Inadequações:

Os pesquisadores incluíram nesta versão do projeto todas as considerações realizadas no parecer anterior (2.927.968).

Não há outras sugestões/recomendações.

Considerações Finais a critério do CEP:

Este parecer foi elaborado baseado nos documentos abaixo relacionados:

\begin{tabular}{|c|c|c|c|c|}
\hline Tipo Documento & Arquivo & Postagem & Autor & Situação \\
\hline $\begin{array}{l}\text { Informações Básicas } \\
\text { do Projeto }\end{array}$ & $\begin{array}{l}\text { PB_INFORMAÇỎES_BÁSICAS_DO_P } \\
\text { ROJETO 1179157.pdf }\end{array}$ & $\begin{array}{c}25 / 10 / 2018 \\
14: 34: 55\end{array}$ & & Aceito \\
\hline $\begin{array}{l}\text { Projeto Detalhado / } \\
\text { Brochura } \\
\text { Investigador }\end{array}$ & Projeto.doc & $\begin{array}{c}25 / 10 / 2018 \\
14: 31: 52\end{array}$ & $\begin{array}{l}\text { Maria Helena } \\
\text { Morgani de Almeida }\end{array}$ & Aceito \\
\hline Outros & carta.docx & $\begin{array}{l}25 / 10 / 2018 \\
14: 31: 13\end{array}$ & $\begin{array}{l}\text { Maria Helena } \\
\text { Morgani de Almeida }\end{array}$ & Aceito \\
\hline $\begin{array}{l}\text { TCLE / Termos de } \\
\text { Assentimento / } \\
\text { Justificativa de } \\
\text { Ausência } \\
\end{array}$ & TCLE.docx & $\begin{array}{c}25 / 10 / 2018 \\
14: 30: 19\end{array}$ & $\begin{array}{l}\text { Maria Helena } \\
\text { Morgani de Almeida }\end{array}$ & Aceito \\
\hline $\begin{array}{l}\text { Declaração de } \\
\text { Instituição e } \\
\text { Infraestrutura }\end{array}$ & CEDEPS.pdf & $\begin{array}{c}01 / 09 / 2018 \\
10: 54: 52\end{array}$ & \begin{tabular}{|l} 
Maria Helena \\
Morgani de Almeida
\end{tabular} & Aceito \\
\hline Outros & CEP.pdf & $\begin{array}{l}15 / 08 / 2018 \\
11: 15: 41\end{array}$ & $\begin{array}{l}\text { Maria Helena } \\
\text { Morgani de Almeida }\end{array}$ & Aceito \\
\hline Folha de Rosto & FR.pdf & $\begin{array}{c}15 / 08 / 2018 \\
11: 12: 21\end{array}$ & $\begin{array}{l}\text { Maria Helena } \\
\text { Morgani de Almeida }\end{array}$ & Aceito \\
\hline
\end{tabular}

Situação do Parecer:

Aprovado

Necessita Apreciaçăo da CONEP:

Não

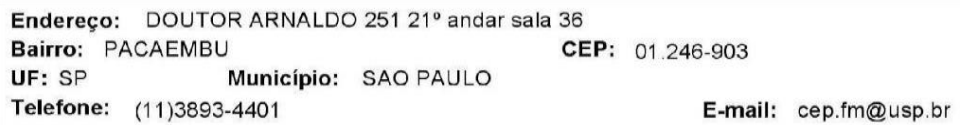




\section{USP - FACULDADE DE}

MEDICINA DA UNIVERSIDADE DE SÃO PAULO - FMUSP

Continuaçăo do Parecer: 3.004 .846

SAO PAULO, 07 de Novembro de 2018

Assinado por:

Maria Aparecida Azevedo Koike Folgueira

(Coordenador(a))

Endereço: DOUTOR ARNALDO $25121^{\circ}$ andar sala 36

Bairro: PACAEMBU

UF: SP Município: SAO PAULO

CEP: $01.246-903$

Telefone: (11)3893-4401

E-mail: cep.fm@usp.br 


\section{ANEXO VI - PARECER CONSUBSTANCIADO DO CÔMITE DE ÉTICA EM PESQUISA DA SECRETARIA MUNICIPAL DE SAÚDE DE SÃO PAULO}

SECRETARIA MUNICIPAL DA
EM PESQUISA.SMS
SAÚDE DE SÃO PAULO -
SMSISP

\section{PARECER CONSUBSTANCIADO DO CEP}

Elaborado pela Instituiçăo Coparticipante

\section{DADOS DO PROJETO DE PESQUISA}

Título da Pesquisa: Capacidade funcional e práticas de autocuidado de idosos: norteadores para atenção integral a idosos a partir da atenção primária a saúde

Pesquisador: Maria Helena Morgani de Almeida

Área Temática:

Versão: 2

CAAE: 97957718.8 .3001 .0086

Instituição Proponente: Secretaria Municipal da Saúde de São Paulo - SMS/SP

Patrocinador Principal: Financiamento Próprio

\section{DADOS DO PARECER}

Número do Parecer: 3.048 .201

Apresentação do Projeto:

Trata-se de pesquisa de ação em duas etapas, que abrangem: coleta e análise das informações e, com base nessas, proposição de intervenções junto à população estudada.

A primeira etapa configura-se de natureza mista (qualitativa e quantitativa), descritiva e analítica a ser realizada por meio de entrevistas com aplicação de Instrumentos padronizados: Avaliação Multidimensional da Pessoa Idosa na Atenção Básica (AMPI-AB) e Instrumento para a Classificação de idosos quanto a Capacidade para o Autocuidado a idosos usuários das unidades básicas de saúde Jd. Camargo Novo e UBS Dr. Júlio de Golveia, ou ao seu cuidador/familiar.

Serão conduzidas análises descritivas e estatisticas das informações visando mapear dificuldades para atividades cotidianas, práticas de autocuidado e sua associação com algumas variáveis demográficas, sociais e de saúde.

A segunda etapa baseia-se nos resultados obtidos na etapa anterior e se refere ao reforço ou proposição de novas práticas de autocuidado para os idosos e/ou cuidadores participantes, bem como proposição ou ampliação de articulações com a rede de serviços para prevenir e reduzir fragilidades e incapacidades de idosos.

Objetivo da Pesquisa:

Objetivo Primário: Avaliar dificuldades funcionais e vulnerabilidade social de idosos no âmbito da

Endereço: Rua General Jardim, 36 - $8^{\circ}$ andar

Bairro: Vila Buarque

UF: SP Município: SAOPAULO

Telefone: (11)3397-2464

CEP: $01.223-010$

E-mail: smscep@gmail.com 


\section{*. Ocomité de SeCRetaria municipal DA SAÚDE DE SÃO PAULO - SMS/SP

Continuaçăo do Parecer: 3.048 .20

atenção primária na região do Itaim Paulista e propor práticas de autocuidado e/ou encaminhamentos implicados para promoção da atenção integral a essa população.

Objetivo Secundário: Avaliar capacidade funcional de idosos das referidas unidades como importante componente de fragilidade; •Identificar fatores sociais, demográficos e condições de saúde associados às possiveis dificuldades funcionais desses idosos; $\cdot$ Conhecer práticas de autocuidado adotadas por esses idosos para preservação e melhora da capacidade funcional;:Propor novas práticas de autocuidado para esses idosos; •Propor ou ampliar articulações em rede para prevenir e reduzir fragilidades e incapacidades de idosos ou seu agravo.

\section{Avaliação dos Riscos e Benefícios:}

Foram adequadamente analisados riscos e benefícios da pesquisa.

Comentários e Considerações sobre a Pesquisa:

A metodologia descrita está adequada aos objetivos propostos.

Considerações sobre os Termos de apresentação obrigatória:

A Folha de Rosto está corretamente preenchida, foram identificadas instituição proponente e coparticipante, autorização para realização da pesquisa foi adequadamente apresentada.

TCLE, Cronograma, fonte financiadora e orçamento detalhado estão adequados.

Conclusões ou Pendências e Lista de Inadequações:

Sem pendências ou inadequações.

Considerações Finais a critério do CEP:

Para início da coleta dos dados, o pesquisador deverá se apresentar na mesma instância que autorizou a realização do estudo (Coordenadoria, Supervisão, SMS/Gab, etc).

Salientamos que o pesquisador deve desenvolver a pesquisa conforme delineada no protocolo aprovado. Eventuais modificações ou emendas ao protocolo devem ser apresentadas ao CEP de forma clara e sucinta, identificando a parte do protocolo a ser modificada e suas justificativas. Lembramos que esta modificação necessitará de aprovação ética do CEP antes de ser implementada.

De acordo com a Res. CNS 466/12, o pesquisador deve apresentar a este CEP/SMS os relatórios semestrais. O relatório final deverá ser enviado através da Plataforma Brasil, ícone Notificação. Uma cópia digital (CD/DVD) do projeto finalizado deverá ser enviada à instância que autorizou a

Endereço: Rua General Jardim, $36-8^{\circ}$ anda

Bairro: Vila Buarque

UF: SP Município: SAO PAULO

CEP: $01.223-010$

Telefone: (11)3397-2464

E-mail: smscep@gmail.com 


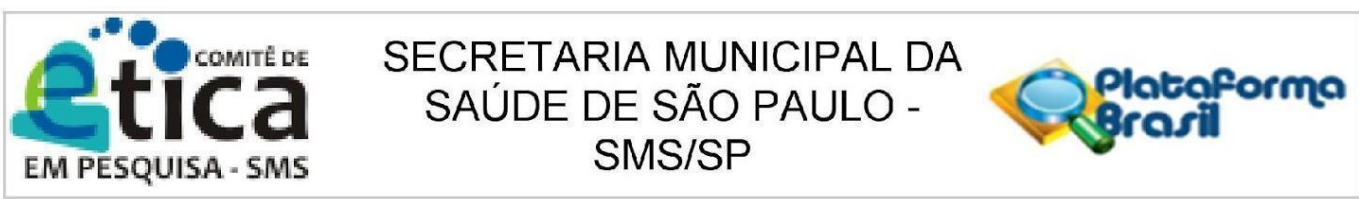

Continuaçăo do Parecer: 3.048 .201

realização do estudo, via correio ou entregue pessoalmente, logo que o mesmo estiver concluído.

Este parecer foi elaborado baseado nos documentos abaixo relacionados:

\begin{tabular}{|c|c|c|c|c|}
\hline Tipo Documento & Arquivo & Postagem & Autor & Situação \\
\hline $\begin{array}{l}\text { Informações Básicas } \\
\text { do Projeto }\end{array}$ & $\begin{array}{l}\text { PB_INFORMAÇÕES_BÁSICAS_DO_P } \\
\text { ROJETO 1253177.pdf }\end{array}$ & $\begin{array}{c}28 / 11 / 2018 \\
14: 24: 45\end{array}$ & & Aceito \\
\hline Outros & Projeto_SMS.doc & $\begin{array}{c}28 / 11 / 2018 \\
14: 23: 13\end{array}$ & $\begin{array}{l}\text { Maria Helena } \\
\text { Morgani de Almeida }\end{array}$ & Aceito \\
\hline Outros & TCLE_SMS.docX & $\begin{array}{c}28 / 11 / 2018 \\
14: 12: 37\end{array}$ & $\begin{array}{l}\text { Maria Helena } \\
\text { Morgani de Almeida }\end{array}$ & Aceito \\
\hline Outros & Respostas_parecer_do_CEP_SMS.docx & $\begin{array}{c}28 / 11 / 2018 \\
14: 07: 39\end{array}$ & $\begin{array}{l}\text { Maria Helena } \\
\text { Morgani de Almeida }\end{array}$ & Aceito \\
\hline Outros & cronograma.docx & $\begin{array}{c}28 / 11 / 2018 \\
13: 39: 41\end{array}$ & $\begin{array}{l}\text { Maria Helena } \\
\text { Morgani de Almeida }\end{array}$ & Aceito \\
\hline $\begin{array}{l}\text { Projeto Detalhado / } \\
\text { Brochura } \\
\text { Investigador }\end{array}$ & Projeto.doc & $\begin{array}{c}25 / 10 / 2018 \\
14: 31: 52\end{array}$ & $\begin{array}{l}\text { Maria Helena } \\
\text { Morgani de Almeida }\end{array}$ & Aceito \\
\hline Outros & carta.docx & $\begin{array}{c}25 / 10 / 2018 \\
14: 31: 13\end{array}$ & $\begin{array}{l}\text { Maria Helena } \\
\text { Morgani de Almeida }\end{array}$ & Aceito \\
\hline $\begin{array}{l}\text { TCLE / Termos de } \\
\text { Assentimento / } \\
\text { Justificativa de } \\
\text { Ausência } \\
\end{array}$ & TCLE.docx & $\begin{array}{c}25 / 10 / 2018 \\
14: 30: 19\end{array}$ & \begin{tabular}{|l} 
Maria Helena \\
Morgani de Almeida
\end{tabular} & Aceito \\
\hline Outros & CEP.pdf & $\begin{array}{l}15 / 08 / 2018 \\
11: 15: 41\end{array}$ & $\begin{array}{l}\text { Maria Helena } \\
\text { Morgani de Almeida }\end{array}$ & Aceito \\
\hline
\end{tabular}

Situação do Parecer:

Aprovado

Necessita Apreciação da CONEP:

Não

Endereço: Rua General Jardim, $36-8^{\circ}$ andar

Bairro: Vila Buarque

UF: SP Município: SAO PAULO

CEP: $\quad 01.223-010$

Telefone: (11)3397-2464

E-mail: smscep@gmail.com 


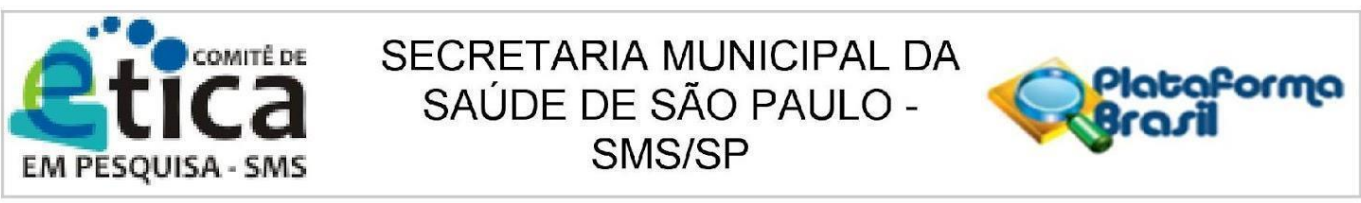

Continuaçăo do Parecer: 3.048.201

SAO PAULO, 30 de Novembro de 2018

Assinado por:

SIMONE MONGELLI DE FANTINI

(Coordenador(a)) 